Proceedings of the U.S. Geological Survey Seventh Biennial Geographic Information Science Workshop, Denver, Colorado, May 12-16, 2008

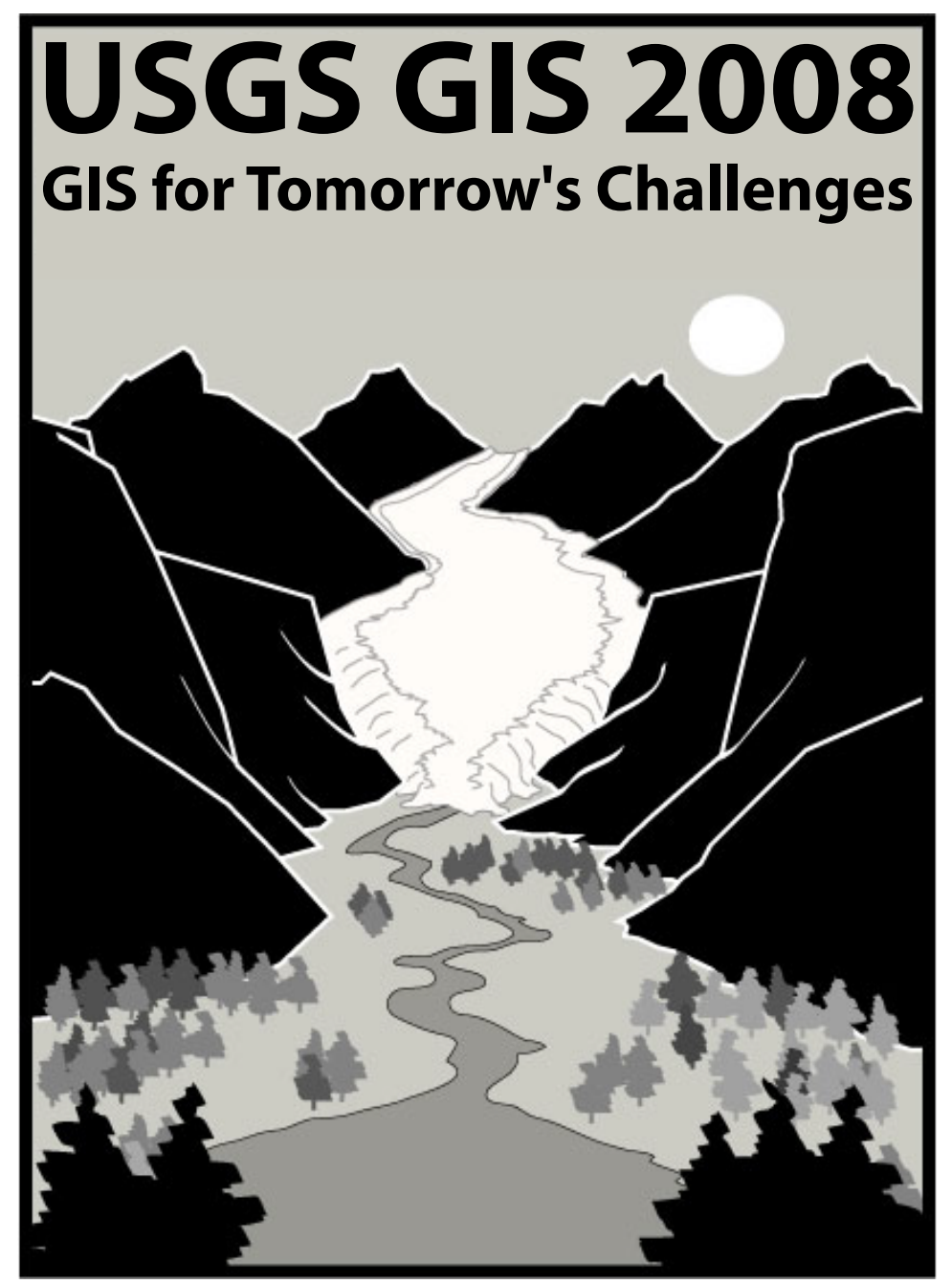

Scientific Investigations Report 2008-5074 



\section{Proceedings of the U.S. Geological Survey Seventh Biennial Geographic Information Science Workshop, Denver, Colorado, May 12-16, 2008}

Edited by Wm. Steve Helterbrand and Jennifer B. Sieverling

Scientific Investigations Report 2008-5074 


\section{U.S. Department of the Interior DIRK KEMPTHORNE, Secretary}

\section{U.S. Geological Survey \\ Mark D. Myers, Director}

\section{U.S. Geological Survey, Reston, Virginia: 2008}

For product and ordering information:

World Wide Web: http://www.usgs.gov/pubprod

Telephone: 1-888-ASK-USGS

For more information on the USGS--the Federal source for science about the Earth, its natural and living resources, natural hazards, and the environment:

World Wide Web: http://www.usgs.gov

Telephone: 1-888-ASK-USGS

Any use of trade, product, or firm names is for descriptive purposes only and does not imply endorsement by the U.S. Government.

Although this report is in the public domain, permission must be secured from the individual copyright owners to reproduce any copyrighted materials contained within this report.

Suggested citation:

Helterbrand, W.S., and Sieverling, J.B., eds., 2008, Proceedings of the U.S. Geological Survey Seventh Biennial Geographic Information Science Workshop, Denver, Colorado, May 12-16, 2008, U.S. Geological Survey Scientific Investigations Report 2008-5074, 66 p. 


\section{Contents}

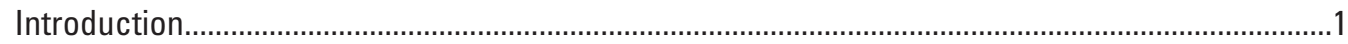

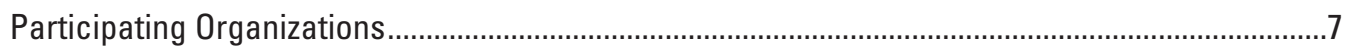

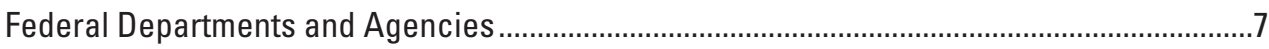

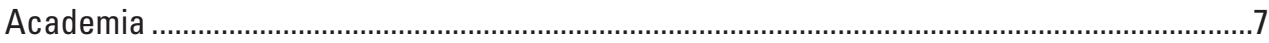

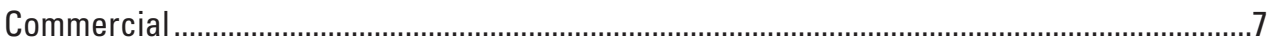

USGS GIS 2008 Planning Committee Members ………....................................................................

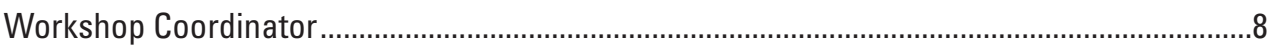

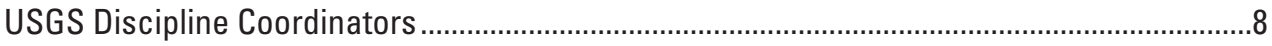

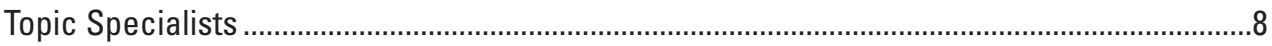

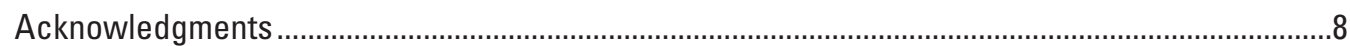

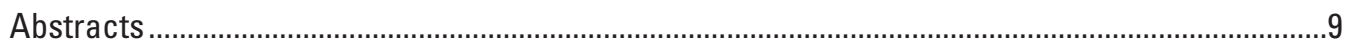

Presentation Titles and Abstracts, Monday May 12, 2008 ............................................................

Monday Plenary, 8:00 am - 11:30 am ..............................................................................

The National Map Overview, By William J. Carswell, Jr ..............................................9

Partnership Strategies for The National Map, By Vicki Lukas.......................................9

The USGS Science Strategy: Why This, Why Us, Why Now? By Jill Baron.....................10

Data Integration and Interoperability, By Eldrich Frazier..............................................10

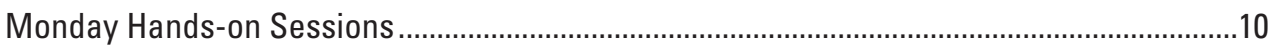

Introduction to Arc Hydro Tools for Watershed Delineation \& Characterization, 1:00 pm - 5:10 pm, By Christine Dartiguenave..................................................10

Using XTools Pro 5 for ArcGIS, 1:00 pm - 2:55 pm, By Viacheslav Ananev and

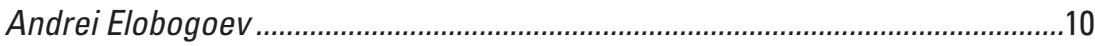

ERDAS IMAGINE Fundamentals, 1:00 pm - 5:10 pm, By Joe Mostowy...........................10

Introduction to Geodatabases, 1:00 pm - 5:10 pm, By Zachary D. Wilson, David E. Ladd, and Tosca Hoffmann .............................................................................11

Spatial Analysis Tools of ArcGIS, 3:15 pm - 5:10 pm, By Steve Kopp ............................11

Monday Lecture Sessions..................................................................................................11

Climate Variability and Change, 1:00 pm - 2:55 pm, Moderated by Mike Mulligan ........11

Land-Cover Mapping of Red Rock Canyon National Conservation Area, By J. LaRue Smith ..................................................................................11

Alaska 2001 National Land-Cover Database_Unique Challenges, By

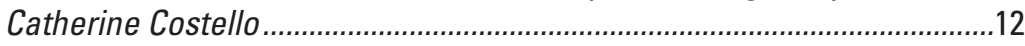

Rapid Land Cover Mapper: An Introduction, By Wm. Matthew Cushing, G.G. Tappan, M. Mathis, and L.L. Tieszen.

Data Integration and Interoperability: Enterprise, 1:00 pm - 2:55 pm, Moderated by

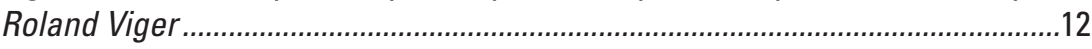

Business Requirements for The National Map: Addressing Emerging Needs,

By Larry Sugarbaker ...........................................................................12

Geospatial One-Stop: What's New in Publishing, Discovering, and Using Data in our National Spatial Data Infrastructure, By Robert Dollison........13

A Data Integration and Interoperability Blueprint for the U.S. Geological Survey, By R. Sky Bristol, Kevin T. Gallagher, and Linda C. Gundersen .....13

Principles of Data Modeling, By Stan Smith 
Custom Tools, Scripting, and Tweaks, 1:00 pm - 2:55 pm, Moderated by

Curtis Price.

Developing a Custom Scale Dependent Renderer for ArcMap using ArcObjects, By David S. McCulloch.

A 3-Dimensional Visualization Technique for Exploring Multivariate Geochemical Data, By Stuart A. Giles.

ArcInfo Workstation Functionality using Python Script Tools, By Curtis Price .......15

Streamlined Geologic and Geochemical Data Collection Using a Personal Digital Assistant and Bluetooth Global Positioning System, By

Edward P. Klimasauskas.

Introduction to Visual Learning Systems Feature Analyst, 1:00 pm - 2:55 pm,

By Raj Mohan Rao.

Understanding Ecosystems and Predicting Ecosystem Change, 3:15 pm - 5:10 pm,

Moderated by Mike Mulligan.

A Newly Revised Federal Geographic Data Committee National Vegetation Classification Standard, By M.P. Mulligan

The Vital Signs Internet Map Service Atlas Project, By Peter Budde. 16

Sensor Fusion for the Preservation of Eagle Habitat, By Mark Romano and Raul Campos-Marquietti

Spatial Modeling of Near-Shore Habitats, Grand Canyon, By Michael Breedlove, Craig Anderson, and Thomas Gushue

Partnerships, 3:15 pm - 5:10 pm, Moderated By Sharon Shin

The Program Partners Working Group: A Critical Federal Collaboration, By Wendy A. Budd.

NativeView: U.S. Geological Survey Geospatial Data for Native America, By James Rattling Leaf, Susan M. Marcus, Gene Napier, and Bonnie Gallahan.

Energy and Minerals for America's Future / Custom Tools, Scripting, and Tweaks,

3:15 pm - 5:10 pm, Moderated By Eric Anderson and Laura Biewick.

Multidisciplinary Geographic Information System (GIS) Computing for a Country-Wide Mineral Resource Assessment Project in Africa: ASTER-based Mineral Mapping and 3-Dimensional Terrain Visualization in a Portable GIS/Global Positioning System Environment, By Eric D. Anderson and Barnaby W. Rockwell.

Sources, Transportation, and Fate of Natural Oil and Gas Seeps, Southern California, By Florence Wong, Tom Lorenson, Pete Dartnell, John Day, Grace Fong, Mary Elaine Helix, Pat Hart, Fran Hostettler, Keith Kvenvolden, Ira Leifer, Ken Peters, Bob Rosenbauer, and Jamie Conrad...

System Administration Suggestions, 3:15 pm - 5:10 pm, Hints, and Insights,

By Ryan M. Stevens

Monday GIS Town Hall Meeting, 5:30 pm - 8:00 pm

Mapping All That is White: Antarctic Science and Operations Viewed Through Geospatial Data, By Thomas Wagner and Paul Morin 


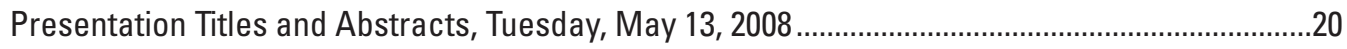

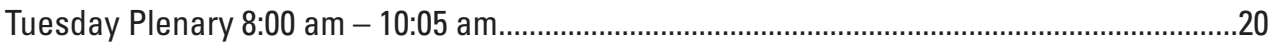

Integrating Data to Accelerate Integrated Science, 8:00 am - 8:50 am,

By Mark Myers, Director, U.S. Geological Survey...............................................20

Center for Disease Control and Prevention's Healthy Communities and

BioPHusion Programs, 8:50 am - 9:45 am, By Brian Kaplan ................................20

Tuesday Hands-on Sessions .................................................................................................20

Workshop about Definiens Software for Operational Image Analysis-Closing the Gap Between Remote Sensing and Geographic Information Systems, 1:00 pm - 5:10 pm, By Gregor Willhauck, Caroline Rogg, Christian Hoffmann, Tilo Schnur, and Juan Caliz.............................................................................20

Getting the Most Out of Your Geobrowser, 1:00 pm - 5:10 pm, By Gregory L. Gunther and Richard W. Spengler..................................................................21

Finding and Using U.S. Geological Survey and Other Spatial Data Online, 1:00 pm - 2:55 pm, By Joseph Kerski . .21

Global Mapper: Geographic Information System Viewing and Editing Software Package, 3:15 pm - 5:10 pm, By Dan Daniels .................................................21

Introduction to ArcGIS, 1:00 pm - 5:10 pm, By Tosca D. Hoffmann ..................................22

Tuesday Lecture Sessions................................................................................................22

A Water Census of the United States, 10:05 am - 12:00 pm, Moderated by Steve Aichele. . .22

The National Hydrography Data Set, By Jeff Simley . .22

NHDPlus Watershed and Reporting Toolset for the Connecticut River Watershed Atlas, By Craig Johnston and John Waterman.

A Method for Estimating Monthly Streamflow Using the Analysis of Flow In Network Channels Regression Model, Water-Use Data, and the National Hydrographic Data Set, By Steve Aichele and David Holtschlag

Center of Excellence for Geospatial Information Science (CEGIS),

10:05 am - 12:00 pm, Moderated by Roland Viger.

Implementing a Research Agenda to Address Challenging Geographic Information Science Issues, By Michael P. Finn and E. Lynn Usery...........23

Quantifying Error Propagation and Prediction Uncertainty for Raster Processing using Raster Error Propagation tool, By Sharon L. Qi, Jason J. Gurdak, and Michael Geisler

Promoting Interoperability with Specifications of Geoprocessing Methodology, By Roland J. Viger, Olaf David, and C.G. O'Hara

The Role of Environment and Wildlife in Human Health, 10:05 am - 12:00 pm, Moderated by Yvonne Baevsky . .25

Risk-Based Targeted Surveillance: Identifying Areas and Populations of Importance for Surveillance of High Path Avian Influenza in the United States, By Ryan Miller, Matthew Farnsworth, William Kendall, Paul Doherty, James Nichols, Gary White, Kenneth Burnham, Alan Franklin, and Jerome Freier.

Pathways Assessment Mapping Tool Aids in Risk Analysis for USDA Veterinary Services-Centers for Epidemiology and Animal Health, By Mary Ann Bjornsen.

Feature Extraction of Aerial Imagery to Establish Spatial Measures of Animal Operations, By Mary Jane McCool. 
Use of an Online Map Service to Provide Maps for Decision Makers, By Andrew Fox .26

Application of Weather and Climate Data in Epidemiological Studies, By Susan Maroney. .26

Spatial Modeling of Piroplasmosis Risk in Horses in Preparation for the World Equestrian Games in 2010, By Angela James. .26

North American (Metadata) Profile: Content, Tips, and Tools, 10:05 am - 12:00 pm, By Sharon S. Shin and Anna Milan...... 26

Spatial Modeling with ArcGIS, 1:00 pm - 2:55 pm, By Cory Tucker and Steve Kopp .....27 Data Integration and Interoperability Enterprise, 1:00 pm - 2:55 pm, Moderated by

Roland Viger. .27

The Status of Data Products and Services in The National Map, By Carl Zulick..27

U.S. Geological Survey Topographic Mapping, By Michael Cooley, Stafford Binder, and Helmut Lestinsky.... 27

Where Can I Plug Into The National Map? By James G. Barrett..... .28

Geospatial Management Information System Data Improvement-Lessons Learned, By Scott McEwen.

The Role of Environment and Wildlife in Human Health, 1:00 pm - 2:55 pm,

Moderated by Yvonne Baevsky 28

Global Wildlife Disease News Map_Putting Wildlife Health News on the Map! By Megan K. Hines, Steven Gustafson, F. Joshua Dein, and Cris Marsh.....

Center for Disease Control and Prevention's Agency for Toxic Substances and Disease Registry's Tracking of Avian Influenza in Birds, By Brian Kaplan and Steven Bullard....

Vendor Solutions: DigitalGlobe Products (Digital Globe) and the GeoPDF File

(TerraGo Technologies), 1:00 pm - 2:55 pm, Moderated By Daniel Pearson......29

DigitalGlobe Incorporated Corporate and System Update, By Brett $P$. Thomassie

The GeoPDF File-A New Solution for the Digital Publication, Distribution, and Collaboration of Geospatial Data, By Jaymes Pardue.

A Water Census of the United States, 3:15 pm - 5:10 pm, Moderated by

Steve Aichele

Great Lakes Aquatic Gap: A Regional Approach and Framework to Identify Gaps in Fish Species and Habitat Conservation for Great Lakes Streams, By Jana Stewart and Steve Aichele.

A Pilot Project to Develop and Implement StreamStats and NHDPlus Applications Using Local Resolution Data in the Upper French Broad River Basin, North Carolina, By Kirsten C. Tighe, Silvia Terziotti, and Chad Wagner.

National Atlas Digital Streams Data Recompilation at 1:1,000,000-Scale Using the 1:100,000-Scale National Hydrography Data set and ArcObjects, By Zachary D. Wilson, Robin H. Gary, and Christy-Ann M. Archuleta .......31

Comparison of Two Stream Networks as Framework for the Spatially Referenced Regression On Watershed Attributes Model for the Southeastern United States, By Silvia Terziotti and Anne Hoos.... 
Data Integration and Interoperability: Operational, 3:15 pm - 5:10 pm, Moderated

by Carma San Juan.

Not Everything is a Map: Browsing Geography by Place Name, By Peter $N$. Schweitzer...

Integrating Data Collection and Management Tools to Support Multidisciplinary Research of Sturgeon on the Lower Missouri River, By Kimberly A. Chojnacki, Emily K. Tracy-Smith, Sandra J. Clark-Kolak, and Aaron J. DeLonay.

Building Texas-Sized Geodatabases, By Daniel K. Pearson, Sachin D. Shah, and Toby L.Welborn

Streamlining Report Map Production, By Christy-Ann M. Archuleta

The Role of Environment and Wildlife in Human Health / A National Program to Assess Hazards, Risk and Resiliency, 3:15 pm - 5:10 pm, Moderated by Yvonne Baevsky.

Are Environmental Exposures to Chlorophenoxy Herbicides Associated With Adverse Human Health Effects? By Dina M. Schreinemachers........34

Environmental- and Health-Hazards Characterization of Ash and Burned Soils from the October 2007 Southern California Wildfires, By Geoffrey $S$. Plumlee, Deborah A. Martin, Todd Hoefen, Raymond Kokaly, Philip L. Hageman, Suzette A. Morman, Ruth E. Wolf, Gregory P. Meeker, Paul J. Lamothe, Robert N. Fisher, Eric Reichard, Michael Anthony, Monique Adams, and Greg Mendez

Geographic Information System-based Assessment of Post Fire Debris-flow Hazards, Southern California, 2007, By Susan H. Cannon, Joseph E. Gartner, John A. Michael, Mark A. Bauer, Susan C. Stitt, Yvonne M. Rique, Donna L. Knifong, and Bernard J. McNamara

Follow Up for Finding and Using U.S. Geological Survey and Other Spatial Data Online and Modeling with ArcGIS 9, 3:15 pm - 4:30 pm

Poster Session and Vendor Gallery at Building 810. 5:15 pm - 7:30 pm.

Areas of Historical Oil and Gas Exploration and Production in the United States, By Laura R.H. Biewick

Minerals for America's Future-U.S. Geological Survey Active Mines and

Mineral Processing Plants Data Sets, By Robert M. Callaghan ...

Stratigraphic Visualization Using RockWorks14: A Three-Dimensional Chronostratigraphic Model of the Colorado Plateau, By Nicole Cordier, Becky Thompson, and Kate Falconer....

Developing a Geodatabase and Three-Dimensional Conceptual Model for Data Management at the Longhorn Army Ammunition Plant, Harrison County, Texas, By Daniel K. Pearson and Sachin D. Shah..

Mapping Bare Ground Using Satellite Imagery at Piñon Canyon Maneuver Site, Colorado, By Susan C.F. Stitt, Carol S. Mladinich, and Jean A. Dupree

Formalizing Model-Specific Geographic Information System Methodology with the GIS Weasel, By Roland J. Viger.

Global Wildlife Disease News Map_-Putting Wildlife Health News on the Map! By Megan K. Hines, Steven Gustafson, F. Joshua Dein, and Cris Marsh. 
Presentation Titles and Abstracts, Wednesday, May 14, 2008........................................................40

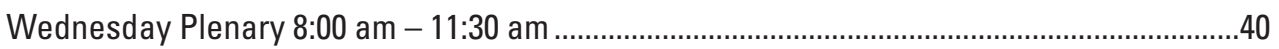

USGS Geographic Analysis and Monitoring Program, By Jonathan Smith.....................40

USGS Land Remote Sensing Program, By Bruce Quirk ..................................................40

New Commercial Satellites Lead to New Exciting Products, By Scott A. Bennett.........40

The NASA Orbiting Carbon Observatory: Measuring Atmospheric Carbon

Dioxide from Space, By Dr. David Crisp.

Plenary Session: Remote Sensing Discussion, 10:50 am - 11:30 am, Moderated by Richard Spengler. 41

Wednesday Hands-on Sessions ...........................................................................................

ENVI Feature Extraction Module, 1:00 pm - 5:10pm, By Adam O'Connor .......................41

Introduction to ArcGIS Server, 1:00 pm - 5:10 pm, By Jeremiah Lindemann ..................41

Geospatial One-Stop: What's New in Publishing, Discovering, and Using Data in our National Spatial Data Infrastructure, 1:00 pm - 2:55 pm, By Robert

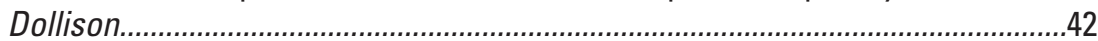

Introduction to Job Tracking for ArcGIS, 1:00 pm - 2:55 pm, By Sandi Belson ..............42

Building Custom Tools with Python, 3:15 pm - 5:10 pm, By Corey Tucker and Jason Pardy.

Blue Marble Geographics Demonstration: the Geographic Calculator and the Geographic Transformer, 3:15 pm - 5:10 pm, By Sam Knight.............................42

Geographic Calculator Demonstration ...............................................................42

Geographic Transformer Demonstration ..............................................................43

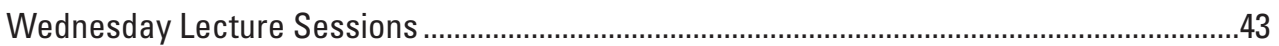

System Design and Administration, 1:00 pm - 2:55 pm, By Dave Peters.........................43

Extending ArcGIS, 1:00 pm - 2:55 pm, Moderated By Curtis Price .................................43

Data East Geographic Information System (GIS) Ware: Productivity Tools for GIS, By Viacheslav Ananev and Andrei Elobogoev...............................43

MAPublisher and Geographic Imager, By Ted Florence and David Andrec...........43

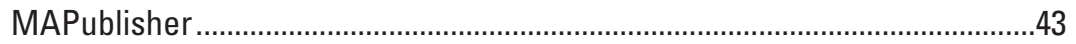

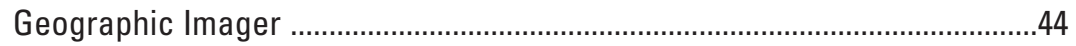

Elevation and Surfaces - Light Detection and Ranging (LiDAR) and Related

Technologies, 1:00 pm - 2:55 pm, Moderated by Silvia Terziotti... .44

Integration of Bathymetric Light Detection and Ranging and Sonar Methods for Hydrographic Surveys, By Nicholas Gianoutsos, Capt. Guy T. Noll, Lt. Benjamin K. Evans, and LTJG Samuel F. Greenaway.

CLICK: The USGS Center for Light detection and Ranging (LiDAR) Information Coordination and Knowledge, By Jordan C. Menig and Jason M. Stoker.

Light Detection and Ranging (LiDAR) Data Management: Maturing Our Approach to an Advancing Technology, By Karl Heidemann

Environmental Systems Research Institute: Discussion on Cartography Topics,

1:00 pm - 2:55 pm. .45

ArcGIS and the Road Ahead, 3:15 pm - 5:10 pm, By David Vaillancourt.........................45

Microsoft Virtual Earth, 3:15 pm - 5:10 pm, By William B. Gail...... 45 
Elevation and Surfaces_-Light Detection and Ranging and Related Technologies

(LiDAR), 3:15 pm - 5:10 pm, Moderated by Silvia Terziotti...................................46

Evaluation of Airborne Light Detection and Ranging (LiDAR) Data to Classify and Predict Vegetation Communities, By Monica Palaseanu-Lovejoy, Amar Nayegandhi, John Brock, Robert Woodman, and C. Wayne Wright.

Laser-Derived Ground Surface, Plant Canopy, and Geomorphology of a Florida Coastal Lowland, By Ellen A. Raabe, Melanie S. Harris, Ramesh L. Shrestha, William E. Carter, and Elizbieta BialkowskaJelinska......

LiDAR: Practical Techniques for Quality Assurance and Analysis, By Michael Umansky.

Follow Up for System Design and Administration and Introduction to Job Tracking for ArcGIS (JTX), 3:15 pm - 4:30 pm ..................................................................47

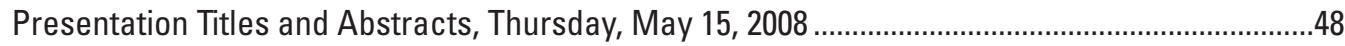

Thursday Plenary 8:00 am - 11:30 am.................................................................................48

Update on Geospatial Line of Business and Geospatial Modernization Blueprint, By Lorri Peltz-Lewis ...........................................................................................48

Update from “0’Reilly Where 2.0 Conference," By Sandy Williamson ............................48

Geographic Information System Trends: Deploying Geographic Information Systems in Government, By Clint Brown.........................................................48

Thursday Hands-on Sessions .49

Putting NHDPlus to Work: Applying a National Geospatial Surface-Water Framework-Basics Session, 1:00 pm - 2:55 pm, By Alan Rea, Richard B.

Moore, and Craig M. Johnston....

Working with ModelBuilder and Geoprocessing Tools, 1:00 pm - 2:55 pm, By Corey Tucker and Jason Pardy.

Cartography with ArcGIS, 1:00 pm - 5:10 pm, By Charlie Frye ..........................................49

Introduction to MAPublisher, 1:00 pm - 2:55 pm, By Ted Florence...................................49

Global Positioning System 101, 1:00 pm - 5:10pm, By Steve Reiter..................................50

Putting NHDPlus to Work: Applying a National Geospatial Surface-Water Framework-Advanced Session, 3:15 pm - 5:10 pm, By Alan Rea,

Richard B. Moore, and Craig M. Johnston

Surface Interpolation with ArcGIS, 3:15 pm - 5:10 pm, By Steve Kopp...........................50

Integrated Geological Data Management, Analysis, and Visualization Using RockWorks14, 3:15 pm - 5:10 pm, By Nicole Cordier, Becky Thompson, and Kate Falconer ..........................................................................................50

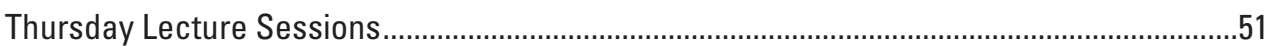

System Design and Administration, 1:00 pm - 2:55 pm, By Dave Peters.........................51

Data Integration and Interoperability: Operational, 1:00 pm - 2:55 pm,

Moderated by Carma San Juan.

When an Ecosystem is your Enterprise, By Sean P. Finn, Linda Schueck, and Thomas Zarriello

Delivering Model Results to Resource Specialists, By Tim Kern . . .51

Leveraging the U.S. Geological Survey National Water Information System (NWIS) with Geodatabases-NWIS on G-I-Steroids, By Robin H. Gary and Brian D. Reece. 
Light Detection and Ranging Solutions (LiDAR), 1:00 pm - 2:55 pm, Moderated

by Silvia Terziotti.

Using LP360 to integrate Light Detection and Ranging (LiDAR) with ArcGIS,

By Torin Haskell and Mike Watry...

Terrains: Light Detection and Ranging (LiDAR) Data Support in ArcGIS 9.2,

By Clayton Crawford ..............................................................................52

Introduction to Visual Learning Systems LiDAR Analyst, By Raj Mohan Rao .........53

Merrick Advanced Remote Sensing (MARS ${ }^{\circledR}$ ) Software Suite

Demonstration, By Bill Emison.

Getting the Most out of ArcGIS Explorer, 1:00 pm - 2:55 pm, By Jeremiah

Lindemann.

Coviz: A Multi-Disciplinary 3-Dimensional Subsurface Data Viewer for

Collaborative Teams, 3:15 pm - 5:10 pm, By Skip Pack......................................54

Extending ArcGIS, 3:15 pm - 5:10 pm, Moderated By Curtis Price................................54

MAPublisher and Geographic Imager, By Ted Florence and David Andrec............54

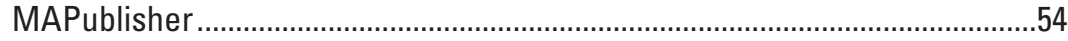

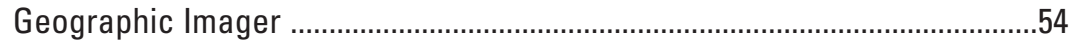

Data East Geographic Information System (GIS) Ware: Productivity Tools for GIS, By Viacheslav Ananev and Andrei Elobogoev. .55

Light Detection and Ranging (LiDAR) Solutions, 3:15 pm - 5:10 pm, Moderated by

Silvia Terziotti .55

An Internet-Based System for the Distribution and Interactive Generation of Digital Elevation Models From Community Light Detection and Ranging (LiDAR) Topography, By Christopher Crosby, Ramon Arrowsmith, Viswanath Nandigam, Newton Alex, Ashraf Memon, and Chaitan Baru.

Light Detection and Ranging (LiDAR) Data Processing and Applications in Open Source Geographic Resources Analysis And Support System Geographic Information System, By Helena Mitasova and Russell S. Harmon.

Follow Up for System Design and Administration and Geoprocessing in ArcGIS,

3:15 pm - 4:30 pm, ESRI .56

Presentation Titles and Abstracts, Friday, May 16, 2008 .............................................................56

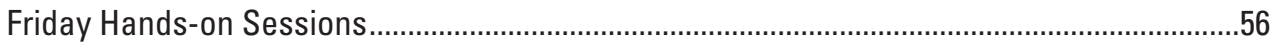

CrossView for ArcGIS, 8:00 am - 9:55 am, By Steve Miller............................................56

Spatial Analysis Tools of ArcGIS, 8:00 am - 9:55 am, By Steve Kopp ...........................57

ArcGIS Mobile GIS Solutions, 8:00 am - 9:55 am, By Jason Channin ............................57

Introduction to Geodatabases, 8:00 am - 11:55 am, By Zachary D. Wilson,

David E. Ladd, and Tosca Hoffmann

Cartography with ArcGIS, 1:00 pm - 5:10 pm, By Charlie Frye .........................................57

Surface Interpolation with ArcGIS, 10:10 am - 11:55 am, By Steve Kopp......................58

Introduction to the Google Maps Application Programming Interface: Leveraging the Geoweb for Publishing Scientific Information, 10:10 am - 3:00 pm, By Gregory L. Gunther

Introduction to Production Line Tool Set Foundation, 1:05 pm - 3:00 pm, By Sandi Belson

Working with ModelBuilder and Geoprocessing Tools, 1:05 pm - 3:00 pm, By Corey Tucker and Jason Pardy. 
Friday Lecture Sessions.

Geobrowser Applications and Web Visualization, 8:00 am - 9:55 am, Moderated

by Luke Blair.

Serving Bay Area Geologic Hazard Information in Google Earth Keyhole

Markup Language; a Network-Link Approach, By James Luke Blair ........59

Integration of Open-Source Tools for Modeling Applications-Part A:

GeoTools and National Aeronautics and Space Administration

World Wind, By Roland J. Viger, Ian Overgard, Steven L. Markstrom, and Olaf David.

Integration of Open-Source Tools for Modeling Applications-Part B:

Object User Interface Example, By Steven L. Markstrom, Roland J. Viger, Olaf David, and lan Overgard.

A Water Census of the United States, 8:00 am - 9:55 am, Moderated By Tim

McKinney.

A Desktop Application to Assess the Sustainable Yields and Surface-Water Resources in Massachusetts, By Peter A. Steeves and Stacey A. Archfield

Status Update on the U.S. Geological Survey StreamStats Web Application, By Alan Rea

A Geographic Information System Approach to Delineate Areas Prone to Ground-water Flooding on Long Island, New York, By Jack Monti, Jr.

Custom Tools, Scripting, and Tweaks, 8:00 am - 9:55 am, Moderated by Bill Oatfield

An Introduction to Interpolation Methods Commonly Used in Geographic Information Systems, By Nicholas Gianoutsos and Philip H. Nelson.........61

ArcGIS and the Road Ahead, 8:00 am - 9:55 am, By David Vaillancourt. .62

Energy and Minerals for America's Future, 10:10 am - 11:55 am, Moderated by Laura Biewick. .62

Mapping Oil Spills with Imaging Spectroscopy in Areas Impacted by Hurricane Katrina, By Gregg Swayze and K. Eric Livo

Geographic Information System Methods for Ranking Mineralization Potential, By Gregory K. Lee.

U.S. Geological Survey Oil and Gas Assessment Explorer: an Interactive Web Application to Access U.S. Geological Survey Assessment Research, By Chris Skinner, Greg Gunther, Dave Ferderer, and Laura Biewick.

Integrated State Geologic Map Database of the United States, By Connie L. Dicken, Suzanne W. Nicholson, Douglas B. Stoeser, Frederic H. Wilson, and Steve D. Ludington

A Water Census of the United States, 10:10 am - 11:55 am, Moderated by Tim

McKinney. 64

A Semi-Automated Hydrologic Unit Naming Method, By Sally L. Holl. .64

Estimating Perennial Streams in Idaho Using a Regression Model Of 7-Day, 2-Year Low Flows, By Alan Rea. 
Custom Tools, Scripting, and Tweaks, 10:10 am - 11:55 am, Moderated by Catherine Costello.

Customizing the ArcGIS Server .NET Mapping Application, By David S. McCulloch

Roadless Space-The Interior Southwest, By Catherine Costello, Roger W. Compton, and Raymond D. Watts... 65

Blue Marble Geographics Demonstration: the Geographic Calculator and the Geographic Transformer, 10:10 am - 11:55 am, By Sam Knight..........................66

Geographic Calculator Demonstration ..............................................................66

Geographic Transformer Demonstration ..............................................................66

\section{Table}

1. U.S. Geological Survey Geographic Information Science Workshop, Denver, Colorado 


\title{
Proceedings of the U.S. Geological Survey Seventh Biennial Geographic Information Science Workshop, Denver, Colorado, May 12-16, 2008
}

\author{
Edited by Wm. Steve Helterbrand' and Jennifer B. Sieverling²
}

\section{Introduction}

The U.S. Geological Survey (USGS) Seventh Biennial Geographic Information Science (GIS) Workshop (USGS-GIS 2008) on May 12 through 16, 2008, at the Denver Federal Center in Denver, Colorado, is unique in that it brings together GIS professionals from all of the USGS disciplines across all regions, and focuses primarily on the needs and accomplishments of the USGS.

The theme for the 2008 workshop, "GIS for Tomorrow's Challenges," provides an opportunity for USGS GIS professionals to demonstrate how they have responded to the challenges set forth in the USGS Science Strategy (http://www.usgs.gov/science strategy/). During this workshop, attendees will have an opportunity to present or demonstrate their work; develop their knowledge by attending hands-on workshops and presentations given by professionals from the USGS and other Federal agencies, GIS-related companies, and academia; and to network with other professionals to develop collaborative opportunities.

In addition to participation in numerous workshops and presentations, attendees will have opportunities to listen to top-level managers from the USGS present updates and goals concerning the future of several USGS programs. Monday evening's Star Guest presentation by Thomas Wagner, NSF Office of Polar Programs, and Paul Morin, Antarctic Geospatial Information Center, entitled "Mapping all that is White: Antarctic Science and Operations Viewed Though Geospatial Data," will be one of many valuable presentations.

This Proceedings volume will serve as an activity reference for workshop attendees, as well as an archive of technical abstracts presented at the workshop. Author, co-author, and presenter names, affiliations, and contact information are listed with presentation titles with the abstracts. Some hands-on sessions are offered twice; in these instances, abstracts submitted for publication are presented in the proceedings on both days on which they are offered. All acronyms used in these proceedings are explained in the text of each abstract.

\footnotetext{
${ }^{1}$ U.S. Geological Survey, Rolla, Missouri.

${ }^{2}$ U.S. Geological Survey, Denver, Colorado.
} 


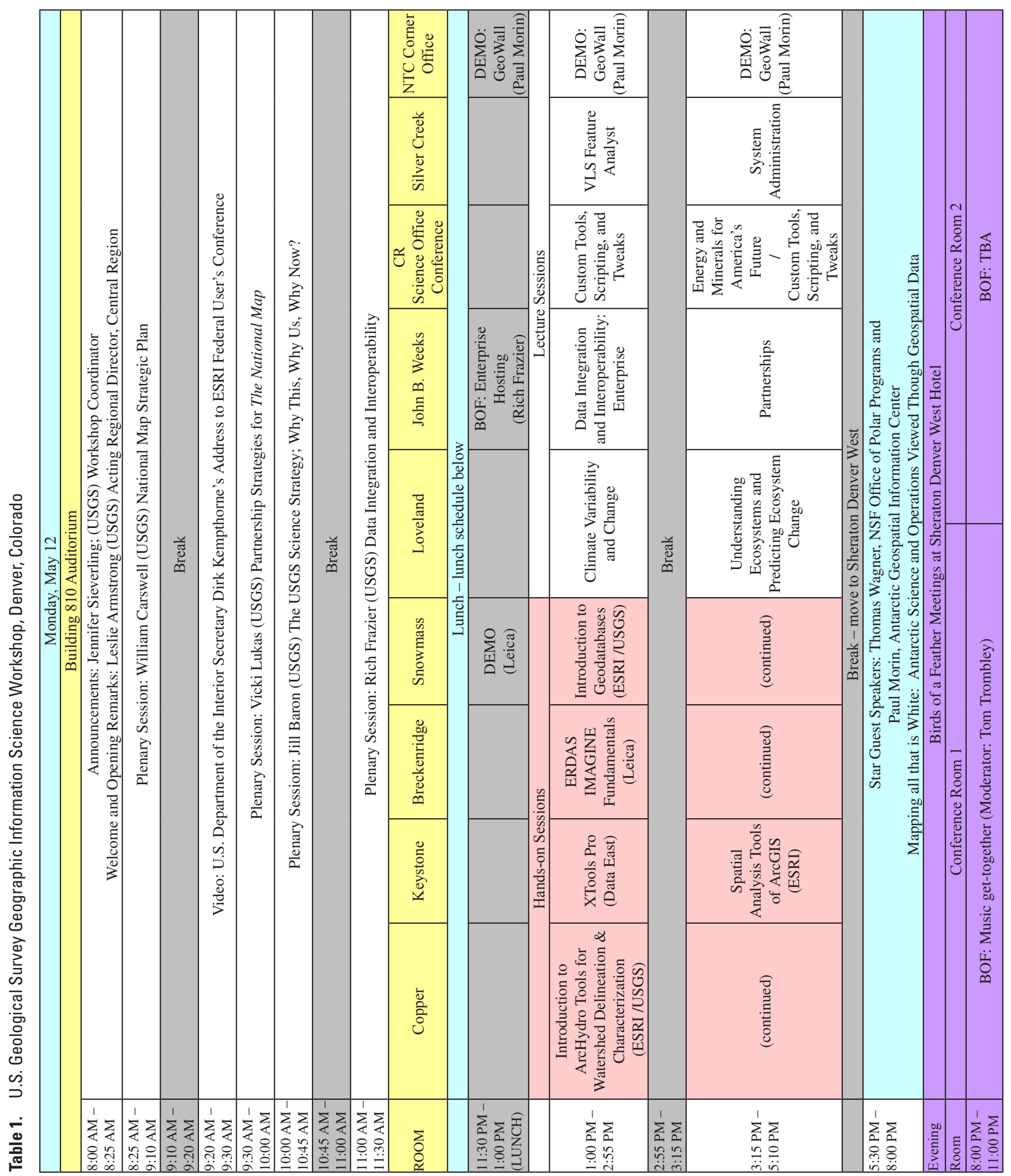




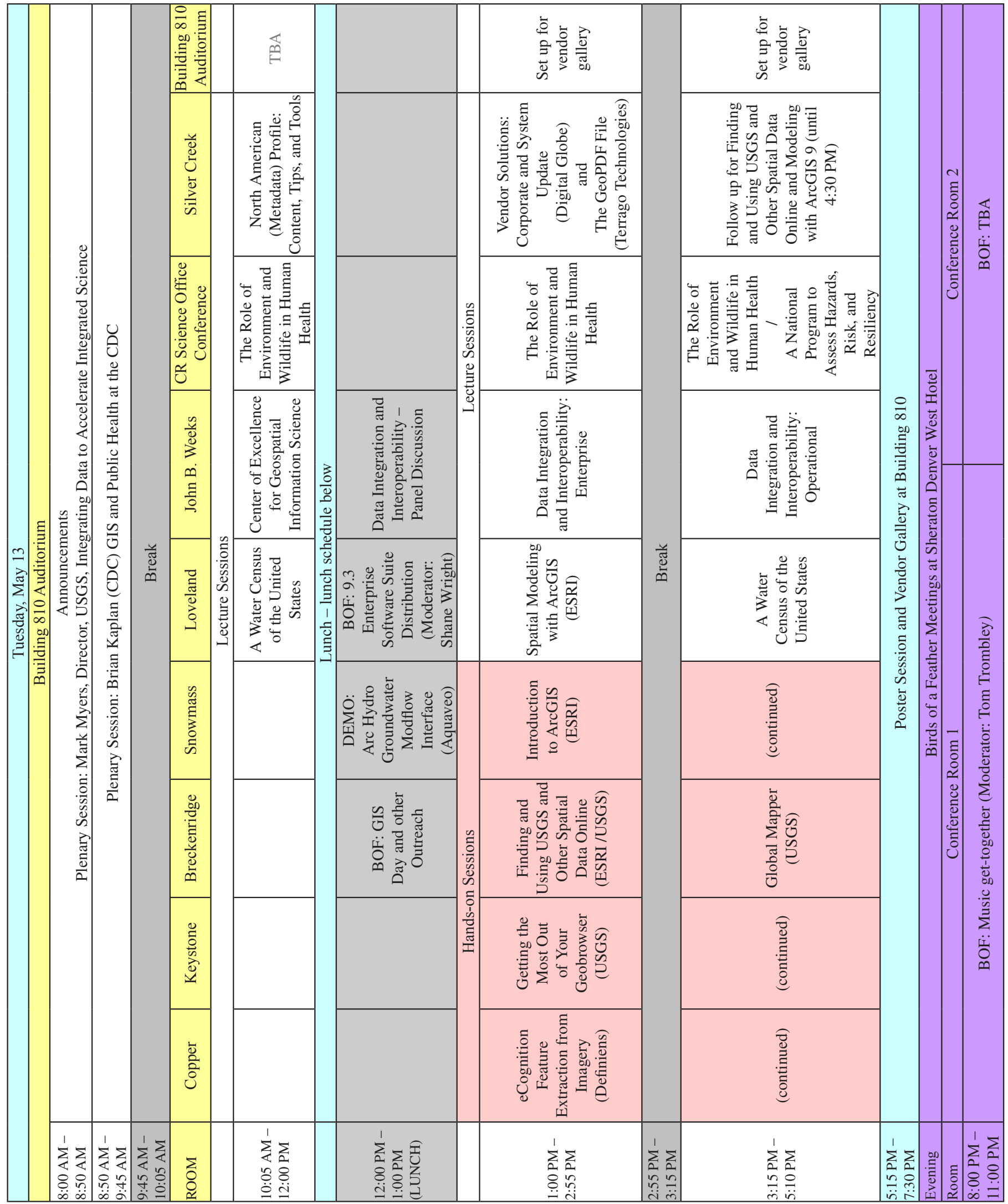




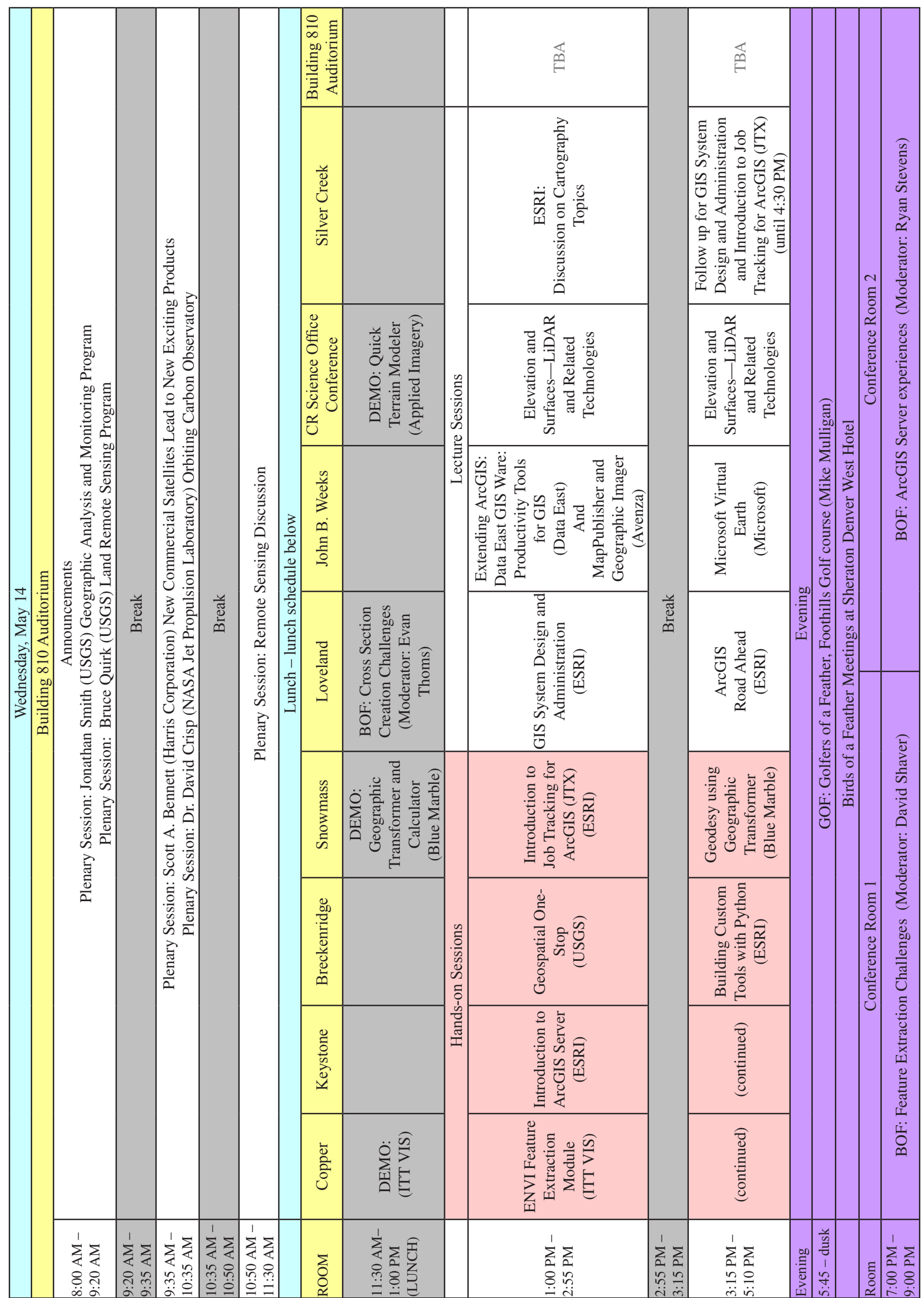




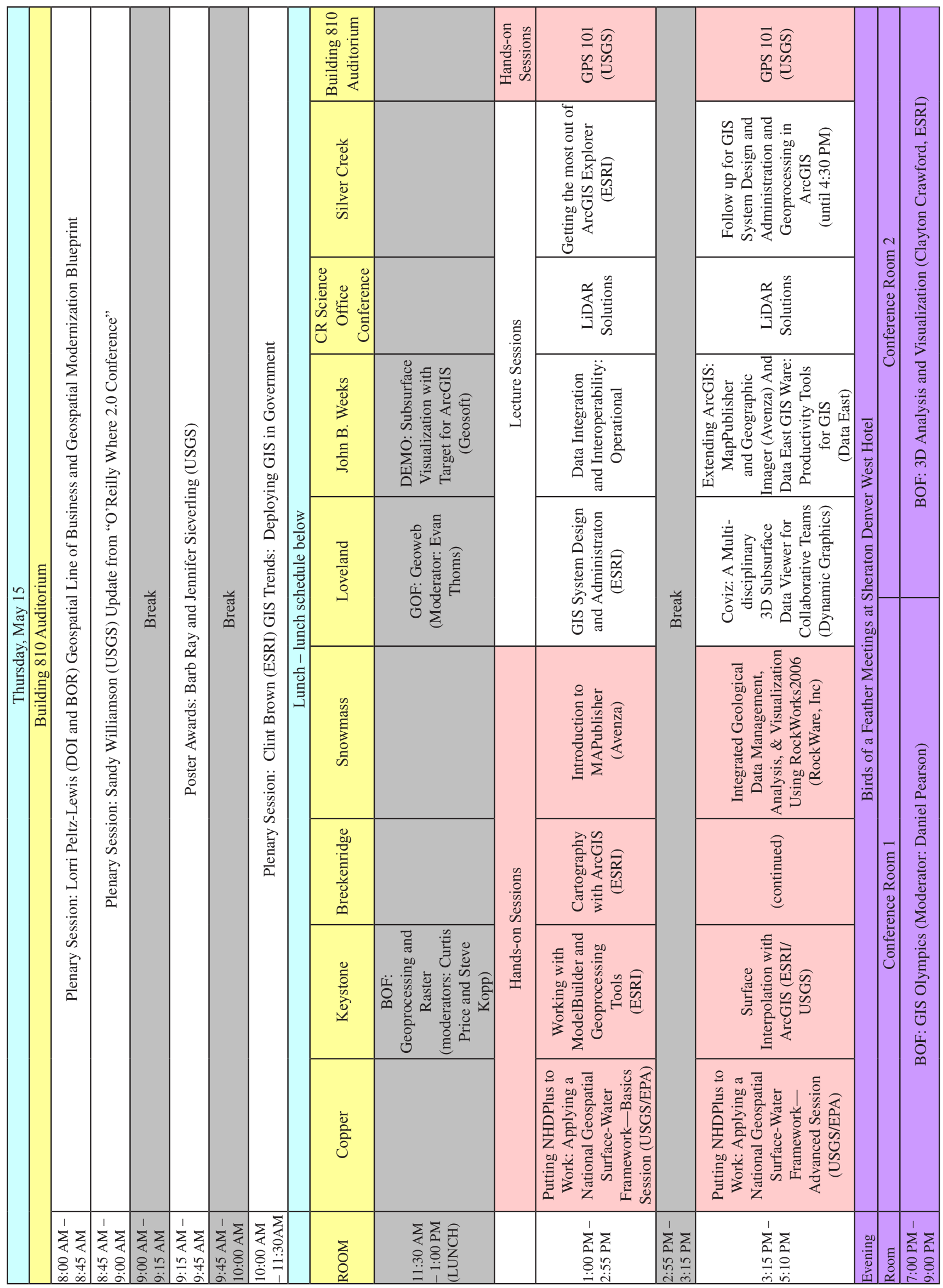




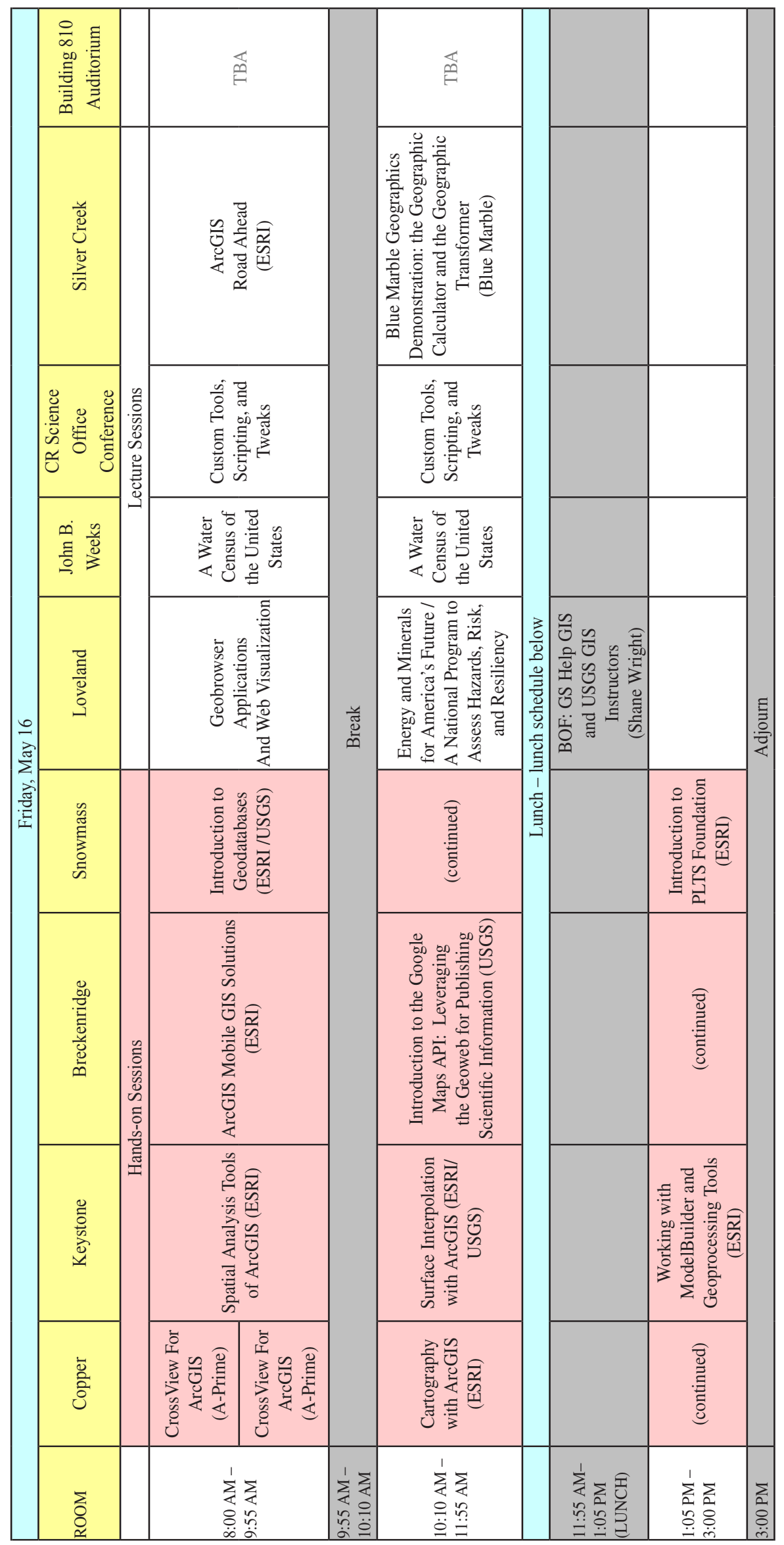




\title{
Participating Organizations
}

\section{Federal Departments and Agencies:}

Centers for Disease Control and Prevention (CDC)

NASA, Jet Propulsion Laboratory

National Geophysical Data Center

U.S. Department of Agriculture (USDA)

Animal and Plant Health Inspection Service (APHIS): Veterinary Services Centers for Epidemiology and Animal Health U.S. Department of Interior (DOI)

Fish and Wildlife Service (FWS)

National Park Service (NPS)

U.S. Geological Survey (USGS)

U.S. Environmental Protection Agency (EPA)

\section{Academia:}

Arizona State University

North Carolina State University

San Diego Supercomputer Center, University of California

Sinte Gleska University

University of California, Santa Barbara

University of Florida

\section{Commercial:}

\author{
A-Prime Software \\ Applied Imagery \\ Avenza Systems, Inc. \\ Blue Marble Geographics \\ Data East, LLC \\ Definiens, Inc. \\ Digital Globe \\ Dynamic Graphics \\ Environmental Systems Research Institute, Inc. (ESRI) \\ Harris Corporation \\ ITT Visual Information Solutions \\ Jacobs Technology Inc. \\ Leica Geosystems \\ Merrick \& Company \\ Microsoft Virtual Earth \\ QCoherent Software \\ RockWare, Inc. \\ SAIC \\ TerraGo Technologies \\ Visual Learning Systems, Inc.
}




\section{USGS GIS 2008 Planning Committee Members}

\section{Workshop Coordinator:}

Jennifer B. Sieverling

\section{USGS Discipline Coordinators:}

Biology: Mike Mulligan

Geography: Wm. Steve Helterbrand

Geology: Evan Thoms

Regional Geospatial Information Office: Ryan Stevens

Water Resources: Tim McKinney

\section{Topic Specialists:}

Laura Biewick (Energy and Minerals for America's Future)

Yvonne Baevsky (The Role of Environment and Wildlife in Human Health)

Catherine Costello (Hospitality)

Wm. Steve Helterbrand (Proceedings Editor)

Tim McKinney (A Water Census of the United States)

Mike Mulligan (Understanding Ecosystems and Predicting Ecosystem Change) and (Climate Variability and Change)

Bill Oatfield (Vendor Coordination)

Daniel Pearson (A National Program to Assess Hazards, Risk, and Resiliency)

Curtis Price (Geoprocessing and Analysis)

Barbara Ray (NSDI Partnerships)

Carma San Juan (Data Integration and Interoperability)

Sharon Shin (Parnerships)

Rick Spengler (Remote Sensing)

Ryan Stevens (System Administraton)

Jason Stoker (Elevation and Surfaces)

Evan Thoms (A National Program to Assess Hazards, Risk, and Resiliency)

Sylvia Terziottti (Elevation and Surfaces)

\section{Acknowledgments}

We thank the many scientists whose contributions and accomplishments are reflected in these proceedings, as their efforts ensure continued success for the USGS. We also acknowledge David Litke and Gary Krizanich for their review comments and Kathy Laub and Felicia Dodd for their assistance with the layout of this manuscript. Thanks are extended to the National Training Center staff for their warm hospitality and to Ben Kelley and Lisa Scales for their onsite assistance. Appreciation is also extended to support efforts of the planning committee for organizing a successful USGS GIS 2008 Workshop. 


\title{
Abstracts
}

\section{Presentation Titles and Abstracts, Monday May 12, 2008}

\author{
Monday Plenary, 8:00 am - 11:30 am
}

\author{
The National Map Overview, By William J. Carswell, Jr.
}

U.S. Geological Survey, Geospatial Information Office, 4821 Quail Crest Place, Lawrence, KS 66049

785-832-3559 carswell@usgs.gov

The National Map is a major project within the U.S. Geological Survey (USGS) National Geospatial Program (NGP) and is a collaborative effort to improve and deliver topographic information for the Nation. The goal of The National Map is to become the Nation's source for trusted, nationally consistent, integrated, and current topographic information available online for a broad range of uses. The National Map is built on partnerships and includes eight data layers: hydrography, elevation, orthoimagery, geographic names, boundaries, transportation, land cover, and structures, and is a significant contribution to the National Spatial Data Infrastructure (NSDI). The USGS has Office of Management and Budget (OMB) Circular A-16 responsibility for five of the eight layers. The National Map data are in the public domain and support USGS topographic maps at 1:24,000 scale; products and services at multiple scales and resolutions; and analysis, modeling and other applications.

Significant accomplishments have been made with The National Map 1.0 including public accessibility of a vast amount of data and metadata from a broad range of sources, and expansion of a large and complex network of NSDI partnerships. Through these partnerships, the language and concepts of the NSDI are becoming familiar to a growing community. The value of the data and partnerships of The National Map 1.0 is significant, but the goal of nationally consistent, trusted, and integrated data and maps has not been fully met. The Nation's need for a common base map across jurisdictional boundaries was demonstrated dramatically during the 2005 hurricane season. The recognition of the need for greater consistency, integration, and direct access to data has lead NGP to move toward a fully centralized approach for the next phases of development in The National Map 2.0. A tactical plan for The National Map has been developed to unify The National Map components such as the National Hydrography Data set, Seamless Server, National Elevation Data set, and Geographic Names, and align partnership activities, systems, and services. The goal of The National Map 2.0 is to provide a range of geospatial products and services that advance the NSDI and underpin USGS science through integrated, quality-assured, seamless databases; revitalize the USGS topographic map in digital form; and improve data delivery to users.

\section{Partnership Strategies for The National Map, By Vicki Lukas}

U.S. Geological Survey, NGP Partnerships and External Coordination, 12201 Sunrise Valley Drive, MS 590, Reston, VA 20192 703-648-4646 vlukas@usgs.gov

State, local, Tribal, and Federal entities produce and maintain a vast array of current, accurate, geospatial data. The U.S. Geological Survey (USGS) National Geospatial Program Office (NGPO) collaborates with a broad range of partners who are essential to the success of The National Map and the advancement of the National Spatial Data Infrastructure. A significant objective and investment focus of NGPO has been the development of mutually beneficial partnerships to coordinate and leverage data acquisition, development, integration, maintenance, and stewardship. USGS Geospatial Liaisons cultivate and maintain long-term relationships with partners and develop supporting agreements for The National Map. Most liaisons are located within USGS Science Centers in the states they represent, offering opportunities for geospatial collaboration in support of USGS science. In this session, partnership strategies for The National Map will be explored together with areas of opportunity for geospatial collaboration within the USGS. 
The USGS Science Strategy: Why This, Why Us, Why Now? By Jill Baron

U.S. Geological Survey, 1499 Campus Deliver, Ft. Collins, CO 80523-1499

970-491-1968 iill_baron@usgs.gov

Abstract Not Submitted

Data Integration and Interoperability, By Eldrich Frazier

U.S. Geological Survey, National Center, 12201 Sunrise Valley Drive, MS 159, Reston, VA 20192-0002

703-648-6839efrazier@usgs.gov

Abstract Not Submitted

Monday Hands-on Sessions

Introduction to Arc Hydro Tools for Watershed Delineation \& Characterization, 1:00 pm - 5:10 pm, By Christine Dartiguenave

ESRI, 380 New York Street, Redlands, CA 92373-8100

909-793-2853 cdartiguenave@esri.com

ArcHydro is a geodatabase design and set of accompanying tools geared for support of water resources applications in the ArcGIS environment. This workshop will provide a brief overview of ArcHydro database design principles and present the ArcHydro tools through a series of practical exercises. Special attention will be placed on the new ArcHydro functionality that allows integration with the ground-water data model component, deranged terrain processing, and geoprocessing framework as the basis for ArcHydro tools.

\section{Using XTools Pro 5 for ArcGIS, 1:00 pm - 2:55 pm, By Viacheslav Ananev and Andrei Elobogoev}

Data East LLC, 23, Musa Jalyl str., Novosibirsk, 630055, Russia

7-383-3320320 info@dataeast.ru

Data East will provide attendees a general overview of the XTools Pro 5 extension for ArcGIS, including a demonstration of the product and hands-on exercises showcasing its popular and powerful tools and features. Usage tips and tricks will be highlighted as well, so participants will become more familiar with all the capabilities of XTools Pro. Any additional discussions, questions or comments will be welcomed and addressed by the Data East presenters.

\section{ERDAS IMAGINE Fundamentals, 1:00 pm - 5:10 pm, By Joe Mostowy}

Leica Geosystems Spatial Imaging, 61 Inverness Drive East, Suite 200, Englewood, CO 80112

303-799-9453x1908 ioseph.mostowy@gi.leica-geosystems.com

This workshop will introduce the software functionality that ERDAS IMAGINE offers in working with remote sensing and photogrammetry applications. The workshop will provide hands-on experience with applications to introduce and enhance the ability of users to use and manipulate image data. The software tools covered will include an overview of the Geospatial Light Table (GLT) viewer, image enhancement and subsetting, creating Area of Interest Layers (AOI's) and Shapefile layers, along with other commonly-used functionality. This is an introductory class; however, more advanced functionality may be addressed if time permits. 


\title{
Introduction to Geodatabases, 1:00 pm - 5:10 pm, By Zachary D. Wilson', David E. Ladd ${ }^{2}$, and Tosca Hoffmann ${ }^{3}$
}

${ }^{1}$ U.S. Geological Survey, Texas Water Science Center, 8027 Exchange Drive, Austin, TX 78754

512-927-3511zdwilson@usgs.gov

${ }^{2}$ U.S. Geological Survey, Tennessee Water Science Center, 640 Grassmere Park, Suite 100, Nashville, TN 37211

615-837-4773 deladd@usgs.gov

${ }^{3}$ ESRI-Denver, One International Court, Broomfield, CO 80021

303-449-7779 thoffmann@esri.com

The geodatabase for ArcGIS offers broad functionality important to scientific research and data management in the U.S. Geological Survey (USGS). Users of coverage and shapefile formats will find familiar elements such as feature classes and topologies in geodatabases; however, enhanced functionality through other geodatabase-specific elements such as relationship classes, subtypes, domains, and geometric networks also is provided. This workshop will introduce geodatabase concepts, describe the geodatabase elements, demonstrate geodatabase use in USGS projects, and provide an opportunity to explore some practical geodatabase applications. Workshop participants can expect to achieve a basic understanding sufficient to begin incorporation of geodatabases in their projects.

\section{Spatial Analysis Tools of ArcGIS, 3:15 pm - 5:10 pm, By Steve Kopp}

ESRI, 380 New York Street, Redlands, CA 92373-8100

909-793-2853 skopp@esri.com

Spatial data analysis, finding answers to problems, is the heart of the geospatial information system (GIS) industry. This session will present an overview of the analysis capabilities available in ArcGIS 9.2 (raster, vector, 3-dimensional, and statistics) and where to find them. It will highlight new capabilities of recent releases, with particular emphasis on the Spatial Analyst extension, http://www.esri.com/software/arcgis/extensions/spatialanalyst/index.html.

\section{Monday Lecture Sessions}

\section{Climate Variability and Change, 1:00 pm - 2:55 pm, Moderated by Mike Mulligan}

\author{
Land-Cover Mapping of Red Rock Canyon National Conservation Area, By J. LaRue Smith \\ U.S Geological Survey, Nevada Water Science Center, 2730 North Deer Run Road, Carson City, NV 98701 \\ 775-887-7630 ilsmith@usgs.gov
}

In cooperation with the Bureau of Land Management, the Nevada Water Science Center (NWSC) is producing a land-cover map of the Red Rock Canyon National Conservation Area, Clark County, Nevada, using QuickBird high resolution satellite imagery acquired during the summer of 2006. The imagery, delivered from DigitalGlobe, was orthorectified and radiometrically corrected. The imagery of Clark County was enhanced by the NWSC to be used as an image base map. Enhancements included solar geometry correction, linear histogram matching of all strips of imagery, mosaicking of partial scenes, and spatial merging of the high resolution panchromatic band with the lower resolution multispectral bands using the wavelet merge technique. The data sets were assembled into an ArcGIS raster catalog for ease of display and color balancing of all images.

The land-cover classification will map vegetation at the floristic levels of alliance and association when possible, using the U.S. National Vegetation Classification (NVC) system. Roads, trails, and spring features will be included. In collaboration with senior faculty in the Biology Department of the College of Southern Nevada, data at sample field plots in Clark County are collected, including location information, environmental descriptions, ground cover, and vegetation descriptions using the protocol of the NVC Program. Ground spectra also were collected during the acquisition period of the QuickBird imagery. This information was used during correction of the imagery for atmospheric effects and conversion to percent reflectance using the ATCOR2 software. Using the field plot information, classification will be performed by feature extraction and hierarchical learning using Feature Analyst software. Spectral classification also will be performed using ERDAS IMAGINE software; final classification 
has not started. The goal is to have concordance between the independently derived and analyzed field data and between the independently derived and analyzed spectral data. It is anticipated that the final land-cover classification produced will include products from Feature Analyst and IMAGINE, and will involve photo interpretation.

\title{
Alaska 2001 National Land-Cover Database-Unique Challenges, By Catherine Costello
}

U.S. Geological Survey, Rocky Mountain Geographic Science Center, Box 25046, DFC, MS 516, Denver, CO 80225-0046 303-202-4278 ccostello@usgs.gov

The final piece of the 2001 National Land-Cover Database (NLCD) to be completed is the state of Alaska. The NLCD, which describes the land surface of each 30-meter land cell in the United States, is a cooperative effort between the U.S. Geological Survey (USGS) and the Multi-Resolution Land Characteristics (MRLC) Consortium. This is the first effort by the USGS to create state-wide land-cover data at this resolution. Nineteen land-cover classes are portrayed in the Alaska NLCD 2001 data set broadly defining the natural vegetation, agriculture, water, and urban areas.

Alaska was divided into 10 workable pieces called map zones. Each map zone presented unique challenges in land-cover classification. Lack of cloud-free imagery, high-resolution imagery, and field data throughout Alaska required the analysts to find alternative information sources for determining what was on the ground. Large temporal differences in Landsat scenes, mountain shadows in the higher latitudes, additional land cover classes unique to Alaska [massive fire scars, terminal moraines, and drunken forests (trees with shallow roots that bow in all different directions when the permafrost melts and the ground sags)], also inspired analysts to seek creative solutions for their interpretation.

\section{Rapid Land Cover Mapper: An Introduction, By Wm. Matthew Cushing', G.G. Tappan', M. Mathis', and L.L. Tieszen² \\ ${ }^{1} S G T$, Contractor to the U.S. Geological Survey, EROS, $47914252^{\text {nd }}$ Street, Sioux Falls, SD 57198 605-594-2766 mcushing@usgs.gol, 605-594-6037tappan@usgs.gol, 605-594-6880 mlmathis@usgs.gov \\ ${ }^{2}$ U.S. Geological Survey, EROS, $47914252^{\text {nd }}$ Street, Sioux Falls, SD 57198 605-594-6056 tieszen@usgs.got}

Mapping land use and land cover (LULC) over large areas and through time has always presented major challenges. There are two contrasting approaches to LULC mapping: automated/semi-automated classifications, and manual photo-interpretation. The first approach is fast and efficient in classifying large areas, but is problematic when comparing two or more periods. The photo-interpretation method produces good results for time-series mapping, but is labor-intensive for large areas. A new tool was developed, the Rapid Land Cover Mapper (RLCM), which addresses these challenges. The RLCM tool is a vector/raster hybrid approach that lends itself to multiple resolution and time series mapping of LULC, and many other geographic themes. Conceptually, it is based on the traditional dot grid method for calculating areas that has long been employed by foresters and other users of aerial photography. The RLCM tool generates a digital dot grid and overlays it on an image within Environmental Systems Research Institutes (ESRI's) ArcMap geographic information system (GIS) software. Using standard photo-interpretation techniques, the interpreter identifies the discrete LULC class for each dot, and the RLCM tool facilitates the selection of dots within a common LULC class and applies that classification attribute to them. Once the dot grid matrix is completely classified for a given period, a raster LULC map can be generated. The same process can be applied to different periods, and the resulting maps can be compared to assess change.

\section{Data Integration and Interoperability: Enterprise, 1:00 pm - 2:55 pm, Moderated by Roland Viger}

\author{
Business Requirements for The National Map: Addressing Emerging Needs, By Larry Sugarbaker \\ U.S. Geological Survey, National Geospatial Program Office, 12201 Sunrise Valley Drive, MS 810, Reston, VA 20192-0002 \\ 703-648-5741 lsugarbaker@usgs.gol
}

The U.S. Geological Survey (USGS) Science Strategy, “Facing Tomorrow's Challenges-U.S. Geological Survey Science in the Decade 2007-2017" sets a natural science agenda of National significance. There are current and emerging needs for a foundation of geospatial data to support the science agenda and a wide range of other government and business needs. The National Map is intended to provide the geospatial framework for integrating data to support these needs. 
The USGS currently is reviewing business requirements and identifying high priority needs for integrated enterprise level geospatial databases and map services. Whereas there is a wealth of contextual data available about geospatial data needs, the current study is designed to identify more specific requirements to strengthen the justification for a more robust national map offering. It also will provide initial specifications for the enterprise spatial data framework and document workflows to support the partnership model needed to achieve a sustainable operation. The requirements analysis will allow the USGS to better prioritize research needs as identified in the National Research Council report, "A Research Agenda for Geographic Information Science at the U.S. Geological Survey". The focus of this business requirements effort will be to inform The National Map 3.0 development plan.

Geospatial One-Stop: What's New in Publishing, Discovering, and Using Data in our National Spatial Data Infrastructure, By Robert Dollison

U.S. Geological Survey, 510 National Center, Reston, VA 20192

703-648-4722 rdollison@usgs.gol

Find out what's new with Geospatial One-Stop (GOS, http://www.geodata.gol). New search result visualizations will be presented-including the ability to launch web services onto globes—and methods for checking the status of your published web map services will be covered. Methods of data publishing a through GOS will be reviewed. Learn how GOS and The National Map are moving forward and the future plans to help improve the National Spatial Data Infrastructure (NSDI). The workshop will give attendees hand-on experience with GOS.

A Data Integration and Interoperability Blueprint for the U.S. Geological Survey, By R. Sky Bristol', Kevin T. Gallagher², and Linda C. Gundersen ${ }^{2}$

\author{
${ }^{1}$ U.S. Geological Survey, Denver Federal Center, Building 810, MS 306, Box 25046, Denver, CO 80225-0046 \\ 303-202-4181_sbristol@usgs.gov \\ ${ }^{2}$ U.S. Geological Survey, National Center, 12201 Sunrise Valley Drive, Reston, VA 20192 \\ 703-648-6823 kgallagher@usgs.gov, 703-648-6601 tgundersen@usgs.gov
}

The U.S. Geological Survey (USGS) Geospatial Information Office currently is leading efforts to develop a long-term plan, or "blueprint," for data integration, accessibility, discovery, and interoperability across the USGS. The Data Integration Blueprint includes projects that provide metadata, data content standards, infrastructure, and informatics that enhance scientific techniques, improve data access, provide management visibility, advance the strategic directions of the USGS Science Strategy, and connect the USGS to its partners and collaborators through participation in international efforts to develop a global science and computing platform for the 21 st century. The plan is comprehensive by design; incorporating the data integration and scientific tools development efforts of all the USGS into a single framework with common practices and a seamless infrastructure. The USGS will work with its partners and national and international cyber infrastructure activities to develop this framework.

The USGS maintains a large number of science data sets at local, regional, and national scales. The USGS ability to integrate these data is critical to the achievement of Department of Interior (DOI) mission objectives in Resource Protection, Resource Use, and Serving Communities and the USGS national federal mission of conducting science and serving earth and biological data. Developing a fully integrated scientific data environment will improve the accessibility of science data and information within the USGS, across the DOI, and with its scientific partners, collaborators, and customers in other federal agencies and the public. Greater access to a broad range of integrated scientific data will spark new discovery and support a wider range of inquiry, better informing and enhancing the decision making of managers, policy makers, and stewards of the Nation's resources.

The conduct of science is changing worldwide. There is widespread recognition that the earth's complex natural systems are interrelated and that scientific inquiry must be equally integrated to develop a new understanding of the implications for the environment, land management, resource utilization, and policy making. Complex scientific questions require the analysis, integration, and modeling of science data and information from multiple disciplines, locations, and timeframes. The USGS and its partners, including industry, federal, state and local governments, universities and associations, as well as international scientific organizations are beginning to connect and integrate the data and research techniques of the world's scientists, making them accessible to a global science community and transforming the way in which research, engineering, and education are conducted. 
Original paper published as:

Gallagher, K.T., Bristol, R.S., and Gundersen, L.C., 2007, A Data Integration and Interoperability Blueprint for USGS, in Brady, S.R., Sinha, A.K., and Gundersen, L.C., editors, 2007, Geoinformatics 2007—Data to Knowledge, Proceedings: U.S. Geological Survey Scientific Investigations Report 2007-5199, p. 58-60.

\section{Principles of Data Modeling, By Stan Smith}

U.S. Geological Survey, Alaska Science Center, 4230 University Drive, Suite 201, Anchorage, AK 99508 907-786-7072 stansmith@usgs.gov

As the U.S. Geological Survey (USGS) faces the increasingly complex and interdisciplinary challenges outlined in the USGS Science Strategy, our scientists will require access to a wealth of cross-disciplinary data. To assist in addressing those challenges, the USGS is planning to develop a comprehensive data framework. The plan is to use data modeling techniques to fully document the data needed and produced by the USGS, and to create a framework for integrating these data for use in a variety of envisioned and yet to be conceived applications. Integrated data are an enabling technology for integrated science; data modeling provides the tools and methodology to develop the integrated data.

This presentation provides an overview of data modeling and is targeted at those who wish to understand what data modeling is and the how the data modeling approach aids in the design of integrated databases. The focus is on defining data-modeling products and providing the audience with the rationale for using data modeling. The subjects are addressed without covering the mechanics of building or interpreting data models.

The topics to be covered are the data modeler's goal of "making data more desirable", defining what is a data model, defining data modeling, previewing the data modeling products, and fitting the data modeling products together in a systems and database development cycle.

\section{Custom Tools, Scripting, and Tweaks, 1:00 pm - 2:55 pm, Moderated by Curtis Price}

\section{Developing a Custom Scale Dependent Renderer for ArcMap using ArcObjects, By David S. McCulloch}

U.S. Geological Survey, 505 Science Drive, Madison, WI 53711

608-238-9333 dmccullo@usgs.gov

ArcMap has a rich set of tools and functionality for developing cartographic products, including map scale dependent rendering; however, ArcMap's map scale-dependent rendering has limitations, especially when the range of required map scales is large. This presentation describes the limitations of ArcMap's map scale-dependent rendering for a particular application, the typical methods for working around those limitations, and finally the development of a custom map scale-dependent renderer for the final solution.

\section{A 3-Dimensional Visualization Technique for Exploring Multivariate Geochemical Data, By Stuart A. Giles \\ U.S. Geological Survey, Denver Federal Center, MS 973, Box 25046, Denver, CO 80225-0046 \\ 303-236-5515 sgiles@usgs.gov}

Traditional 2-dimensional (2D) mapping techniques become inadequate when dealing with large amounts of precise pointsource geochemical data, particularly when comparing data sets for dozens of elements from multiple media types. This especially is the case when the samples have been analyzed by several laboratories using differing analytical methods. A 3-dimensional (3D) mapping technique using oblique perspective views with manipulation of symbolization layers and camera angles provides a basis for creating information-dense maps that explore the relation between multiple overlapping geochemical values, landscape, and geology. Advantages of the technique include reducing mapping time, effort, and printed materials while generating a variety of high-quality digital map products with interactive layering and animations tailored for a professional audience.

The technique utilizes Environmental Systems Research Institute (ESRI) geographic information system (GIS) and web server software, a combination of 2D and 3D symbolization layers for the geochemical data, and high-resolution digital elevation 
data. First, a base map is constructed with topography, shaded relief, and layers consisting of sampling sites and other relevant features located at or below ground level. Point shapefiles are generated from the various geochemistry data, classified by percentiles, and symbolized with 3D spheres sized and colored according to their respective classes. The symbolized layers are assigned artificial elevations to arrange them in the map volume, and the individual symbols are then connected to the ground sampling sites using extruded lines. Camera angles, elevation, and zoom are then manipulated with the software to create views and animations that maximize information value.

The technique was applied to analyze multiple geochemical data sets for samples collected in the summer of 2007 at and near the Pebble porphyry Cu-Au-Mo deposit in southwest Alaska. Simultaneous comparison of many factors was possible, including values of a single element or entire elemental suites across multiple sites, analytical results relative to totals or factors such as $\mathrm{pH}$, relation between surface geochemistry and the geology and structure of the deposit, surface geochemistry relative to drill core geochemistry or geophysical data, and comparisons of the analytical methods and performance from multiple laboratories. The software also was used to export the maps as 2D images, generate fly-through animations, and web serve the maps in a form that could be viewed and explored by individuals with no GIS experience.

\section{ArcInfo Workstation Functionality using Python Script Tools, By Curtis Price}

U.S. Geological Survey, South Dakota Water Science Center, 1608 Mountain View Road, Rapid City, SD 57702 605-394-3242 cprice@usgs.gov

ArcInfo Workstation software, despite limitations and no substantial modifications or updates for almost a decade, is still an important part of the ArcInfo Desktop system. The older Workstation system is useful for certain geographic information system (GIS) applications because of stability, performance, and system independence (it is supported on Windows and several UNIX operating systems). In addition, ArcInfo Workstation includes certain functionality not available in ArcInfo Desktop, such as data conversion of legacy GIS file formats and coverage processing.

The usual access methods applied to ArcInfo Workstation functionality from ArcGIS Desktop include using the Coverage Toolbox (which uses a version of the Workstation command-line interface encapsulated in Microsoft "COM" objects), and running Arc Macro Language (AML) programs in the ArcGIS Geoprocessing toolbox "script tool" interface. The "script tool" method requires special configuration of the Windows operating system to make AML files executable.

An alternative method has been implemented to access ArcInfo Workstation using a Python script tool through the ArcGIS geoprocessing environment. A method from the Python standard libraries (os.popen2) was used to open an ArcInfo Workstation session in a system shell and interact with it from the Python script.

This Python-based access to ArcInfo Workstation offers several advantages over other approaches, including relative system independence (as this approach could be used on the UNIX platforms that support ArcInfo Workstation and ArcGIS Server), better performance, and the ability to pass ArcInfo system messages (including error messages) to the ArcGIS geoprocessing environment.

\section{Streamlined Geologic and Geochemical Data Collection Using a Personal Digital Assistant and Bluetooth Global Positioning System, By Edward P. Klimasauskas}

U.S. Geological Survey, Minerals Program-Alaska Science Center, 4200 University Drive, Anchorage, AK 99508 907-786-7436 eklimasa@usgs.gov

A low cost digital data collection system was developed using a Personal Digital Assistant (PDA), Bluetooth Global Positioning System (GPS), and Pocket PC Creations software to streamline the process of documenting geological sample collection. Customized "sample cards" allow for the simultaneous collection of location and desired attribute data. Transferring these data and converting to Excel format facilitates rapid sample tracking and submittal procedures for geochemical analysis. Analytical results can later be easily linked with field data. Subsequent conversion to point coverage provides a rapid means of visually exploring geochemical data on a local or regional scale and plotting on maps. 


\title{
Introduction to Visual Learning Systems Feature Analyst, 1:00 pm - 2:55 pm, By Raj Mohan Rao
}

Visual Learning Systems, Inc., P.O. Box 5012, Missoula, MT 59806

1-866-your-vls

Abstract Not Submitted

\section{Understanding Ecosystems and Predicting Ecosystem Change, 3:15 pm - 5:10 pm, Moderated by Mike Mulligan}

\author{
A Newly Revised Federal Geographic Data Committee National Vegetation Classification Standard, By M.P. Mulligan \\ U.S. Geological Survey, Denver Federal Center, MS 302, Building 810, Denver, CO 80225-0046 \\ 303-202-4242 mpmull@usgs.gov
}

The Federal Geographic Data Committee (FGDC) has recently (2/25/08) approved a major revision to the National Vegetation Classification Standard (FGDC-STD-005, Version 2). Originally released in 1997, the current revision expands this hierarchical standard for natural extant vegetation to middle and lower classification levels (that is, ecologically based physiognomic and floristic) and for the first time extends classification to cultural vegetation. The revised standard also has been introduced with a dynamic implementation plan, which will allow for more timely and flexible extensions, as needed in the future. The interim prototype of this standard currently is in use in the National Park Service's Vegetation Mapping Program and by U.S. Geological Survey (USGS) cooperators in that effort.

In its extended form, the standard will be more useful in achieving its original purpose; to support the development and use of a consistent national vegetation classification. The standard establishes national procedures for classifying existing vegetation for the United States and Trust Territories that shall be used by federal agencies to share or crosswalk vegetation information and to facilitate reporting of national statistics across ownerships. If implemented as envisioned, it likely will play a substantial role in facilitating USGS Science Strategy Topic "Understanding Ecosystems and Predicting Ecosystem Change", by providing a scientifically robust and detailed protocol for describing existing vegetation at various geospatial scales. The discussion will include history, partners, revision, and implementation plan strategy. Work performed under USGS contract 03CRCN0001

\section{The Vital Signs Internet Map Service Atlas Project, By Peter Budde}

National Park Service, Natural Resources Program Center, 1201 Oakridge Drive, Suite 150, Fort Collins, CO 80525 970-225-3559 peter_budde@nps.gov

The Vital Signs Internet Map Service (VSIMS) Atlas project is designed to distribute web-based geographic information system (GIS) maps while tolerating several users. The VSIMS Atlas uses unique technologies such as tiled imagery, data snapshots, Adobe Flex, and compressed eXtensible Markup Language (XML) data to accomplish this task. The difficulties of standard web mapping technologies, such as ArcIMS and ArcGIS Server, will be discussed, and how the Atlas's alternative technologies allow for higher-volume data access and dissemination.

\section{Sensor Fusion for the Preservation of Eagle Habitat, By Mark Romano and Raul Campos-Marquietti}

Merrick \& Company, 2450 S. Peoria Street, Aurora, CO 80014

Mark.ramono@merrick.com Rau.campos-Marquetti@merrick.com

www.merrick.com/mars

This presentation describes the fusion of remotely-sensed data for streamlined decision making about a wildlife habitat. The fusion methodology uses 0.33 meter Digital Airborne Camera (DACS-II) digital orthophotography, 1.0 meter light detection and ranging (LiDAR), and hyperspectral visible and near-infrared (VNIR) imagery to identify cottonwood trees that serve as eagle habitats along the Missouri River.

Analysis results include the generation of individual and clusters of cottonwood trees as canopy point clouds and 3-D objects. Each 3-D object was attributed as to tree type, maximum tree height, crown diameter, estimated trunk diameter at breast-height, 
and suitability as a potential bald eagle nesting platform. All data processing and analysis was conducted within MARS® Explorer, ENVI and ArcMap software packages.

Merrick \& Company and the U.S. Army Corps of Engineers concluded that the integration of LiDAR, digital orthophotography, and hyperspectral data created superior scientific results compared to traditional approaches.

Spatial Modeling of Near-Shore Habitats, Grand Canyon, By Michael Breedlove, Craig Anderson, and Thomas Gushue

U.S. Geological Survey, 2255 North Gemini Drive, Flagstaff, AZ 86001

928-556-7344 mbreedlove@usgs.go, 928-556-7117 canderson@usgs.go, 520-556-7370 tgushue@usgs.gov

Abstract Not Submitted

Partnerships, 3:15 pm - 5:10 pm, Moderated by Sharon Shin

\author{
The Program Partners Working Group: A Critical Federal Collaboration, By Wendy A. Budd
}

U.S. Geological Survey, National Center, MS 590, 12201 Sunrise Valley Drive, Reston, VA 20192-0002

703-648-4786wbudd@usgs.gol

The U.S. Geological Survey (USGS) in collaboration with the National Geospatial-Intelligence Agency (NGA), and the Department of Homeland Security (DHS) formed The Program Partners Working Group (PPWG) in late 2007 to create and maintain geospatial information needed to support homeland security. The intersection of the USGS mission for geospatial information, NGA's mission in support of national security objectives, and DHS's role in homeland security makes this partnership essential to providing comprehensive geospatial information to Federal, state, and local organizations responsible for homeland security. Initial work of the PPWG has focused on two areas: data acquisition and development of the Homeland Security Infrastructure Program (HSIP), Freedom. By leveraging funds from Federal and State organizations, the PPWG facilitates the acquisition of high resolution imagery and light detection and ranging (LiDAR) data, which become available through The National Map. HSIP Freedom fosters collaboration with state and local governments for data as a follow-on to the HSIP Gold Database. The HSIP Gold Database is a compilation of geospatial data characterizing domestic infrastructure and boundaries assembled from a variety of Federal agencies and commercial vendors. Whereas HSIP Gold includes licensed data restricted to Federal use, HSIP Freedom is being compiled in collaboration with state and local governments and will be license-free. HSIP Freedom will be a unified homeland infrastructure geospatial data inventory assembled for common use by the Federal Homeland Security and Homeland Defense Community across all levels of government.

NativeView: U.S. Geological Survey Geospatial Data for Native America, By James Rattling Leaf, Susan M. Marcus², Gene Napier ${ }^{3}$, and Bonnie Gallahan ${ }^{4}$

${ }^{1}$ Institute of Atmospheric Science, 501 East St. Joseph Street, Rapid City, SD 57701

605-394-1983 james.rattlingleaf@sintegleska.edu

${ }^{2}$ U.S. Geological Survey, Office of the Director, 104 National Center, 12201 Sunrise Valley Drive, Reston, VA 20192

703-648-4437smarcus@usgs.gov

${ }^{3}$ U.S. Geological Survey, EROS, $47914252^{\text {nd }}$ Street, Sioux Falls, SD 57198

enapier@usgs.gov

${ }^{4}$ U.S. Geological Survey, 590 National Center, 12201 Sunrise Valley Drive, Reston, VA 20192

703-648-6084 bgallahan@usgs.gol

NativeView is part of an initiative to make geospatial information, particularly U.S. Geological Survey (USGS) geospatial information, available to tribes, native students, and their communities. NativeView is a uniquely Native American version of the AmericaView activity. AmericaView is state-based and run through state universities. Tribes are not parts of States and have different information needs, infrastructure, funding, and research capabilities. Although it was initially thought that tribal colleges could participate in AmericaView through the State universities, this did not prove feasible. NativeView is run by a board of tribal college instructors and has received no direct funding from the USGS, although USGS helped establish the group and provides guidance to it. Tribal colleges and universities serve mostly rural, tribe-specific populations. Most of the 34 tribal colleges and universities are accredited 2-year institutions, though more are offering 4-year degrees as well. The USGS created the Tribal College Forum in support of NativeView, and has sponsored it for each of the past six years. The Forums include panel 
discussions of tribal and tribal college needs, presentations of geospatial information uses by USGS, National Aeronautics and Space Administration (NASA), and other scientists, and tribal college presidents, professors, and students. NativeView provides an organizational focus for the distribution of USGS geospatial information to Native American governments through their academic institutions. The Tribal College Forum provides a means for demonstrating the relevance and usefulness of geospatial techniques and data. We look forward to working with USGS geographic information system (GIS) experts to expand the distribution of USGS information to Native American institutions and supporting tribal capacity-building to make USGS information more relevant to tribes.

\title{
Energy and Minerals for America's Future / Custom Tools, Scripting, and Tweaks, 3:15 pm - 5:10 pm, Moderated by Eric Anderson and Laura Biewick
}

\author{
Multidisciplinary Geographic Information System (GIS) Computing for a Country-Wide Mineral Resource Assessment \\ Project in Africa: ASTER-based Mineral Mapping and 3-Dimensional Terrain Visualization in a Portable GIS/Global \\ Positioning System Environment, By Eric D. Anderson' and Barnaby W. RockwelR \\ ${ }^{1}$ U.S. Geological Survey, Denver Federal Center, Crustal Imaging and Characterization Team, MS 964, Box 25046, Denver, CO \\ 80225-0046 \\ 303-236-5652 ericanderson@usgs.gov \\ ${ }^{2}$ U.S. Geological Survey, Denver Federal Center, Mineral Resource Team, MS 973, Box 25046, Denver, CO 80225-0046 \\ 303-236-1851 barnabyr@usgs.gov
}

Desktop geographic information system (GIS) has proven to be a tremendously powerful office tool for geoscientists. It allows multidisciplinary data to be viewed and analyzed within one system, thereby facilitating data interpretation. The capabilities and power of laptop computers have become sufficient to run GIS applications for scientists working in the field. Furthermore, a handheld or internal Global Positioning System (GPS) unit can be integrated with the laptop GIS, thereby transforming the system into a real-time, mobile GIS workstation with relevant data and current position displayed on the screen, even further enhancing data interpretation and analysis while making field observations. Three GPS-enabled laptop computers were set up for a four week field campaign in the Islamic Republic of Mauritania (IRM) that took place during the fall of 2007. The main objective of the fieldwork was to visit and sample as many reported mineral occurrences as possible to gain a better understanding of Mauritanian geologic environments and deposit types as part of a country-wide mineral resource assessment funded by the World Bank. The multi-scale and multidisciplinary geospatial data for the Mauritania project include geology, geochemistry, geophysics, remote sensing, and hydrology. Geospatial data from each geologic discipline consists of numerous derivative products that were integrated in a master GIS project. A mineral occurrence database was used to provide GPS waypoints. All travel was tracked in real time and the routes were saved as shapefiles to be used in subsequent trip documentation. A GPS-enabled camera was used to document the mineral occurrences by producing geolocated photographs. Multispectral image data collected by the Advanced Spaceborne Thermal Emission and Reflection Radiomenter (ASTER) sensor were analyzed to aid in lithologic discrimination and hydrothermal alteration detection and characterization in five areas with high potential for undiscovered metallic mineral resources. The mineral maps generated from the ASTER data were integrated with ASTER-derived Digital Elevation Models (DEM) for three-dimensional visualization using ERDAS IMAGINE VirtualGIS Software. The integration of the GPS and GIS greatly facilitated the fieldwork. The vast expanses of desert and savannah backcountry proved to be difficult terrain in which to navigate using traditional hardcopy maps that often were inaccurate and/or outdated. Real-time geolocation was essential for finding individual mineral/metal occurrences, route-finding in roadless areas, and for facilitating interpretation of the numerous GIS data sets. The portable GIS thus served as an essential and efficient field mapping and geolocation tool that substantially contributed to the success of the field campaign. 
Sources, Transportation, and Fate of Natural Oil and Gas Seeps, Southern California, By Florence Wong', Tom Lorenson', Pete Dartnell', John Day², Grace Fong ${ }^{3}$, Mary Elaine Helix', Pat Hart', Fran Hostettler', Keith Kvenvolden', Ira Leifer ${ }^{5}$, Ken Peters ${ }^{1}$, Bob Rosenbauer', and Jamie Conrad"

${ }^{1}$ U.S. Geological Survey, Coastal and Marine Geology Team, MS 999, 345 Middlefield Road, Menlo Park, CA 94025 650-329-5327fwong@usgs.gov, 650-329-4186tlorenson@usgs.gov, 650-329-5460 pdartnell@usgs.gov, 650-329-5160 hart@usgs.gov, 650-329-4584fdhostet@usgs.gov, 650-329-4196kkvenvolden@usgs.gov, 650-329-5171 kpeters@usgs.gov, 650-329-4198brosenbauer@usgs.gov, 650-329-5402 jconrad@usgs.gov

${ }^{2}$ County of Santa Barbara Energy Division, Santa Barbara, CA 93101

805-568-2045 jday@co.santa-barbara.ca.us

${ }^{3}$ Burlingame, CA 94010

415-515-7290 grace_fong@comcast.net

${ }^{4}$ Minerals Management Service, Oakland, CA 94607

510-817-1477 maryelaine.helix@mms.gov

${ }^{5}$ University of California, Santa Barbara, CA 93106

805-893-4931ira.leifer@bubbleology.com

Tar and oil residues are common on California beaches, especially in southern California where natural oil seeps are present. Baseline information on tar and oil accumulations from natural seeps and man-made spills is sought in order to manage the offshore production of oil and gas. The Minerals Management Service and the County of Santa Barbara have funded the U.S. Geological Survey (USGS) organic geochemistry group in Menlo Park, California, to provide geochemical information that can be used to discriminate between natural seep and anthropogenic tar sources. Phase 1 of the study identified three geochemically distinct hydrocarbon groups refined into 13 subgroups from almost 400 beach and seep samples, all attributable to the Miocene Monterey Formation. Phase 2 will include geochemical analyses of the oils on and near production platforms, natural oil seepage rates, and regional geologic mapping. Data and analyses are managed in an extensive geographic information system (GIS). A database of geochemical analyses for 684 samples collected since 2001 include descriptions of sample locations, values for as many as 36 analytes, and the hydrocarbon group determined by chemometric modeling. Maps of the data show the relation of the samples to Monterey Formation exposures, previously mapped oil and gas fields, and ocean surface oil slicks detected in satellite imagery. http://walrus.wr.usgs.gov/research/projects/oilandgasseep.html

\section{System Administration Suggestions, 3:15 pm - 5:10 pm, Hints, and Insights, By Ryan M. Stevens}

\section{U.S. Geological Survey, 2255 North Gemini Drive, Flagstaff, AZ 86001}

928-556-7116 rmstevens@usgs.gov

A team of Information Technology (IT) and Geographic Information System (GIS) specialists from the U.S. Geological Survey will present suggestions regarding successful ArcGIS installation and implementation within the Bureau. Specific topics will include hardware selection available via the Department of the Interior (DOI) contract, the outlook for implementing GIS software through Active Directory Group Policy Objects (GPO), security considerations (including separated credentials and data encryption), and software upgrade strategies.

\section{Monday GIS Town Hall Meeting, 5:30 pm - 8:00 pm}

\section{Mapping All That is White: Antarctic Science and Operations Viewed Through Geospatial Data, By Thomas Wagner' and Paul Morin²}

${ }^{1}$ NSF, Office of Polar Programs, 4201 Wilson Blvd., Rm 755, Arlington, VA 22230

703-292-4746 twagner@nsf.gov

${ }^{2}$ Antarctic Geospatial Information Center, Department of Geology and Geophysics, University of Minnesota

612-978-2964lpaul@umn.edu

Abstract Not Submitted 


\title{
Presentation Titles and Abstracts, Tuesday, May 13, 2008
}

\author{
Tuesday Plenary 8:00 am - 10:05 am
}

Integrating Data to Accelerate Integrated Science, 8:00 am - 8:50 am, By Mark Myers, Director, U.S. Geological Survey

U.S. Geological Survey, Director, 12201 Sunrise Valley Drive, MS 100, Reston, VA 20192-0002

703-648-7411 mmyers@usgs.gor

Abstract Not Submitted

Center for Disease Control and Prevention's Healthy Communities and BioPHusion Programs, 8:50 am - 9:45 am, By Brian Kaplan

Geospatial Research, Analysis, and Services Program, ATSDR, Centers for Disease Control and Prevention, 4770 Buford

Highway NE, MS F09, Atlanta, GA 30341-3717

770-488-3856 bkaplan@cdc.gov

Abstract Not Submitted

Tuesday Hands-on Sessions

Workshop about Definiens Software for Operational Image Analysis-Closing the Gap Between Remote Sensing and Geographic Information Systems, 1:00 pm - 5:10 pm, By Gregor Willhauck', Caroline Rogg', Christian Hoffmann², Tilo Schnur', and Juan Caliz'

${ }^{1}$ Definiens AG, Trappentreustrasse 1,80339 Munchen, Germany

49-089-231180-0 earth@definiens.com

${ }^{2}$ Definiens Inc., 55 Madison Avenue, Suite 400, Morristown, NJ 07960

1-973-285-3291 earth@definiens.com

The Definiens Cognition Network Technology is different from conventional data analysis. The technology emulates human cognitive processes by recognizing image objects and their context within an overall scene. This approach is different than analyzing groups of image pixels. The context analysis of the neighboring objects is used to formulate rules not depending on spectral information, like 'Island objects are always surrounded by water'.

Definiens technology enables extraction of geo-information from any kind of remote sensing imagery such as Synthetic aperture Radar (SAR), Light Detection and Ranging (LiDAR), panchromatic, multispectral, and hyperspectral sensors mounted on satellite and aerial platforms.

Definiens core products are Definiens Developer, Definiens eCognition TM Server, and Definiens Architect. Definiens Developer facilitates and accelerates the development of image analysis applications and includes a Software Development Kit (SDK). Definiens eCognition TM Server software provides a processing environment for the batch execution of image analysis jobs. Based on a specialized grid architecture designed specifically for large scale image analysis projects, the Definiens eCognition ${ }^{\circledR}$ Server can automatically process thousands of images and perform detailed analyses in a single, fully-automated step. The Definiens Architect is a simple end user tool that enables domain experts and other users to calibrate and run pre-packaged image analysis applications created with Definiens Developer. 
The workshop topics will range from Rule Set development with Definiens Developer, to batch processing, and working with a simple user interface provided by Definiens Architect. The workshop uses an example of shrub density classification. The individual shrubs will be classified and their density analyzed, resulting in a heat map. The concepts of creating image objects, different methods and strategies of classification, and interactions with Definiens products will be explained

\section{Getting the Most Out of Your Geobrowser, 1:00 pm - 5:10 pm, By Gregory L. Gunther and Richard W. Spengler}

U.S. Geological Survey, Denver Federal Center, MS 939, Box 25046, Denver, CO 80225

303-236-5884 ggunther@usgs.gov, 303-236-5050x238 rspengle@usgs.gov

The abundance of and necessity to use geographically-oriented data in business and science today has fostered the development of a new set of innovative tools designed to help users publish, discover, and access information in a collaborative environment. Recently termed Geobrowsers, these powerful and easy to use tools facilitate one's ability to display, update, analyze, or annotate data or information in a fully immersive, three-dimensional representation of the globe directly from an office desktop or laptop in the field. This 4-hour workshop provides an introduction to these innovative platforms and examines methods to maximize their use for data and information delivery, discovery, and use in collaborative projects. It also presents a brief survey of the most popular options available, focusing in detail on Environmental Systems Research Institute (ESRI) ArcGIS Explorer and Google Earth, but also including Microsoft Live 3-dimensional (3D) and National Aeronautics and Space Administration (NASA) World Wind. Discussions, demonstrations, and hands-on exercises will include authoring tools and techniques; preliminary examination of the Keyhole Markup Language (KML); and advanced topics such as extending the ArcGIS Explorer task framework and accessing web resources as well as services.

\section{Finding and Using U.S. Geological Survey and Other Spatial Data Online, 1:00 pm - 2:55 pm, $B y$ Joseph Kerski}

ESRI, One International Court, Broomfield, CO 80021-3200

303-449-7779 jkerski@esri.com

The proliferation of data portals from local, state, national, tribal, and international governmental organizations, private companies, universities, and nonprofit organizations has made it easier than ever to find public domain spatial data sets. In addition, many of these data portals operate as web mapping services that can be brought into ArcGIS while still online. However, formats, projections, and scales of available data vary, and the lack of a true "one stop shop" for all spatial information means that mining the Internet for spatial data can sometimes be difficult. This hands-on session will allow attendees to practice with real-world examples in demography, geology, hydrology, biology, and other disciplines. Attendees will gain experience downloading, formatting, and using data from major and minor spatial data portals to solve problems within the geographic information system (GIS) environment.

\section{Global Mapper: Geographic Information System Viewing and Editing Software Package, 3:15 pm - 5:10 pm, By Dan Daniels}

U.S. Geological Survey, Denver Federal Center, MS 510, Box 25046, Denver, CO 80225-0046

303-202-4401 ddaniels@usgs.gov

This overview/hands-on session will cover a range of Global Mapper capabilities using imagery, elevation, and vector data sets. Attendees will learn to create diagrams and other visual aids for two-dimensional (2D) and three-dimensional (3D) data. Projection and data conversion along with Light Detection and Ranging (LiDAR) 3D point triangulation and raster processing will be covered using interactive and batch methods. Other Global Mapper software functions to be presented include contour generation, view shed analysis, and profiling. 


\title{
Introduction to ArcGIS, 1:00 pm - 5:10 pm, By Tosca D. Hoffmann
}

ESRI-Denver, One International Court, Broomfield, CO 80021

303-449-7779 thoffmann@esri.com

ArcGIS Desktop is one of Environmental Systems Research Institutes (ESRI's) main products for geographic information system (GIS) data management, metadata, map production, analysis, and cartography. This product has been used by the U.S. Geological Survey to perform these varied GIS tasks. ArcGIS Desktop was unveiled in 1999 (v. 8.0) and has progressed significantly to its current version (9.2). Former users of ARC/INFO Workstation 7.x and ArcView 3.2 have been migrating to ArcGIS Desktop to manage their GIS data and projects. This workshop will highlight the purpose of each application, its specific functionality, and best practices workflow for each ArcGIS Desktop application-ArcCatalog, ArcMap, and ArcToolbox. Those attending will learn 'what' each application (and tool) does, the 'why' behind its design, and 'how' it works.

\section{Tuesday Lecture Sessions}

\section{A Water Census of the United States, 10:05 am - 12:00 pm, Moderated by Steve Aichele}

\author{
The National Hydrography Data Set, By Jeff Simley \\ U.S. Geological Survey, Denver Federal Center, MS 510, Box 25046, Denver, CO 80225-0046 \\ 303-202-4131 jdsimley@usgs.gov
}

The National Hydrography Data set (NHD) is the surface water component of The National Map, which provides the United States with access to basic geographic information that describes the landscape of the nation. The NHD is a comprehensive set of digital spatial data that represents the surface water using common features such as lakes, ponds, streams, rivers, canals, and oceans. These data are designed to be used in general mapping and in the analysis of surface-water systems using geographic information systems. In mapping, the NHD is used with other themes of data such as elevation, boundaries, and transportation to produce general reference maps. In analysis, the NHD is used by scientists to study surface water using geographic information system technology. This takes advantage of a rich set of embedded attributes that can be processed to generate specialized information largely possible because the NHD contains a flow direction network that traces the water downstream or upstream. It also uses an addressing system to integrate specific information about the water such as water discharge, water quality, and fish population. Using the basic water features, flow network, linked information, and other characteristics, it is possible to study cause and affect relations, such as how a source of poor water quality upstream might affect a fish population downstream.

\section{NHDPlus Watershed and Reporting Toolset for the Connecticut River Watershed Atlas, By Craig Johnston and John Waterman ${ }^{2}$}

${ }^{1}$ U.S. Geological Survey, 361 Commerce Way, Pembroke, NH 03275

603-226-7843 cmjohnst@usgs.gov

${ }^{2}$ GSC Research LLC, 115 South $4^{\text {th }}$ Street West, Missoula, MT 59801

802-473-4009jwaterman@gcs-research.com

The Connecticut River Watershed Atlas is a web mapping application that serves to share natural resource and environmental databases in a watershed setting tied to stream network and catchment features of the National Hydrography Data set Plus (NHDPlus). To meet the project objective, a Service-Oriented Architecture (SOA) toolset has been developed for the Connecticut River Watershed Atlas. The benefits of the custom toolset allow organizations to perform geospatial analysis by delineating watersheds on-the-fly via the NHDPlus navigation functionality performed on the server side of the application. The NHDPlus Watershed and Feature Report tools allow users to access multiple precomputed stream and watershed characteristics for approximately 12,500 stream segments. The SOA will include a web application and ArcGIS Explorer clients. ArcGIS Server 9.3 beta technology will be used as the foundation for geospatial feature extraction. Custom query tools built using ArcGIS Server allow users to explore the data and locate features. Linkages to stream-gaging information in near real-time from the U.S. Geological Survey National Water Information System also has been incorporated into the Atlas. Future possibilities will be discussed including incorporation of higher-resolution StreamStats web services. 
A Method for Estimating Monthly Streamflow Using the Analysis of Flow In Network Channels Regression Model, Water-Use Data, and the National Hydrographic Data Set, By Steve Aichele and David Holtschlag

U.S. Geological Survey, Michigan Water Science Center, 6520 Mercantile Way, Suite 5, Lansing, MI 48911 517-887-8918 saichele@usgs.gov. 517-887-8910dholtschlag@usgs.gov

Analysis of Flow in Networks of Channels (AFINCH) is a constrained regression model to estimate monthly streamflow in reaches and natural runoff from associated catchments described by the National Hydrographic Data set (NHD) and associated catchments (NHDPlus). Estimates are based on monthly streamflow measured at gaging stations, water-use information at specified locations along reaches, climatic data across catchments, and persistent basin characteristics. Monthly estimates conserve flow throughout the network and are constrained to match measured monthly flows. The estimation technique adapts to annual changes in the streamflow-monitoring network.

The AFINCH approach provides a natural framework to integrate water-use information into streamflow analyses. This presentation describes concepts and challenges associated with application design, data requirements, development techniques, implementation methods within AFINCH, and preliminary results for hydrologic subregion 0405, which drains the southwestern corner of Michigan's Lower Peninsula. These results provide estimates of flow each month from 1971 to 2003 at more than 10,000 NHD reaches (flowlines) in the subregion. These monthly flow estimates at each reach can be tested for trends and used to compute flow-duration characteristics and are being used in the Great Lakes Basin Pilot of the National Water Availability Program to understand the variability of surface-water resources in the context of both increasing human use and climate change.

\section{Center of Excellence for Geospatial Information Science (CEGIS), 10:05 am - 12:00 pm, Moderated by Roland Viger}

Implementing a Research Agenda to Address Challenging Geographic Information Science Issues, By Michael P. Finn and E. Lynn Usery

U.S. Geological Survey, Center of Excellence for Geographic Information Science, 1400 Independence Road, Rolla, MO 65401 573-308-3931 mfinn@usgs.gon.573-308-3837usery@usgs.gov

Two years ago, the U.S. Geological Survey (USGS) requested the National Research Council (NRC) to develop recommendations for a research agenda in geographic information science to support The National Map and the National Spatial Data Infrastructure (NSDI). The NRC provided short- and long-term recommendations on research priorities for the USGS Center of Excellence for Geospatial Information Science (CEGIS). This year, CEGIS began implementation of the recommendations from the NRC report with five short-term research projects of high priority in the areas of design of the electronic topographic map, user-centered design of a Web interface, data integration, generalization, and ontology for The National Map.

Long-term research includes fusing geospatial data with non-spatial data, determining how an ontology of features can operationally support The National Map, temporal and spatial change representations, and other topics. CEGIS will continue to develop research projects based on the recommendations in the report. As a distributed virtual center, CEGIS relies on government, academic, and private industry staff, and on broad area announcements and grants to support the research agenda. This research will significantly contribute to the goals of the NSDI and The National Map towards integrating capabilities that allow for innovative examination and representation of the Earth's system as a whole.

Quantifying Error Propagation and Prediction Uncertainty for Raster Processing using Raster Error Propagation tool, By Sharon L. Qi', Jason J. Gurdak², and Michael Geisler

${ }^{1}$ U.S. Geological Survey, Cascades Volcano Observatory, 1300 SE Cardinal Court, Bldg. 10, Suite 100, Vancouver, WA 98683 360-993-8977slqi@usgs.gov

${ }^{2}$ U.S. Geological Survey, Denver Federal Center, MS 415, Box 25046, Lakewood, CO, 80225-0046

303-236-4882x222 ijgurdak@usgs.gov.303-236-4882x257 mgeisler@usgs.gov

Errors associated with geospatial data can propagate through natural-science models that use raster processing and result in substantial and spatially variable prediction uncertainty. Prediction uncertainty affects how model results are interpreted and how well they are accepted by scientists, environmental regulators, resource managers, elected officials, and the general public. 
However, the propagation of input errors from geospatial data and resulting prediction uncertainty of raster-based models are rarely quantified, in part, because of the lack of a universally available modeling tool and methodology. To address this need, the Raster Error Propagation tool (REPTool) is being developed under the U.S. Geological Survey Center of Excellence for Geospatial Information Science (CEGIS) research program. REPTool is a Python-based ArcGIS raster-processing tool that will allow users to estimate the propagation of input errors associated with geospatial data during raster processing and quantify the prediction uncertainty of a user-defined geospatial model. The input for REPTool includes a user-defined map-algebra model equation, raster data sets used in the model equation, and errors that are associated with model coefficients and data inputs. REPTool uses Latin Hypercube Sampling, a stratified stochastic approach similar to Monte Carlo analysis, to quantify the propagation of errors through the geospatial operator(s) in the model equation. The output from REPTool is a spatially variable, cell-by-cell distribution of the geospatial model output values that represents the possible range of prediction uncertainty because of the error propagation. Percentiles from the distribution of output values can be selected and evaluated by the user to determine the model prediction interval(s) of interest. Additionally, REPTool allows the user to quantify the relative variance contribution (RVC) and evaluate the relative effect of each model-coefficient and data error terms on the overall prediction uncertainty of the geospatial model. The RVC analysis can provide important information on the sources of error for users of geospatial model output that are faced with uncertain model predictions, limited resources, and the need to reduce prediction uncertainty because of error propagation through the collection of additional data or improved model development. To demonstrate REPTool, results from an application with a raster model of the High Plains aquifer $\left(450,000 \mathrm{~km}^{2}\right)$ are presented and reveal spatially-variable prediction uncertainty and the potential to reduce the uncertainty in future iterations of the model using the RVC method.

\section{Promoting Interoperability with Specifications of Geoprocessing Methodology, By Roland J. Viger', Olaf David ${ }^{2}$, and C.G. O'Hara ${ }^{3}$}

${ }^{1}$ U.S. Geological Survey, Denver Federal Center, MS 412, Box 25046, Denver, CO 80225-0046

303-236-5030 rviger@usgs.gov

${ }^{2}$ U.S. Agricultural Research Service, Bldg. D, 2150 Center Avenue, Fort Collins, CO 80526

970-492-7316 olaf.david@ars.usda.gov

${ }^{3}$ Mississippi State University, 2 Research Blvd., Mississippi State, MS, 39759

662-325-2067 cgohara@ gri.msstate.edu

This paper describes research to improve the loose integration of geographic information system (GIS)-based processing services with client software, primarily environmental simulation models (ESMs). The approach taken avoids implementing client business logic within a GIS server environment or forcing large changes in the client architecture to internalize geoprocessing. Instead, metadata is used to map ESM-specific knowledge about geoprocessing methodology to the terminology used to signify the geographic information concepts within an ESM. This mapping provides an explicit operational definition of an ESM concept by describing how to manufacture of it an appropriate representation. The metadata is therefore more semantically relevant in a computational environment than standard forms of metadata that provide natural language descriptions or terminological crosswalks. To exploit the geoprocessing knowledge contained in the metadata, a middleware called Geospatial Object Library for Environmental Modeling (GEOLEM), has been developed. GEOLEM controls the execution of the methodological specifications, marshalling geoprocessing services that provide implementations of basic GIS commands as needed. Beyond the standard benefits of encapsulation and interoperability that this or any of a number of other middleware approaches can yield, this research seeks to provide semantic definition of client-specific geographic information concepts based on the geoprocessing methodology used to derive representation of instances of the concepts. The authors seek to develop techniques to analyze a database of these definitions to promote methodological reuse and the appropriate exchange of geographic information between ESMs.

Previously published as:

Viger, R. J., O. David, and O'Hara, C.G. (2007). Using Geoprocessing Specification as Semantic Metadata with GEOLEM, in Samet, H., Schneider, M., and Shahabi, C., eds.,15th ACM International Symposium on Advances in Geographic Information Systems, Seattle, WA, Association for Computing Machinery (ACM), 1: 340-343. 


\section{The Role of Environment and Wildlife in Human Health, 10:05 am - 12:00 pm, Moderated by Yvonne Baevsky}

Risk-Based Targeted Surveillance: Identifying Areas and Populations of Importance for Surveillance of High Path Avian Influenza in the United States, By Ryan Miller', Matthew Farnsworth², William Kendalß, Paul Doherty', James Nichols's, Gary White ${ }^{4}$, Kenneth Burnham ${ }^{5}$, Alan Franklin², and Jerome Freier ${ }^{1}$

${ }^{1}$ USDA-APHIS-VS-Centers for Epidemiology and Animal Health, 2150 Centre Ave., Bldg. B, MS 2W4, Fort Collins, CO 80526

970-494-7327 ryan.s.miller@aphis.usda.gov,

${ }^{2}$ USDA-APHIS-WS-National Wildlife Research Center, 4101 LaPorte Avenue, Fort Collins, CO 80521

970-266-6000

${ }^{3}$ USGS Patuxent Wildlife Research Center, 11510 American Holly Drive, Laurel, MD 20708-4019

301-497-5868 wkendall@usgs.gov, 303-497-5660 inichols@usgs.gov

${ }^{4}$ Colorado State University, WCNR Department of Fish, Wildlife and Conservation Biology, 109D Wagar Building, 1484 Campus

Delivery, Fort Collins, CO 80523-1413

9700-491-6678 gwhite@warnercnr.colostate.edu

${ }^{5}$ Colorado Cooperative Fish and Wildlife Research Unit, Colorado State University, 201 Wagar Building, 1484 Campus

Delivery, Fort Collins, CO 80523-1413

970-491-5396kenb@lamar.colostate.edu

The recent emergence of Asian influenza A subtype H5N1 and its rapid spread throughout Asia, Europe, and Africa has focused attention on the need for enhanced avian influenza (AI) surveillance in domestic poultry and migratory waterfowl within the United States. Waterfowl and shorebirds appear to be the primary natural reservoirs for type-A influenzas and have been implicated as the progenitors of previous human flu pandemics. Wild waterfowl can be asymptomatic, excrete virus in feces for long periods, may be infected with more than one subtype, and often do not develop a detectable antibody response. In addition, seasonal infection with AI virus occurs in conjunction with breeding and subsequent migration of juveniles from northern latitude breeding areas to southern latitude wintering areas.

Nationally, avian influenza surveillance programs have been established to detect the H5 and H7 subtypes of AI in domestic poultry and wild waterfowl. Early detection of Asian H5N1 will require targeted surveillance of populations at highest risk for emergence of the virus. Using knowledge about the ecology of migratory waterfowl and type-A influenzas, while considering the complications of national scale data collection, areas of importance for surveillance of wild waterfowl and domestic poultry were identified.

With limitations, continental movements of waterfowl can be estimated using data from bird band recoveries. Analysis focused on primary avian functional groups (dabbling ducks, light geese, dark geese, and swans) thought to be responsible for large-scale movements of Asian H5N1. Recoveries of banded birds from 1991 to $2006(n=241,619)$ were used to identify areas within the mainland United States where higher proportions of migrant waterfowl, originating from Asia, Alaska, and Canada, stay over winter.

These bird banding data were used in conjunction with United States National Census of Agriculture data to rank counties having a high prevalence of domestic poultry production and relatively high numbers of migrant waterfowl. Analysis identified 483 counties (15 percent) as high priority for domestic poultry surveillance. These counties account for 29 percent of poultry farms and 26 percent of domestic poultry production.

In addition, National Wildlife Refuges and State Wildlife Areas were ranked ordinaly according to the number of band recoveries on and adjacent to these management areas. These sites represent 9 percent (918) of all National and State Wildlife Refuges and represent 72 percent of all band recoveries for birds originating from Alaska and Asia recovered on refuges. These management areas were then prioritized for environmental samples based on this ranking. 
Pathways Assessment Mapping Tool Aids in Risk Analysis for USDA Veterinary Services—Centers for Epidemiology and Animal Health, By Mary Ann Bjornsen

USDA, APHIS, Veterinary Services, Center for Epidemiology and Animal Health, Natural Resource Research Center, 2150 Centre Ave., Building B, MS 2W4, Fort Collins, CO 80526-8117

Maryann.bjornsen@aphis.usda.gov

Abstract Not Submitted

Feature Extraction of Aerial Imagery to Establish Spatial Measures of Animal Operations, By Mary Jane McCool

USDA, APHIS, Veterinary Services, Center for Epidemiology and Animal Health, Natural Resource Research Center, 2150

Centre Ave., Building B, MS 2W4, Fort Collins, CO 80526-8117

Abstract Not Submitted

Use of an Online Map Service to Provide Maps for Decision Makers, By Andrew Fox

USDA, APHIS, Veterinary Services, Center for Epidemiology and Animal Health, Natural Resource Research Center, 2150 Centre Ave., Building B, MS 2W4, Fort Collins, CO 80526-8117

Abstract Not Submitted

Application of Weather and Climate Data in Epidemiological Studies, By Susan Maroney

USDA, APHIS, Veterinary Services, Center for Epidemiology and Animal Health, Natural Resource Research Center, 2150 Centre Ave., Building B, MS 2W4, Fort Collins, CO 80526-8117

Abstract Not Submitted

Spatial Modeling of Piroplasmosis Risk in Horses in Preparation for the World Equestrian Games in 2010, By Angela James

USDA, APHIS, Veterinary Services, Center for Epidemiology and Animal Health, Natural Resource Research Center, 2150

Centre Ave., Building B, MS 2W4, Fort Collins, CO 80526-8117

Abstract Not Submitted

North American (Metadata) Profile: Content, Tips, and Tools, 10:05 am - 12:00 pm, By Sharon S. Shin and Anna Milan²

${ }^{1}$ U.S. Geological Survey, Denver Federal Center, MS 320, Box 25046, Denver, CO 80225-0046

303-202-4230 sshin@usgs.gov

${ }^{2}$ Cooperative Institute for Research in Environmental Sciences, Enterprise Data Systems Group, NGDC/NESDIS/NOAA, 325

Broadway, Mail Code E/GC4, Boulder, CO 80305-3328

303-497-5099303-497-6513 anna.milan@noaa.gov

Since mid-year 2005, the United States and Canada geospatial standards bodies have been striving to create national profiles of the International Organization for Standardization (ISO) 19115 Geographic Information-Metadata. A profile is a community tailored version of the standard that narrows the focus, provides more specifics, moves from optional to mandatory elements, invokes code lists were appropriate, and is easier to implement. Editorial committees from both countries have engaged in colocated meets which have, in successive rounds, discussed, negotiated, and arrived at a draft profile that was accepted by the American National Standards Institute in 2008. The national standards will be released by the respective countries on the same date and time and become collectively named the North American Profile (NAP). The next meeting in March will, again, adjudicate comments and discuss ISO 19110 Feature Catalog, which both communities felt was not fully addressed in ISO 19115. An additional topic of discussion will be the validation tool for the NAP. 
This presentation includes a broad discussion of the NAP, some advantages of the NAP over the Content Standard for Digital Geospatial Metadata, the actions recommended for Feature Catalog and validation tool from the March adjudication, and a review of the recent ISO tool review.

\section{Spatial Modeling with ArcGIS, 1:00 pm - 2:55 pm, By Cory Tucker and Steve Kopp}

ESRI, 308 New York Street, Redlands, CA 92373-8100

909-793-2853 ctucker@esri.com skopp@esri.com

This session is about looking at the big picture of what the attendees may already know about geographic information system (GIS) analysis and modeling, and applying that knowledge to solve problems that may be new to the attendees. Some new capabilities from 9.2 and 9.3 will be presented, such as feedback loops, random number generators, and statistical tools, and they will be used to illustrate how to build dynamic process models, evaluate model parameter sensitivity, and perform error analysis.

\section{Data Integration and Interoperability Enterprise, 1:00 pm - 2:55 pm, Moderated by Roland Viger}

\section{The Status of Data Products and Services in The National Map, By Carl Zulick}

U.S. Geological Survey, GIO, 12201 Sunrise Valley Drive, Reston, VA 20192

703-648-5491 czulick@usgs.gov

The National Map provides public access to geospatial data and services to help support decision making, and is the product of a consortium of Federal, state, and local partners who provide geospatial data for integration into The National Map. By working with partners, the U.S. Geological Survey (USGS) will ensure access to current, accurate, and nationally consistent digital data and topographic map products.

The National Map includes:

- High-resolution digital orthorectified imagery.

- High-resolution surface elevation data to derive contours for primary series topographic maps and to support Earth surface modeling and the production of accurate orthorectified imagery.

- Vector feature data for hydrography (rivers and water bodies), transportation (roads, railways, and waterways), structures, and governmental unit boundaries.

- Geographic names for physical and cultural features to support the U.S. Board on Geographic Names.

- Land-cover data that classify the land surface into categories such as open water and high-density residential.

- The USGS will continue the tradition of maintaining the primary series 7.5 minute topographic map with an image layer that can be turned on or off, as well as other digital graphic products derived from The National Map data.

This session will discuss the current status, condition, and coverage of each of The National Map data layers, and will provide an update on the systems being developed to plan, manage, and disseminate the data.

\section{U.S. Geological Survey Topographic Mapping, By Michael Cooley', Stafford Binder ${ }^{2}$, and Helmut Lestinsky ${ }^{2}$ \\ ${ }^{1}$ U.S. Geological Survey, GIO, 12201 Sunrise Valley Drive, Reston, VA 20192 \\ 703-648-5528 mcooley@usgs.gor. \\ ${ }^{2}$ U.S. Geological Survey, DFC, MS 510, Box 25046, Denver, CO 80225-0046 \\ 303-202-4444 sgbinder@usgs.gov.303-202-4324 hlestinsky@usgs.gov}

In the early 1990s, the Primary Series Topographic Quadrangle mapping was completed. Since then, the agency's base-mapping program has focused on development of The National Map and digital-mapping products. Conceptually, The National Map will bring together a seamless, consistent, current set of base geographic data for the Nation. The organization is now focusing on the best way to produce its signature product—-the topographic map-from data contained in The National Map. These next-generation products need to contain most of the desirable characteristics of the classic topographic map. The production process uses source data to make maps that are integrated, quality checked, and contain up-to-date information. To accomplish these goals and produce map products, the U.S. Geological Survey (USGS) must continue to tailor its processes to make maximum use of 
partner-produced data. Additionally, the USGS will focus on product and standards development, data assessment and translation, quality assurance, data management and delivery, and contract management. Production of enhanced topographic and image maps will begin in 2009 using suitable data from The National Map. In addition, production of high-resolution scanned and enhanced digital copies of the published maps has begun. Map users will easily obtain all types of these new maps as a digital file or by print-on-demand. Eventually, the enhanced topographic maps will be available by a web-enabled, automated, user-controlled production process.

Where Can I Plug Into The National Map? By James G. Barrett

U.S. Geological Survey, Denver Federal Center, Building 810, Box 25046, Denver, CO 80225 703-268-3769 igbarrett@usgs.gov

As The National Map moves from its current 1.0 version of map visualization and selected data download into its next generation of providing integrated digital cartographic information and online services, there will be numerous opportunities for the U.S. Geological Survey (USGS) Geographic Information System (GIS) community to engage the services of the The National Map. Improvements to The National Map are anticipated that will allow us to broadly communicate available data holdings and planned data acquisitions, including their location and quality, that will help USGS Scientific communities plan to meet their business needs. The development plan for The National Map seeks to balance the dynamic needs of the broader national geospatial community, the needs of the USGS and its available program resources. The National Map 2.0 will provide improvements to how we define, promote, and deliver the data products and services to support user downloads and Web-based service models. This talk will focus on how the USGS GIS communities and their customers can interact with the The National Map.

\title{
Geospatial Management Information System Data Improvement-Lessons Learned, By Scott McEwen
}

U.S. Geological Survey, Denver Federal Center, Building 801, MS 306, Lakewood, CO 80225

303-202-4663wsmcewen@usgs.gov

The Geospatial Management Information System (GMIS) Data Improvement Initiative was requested by U.S. Geological Survey (USGS) Director Myers to verify and improve the geographic extents of all active science projects in Budget and Science Information System Plus (BASIS+). The effort involved interaction between the Geospatial Information Office and all USGS science centers. This talk will review the approaches used to collect geographic information on this scale, reusability of this information, and lessons learned about the collection process.

\section{The Role of Environment and Wildlife in Human Health, 1:00 pm - 2:55 pm, Moderated by Yvonne Baevsky}

\author{
Global Wildlife Disease News Map_-Putting Wildlife Health News on the Map! By Megan K. Hines', Steven \\ Gustafson², F. Joshua Dein'2, and Cris Marsh' \\ ${ }^{1}$ NBII Wildlife Disease Information Node, Room 60, Science Hall, 550 North Park Street, Madison, WI 53076 \\ 608-270-2400x2333 mkhines@wisc.edu \\ ${ }^{2}$ U.S. Geological Survey, National Wildlife Health Center, 6006 Schroeder Road, Madison, WI 53711 \\ 608-262-7785 sgustafson@usgs.gol, 608-270-2450 fidein@usgs.gol, 608-270-2459 cmarsh@usgs.gov
}

The National Biological Information Infrastructure (NBII) Wildlife Disease Information Node (WDIN) is a collaborative project to develop web-based tools to provide state and federal resource managers, animal disease specialists, veterinary diagnostic laboratories, physicians, public health workers, educators, and the general public with access to data on wildlife diseases, mortality events, and related information.

This new WDIN Google Mapping application creates a visual way to explore wildlife health news provided by the WDIN Wildlife Disease News Digest. The Google Map application captures the last 45 days of georefenced entries from the Digest, and allows users to filter the contents shown on the map by wildlife health topic, wildlife/human topic, domestic animal/wildlife topic, disease type, species, or country. 
WDIN populates the map by combing through authoritative Really Simple Syndication (RSS) news service feeds and email alerts, and then cataloging the metadata into a Dublin core-based database. The relevant articles also are tagged with keywords that the user can select to filter the content shown on the map.

The georefenced articles are displayed with unique pushpin icons that inform the user as to what level of geographic detail the article refers to. The locations are referenced by place, county, administrative unit, country, or continent. Locations are georefenced with latitude and longitude values from either the U.S. Geological Survey (USGS) Geographic Names Information System (GNIS) database, or internationally from the National Geospatial-Intelligence Agency's GeoNet Names Server (NGA GNS) database. Places that cannot be successfully geocoded with those two authorities often are approximated using Google Earth or referenced at the next available geographic level. Polygon level geographic information is geocoded as a geographic center of the feature (centroid). An eXtensible Markup Language (XML) file is generated on-demand from the published articles, which organizes the contents by unique latitude and longitude locations called markers. Each unique marker is linked to the associated article that populates the information windows when an icon is selected.

The Google Map application connects to an initial XML file containing markers for all georefenced entries in the last 45 days. If a user selects an available filter topic, the XML file with the filtered results is requested via Asynchronous JavaScript (AJAX), $\mathrm{X}$-standard Hypertext Transfer Protocol (XHTTP) request and the map display is refreshed to display those markers where the filter is present.

With no global surveillance system in existence for the monitoring of wildlife health, this tool helps to fill the void by harvesting unstructured, disparate information about disease outbreaks and other wildlife-related topics. The application is expected of be useful to professions working in the wildlife, domestic-animal, and human-health communities.

\title{
Center for Disease Control and Prevention's Agency for Toxic Substances and Disease Registry's Tracking of Avian Influenza in Birds, By Brian Kaplan and Steven Bullard
}

Geospatial Research, Analysis, and Services Program, ATSDR, Centers for Disease Control and Prevention, 4770 Buford

Highway NE, MS F09, Atlanta, GA 30341-3717

770-488-3856 bkaplan@cdc.gov 770-488-3867 sbullard@cdc.gov

Abstract Not Submitted

\section{Vendor Solutions: DigitalGlobe Products (Digital Globe) and the GeoPDF File (TerraGo Technologies), 1:00 pm - 2:55 pm, Moderated by Daniel Pearson}

\author{
DigitalGlobe Incorporated Corporate and System Update, By Brett P. Thomassie \\ DgitalGlobe Mississippi Operations, Building 1003, Suite 202B, Stennis Space Center, MS 39529 \\ 228-688-1607bthomassie@digitalglobe.com
}

DigitalGlobe currently operates the world's highest-resolution commercial satellite constellation that includes QuickBird and the first of two next-generation satellites, WorldView-1. The company plans to complete construction of its second next-generation satellite, WorldView-2, in late 2008. The company's updated and growing Image Library contains more than three hundred and fifty million square kilometers of satellite and aerial imagery suited to countless applications for people who map, view, navigate, and study the earth and its natural resources.

QuickBird satellite imagery and information products have been used successfully for a wide variety of federal/state/local government and research applications including forestry, grassland, coastal management, and for monitoring, emergency response/ disasters, GIS/mapping, mining, and management of other natural resources management, to name a few.

The $60 \mathrm{~cm}$ resolution QuickBird satellite has been producing high quality imagery since reaching operational capacity in early 2002. The recently launched 50cm WorldView-1 satellite system also reached full operational capacity in late 2007.

The new WorldView-1 and upcoming WorldView-2 satellite systems offer:

- Half-meter resolution;

- 8-band multispectral capability; 
- Substantially improved agility;

- Daily revisit capability at one-meter resolution or better;

- Improved geo-location accuracy;

- Substantially improved collection capacity with greater on-board storage and a higher data downlink rate;

- Simultaneous image collection and downlinking.

The WorldView 1 satellite is collecting imagery of the Earth at 50 centimeter panchromatic resolution with an orbit altitude of 450 kilometer. WorldView 2 will provide the same panchromatic 50 centimeter resolution imagery as WorldView 1, in addition to offering 1.8-meter spatial resolution 8-band multispectral imagery. The WorldView 2 satellite also will orbit at a higher altitude of 770 kilometer.

The addition of WorldView 1 and 2 will allow DigitalGlobe's customers to revisit collection areas more frequently with the capability of providing repeat coverage over global areas of interest about once daily. The WorldView ground system (presently in use with QuickBird) also includes a more efficient image processing system, multi-satellite collection planning, shorter tasking timelines, and an expanded network of remote ground receiving terminals.

DigitalGlobe's imaging constellation consisting of WorldView satellites and QuickBird will be capable of collecting more than 4.5 times the imagery of any current commercial imaging system. WorldView-1 alone is capable of collecting nearly 500,000 square kilometers $(200,000$ square miles) per day of half-meter imagery.

In January 2007, DigitalGlobe also acquired GlobeXplorer/AirPhoto USA. The newly combined DigitalGlobe capabilities will now offer end user customers instant Internet access to the world's largest aerial, satellite, and map image content databases as well as access to customizable subscription/bundled imagery and software tool packages.

\section{The GeoPDF File-A New Solution for the Digital Publication, Distribution, and Collaboration of Geospatial Data, $B y$ Jaymes Pardue}

TerraGo Technologies, Inc., 19124 W $60^{\text {th }}$ Lane, Golden, CO 80403

ipardue@terragotech.com

As the demand for geospatial data continues to increase, the GeoPDF file format is pioneering digital data workflows that bridge the technology divide between geospatial professionals and the rest of the world. In today's information age, it is not enough that our geospatial data is accurate, readable, and understandable. Today, geospatial data also must be accessible, useable, and dynamic. The biggest barrier facing the geospatial community today is a lack of tools to help everyone not only view interactive mapping data, but also to be able to collaborate with other users whether or not they are Geographic Information System (GIS) enabled.

The GeoPDF file format leverages the Adobe portable document formatting (PDF) standard to allow geospatial users to convert geospatial data from popular GIS systems into a file that is geospatially active. A map exported into a GeoPDF file contains all of the geospatial information including coordinate systems, attribute data, and layered features that are available in a typical GIS. GeoPDF files can be easily distributed and used by virtually anyone in a secure and manageable environment. This presentation will explore the GeoPDF dynamic of the publication, distribution, and collaboration of vector and raster data in connected and disconnected digital workflows. Recent case studies will be presented and discussed.

\section{A Water Census of the United States, 3:15 pm - 5:10 pm, Moderated by Steve Aichele}

\section{Great Lakes Aquatic Gap: A Regional Approach and Framework to Identify Gaps in Fish Species and Habitat Conservation for Great Lakes Streams, By Jana Stewart' and Steve Aichele ${ }^{2}$}

${ }^{1}$ U.S. Geological Survey, Wisconsin Water Science Center, 8505 Research Way, Middleton, WI 53562 608-821-3855 isstewar@usgs.gov

${ }^{2}$ U.S. Geological Survey, Michigan Water Science Center, 6520 Mercantile Way, Suite 5, East Lansing, MI 48911 517-887-8918 saichele@usgs.gov

The Great Lakes Aquatic Gap (GLGAP) project uses a regional approach to characterize the habitat of stream reaches, predict fish species distributions, and identify conservation gaps for fish species distributions and aquatic habitats. The results are 
being used to develop a hierarchical classification of stream habitat types across the Great Lakes watershed that can be used by scientists, managers, and decision-makers at local and regional scales for data summarizing, reporting, assessing, prioritizing, and managing stream aquatic resources. Resource managers also may use the results to explore potential effects of various landscape-scale habitat characteristics on stream fish communities, water temperature, and other hydroecological characteristics including stream flow distributions, flood frequency, base flow, and water quality. This project uses a geographic information system (GIS) to capture and store physical habitat characteristics for inter-confluence stream reaches of the 1:100,000 scale National Hydrography Data set (NHD), using methods similar to and implemented before NHDPlus development. Physical habitat includes GIS-derived landscape-scale data at multiple spatial scales (channel, riparian zone, and watershed) that may potentially affect fish species distribution in streams. While not ideal, landscape-scale habitat data provide surrogates for finer scale site-specific habitat measurements that are impractical to measure over large areas. Habitat characteristics consist of attributes that describe land cover, geology, and climate for multiple spatial scales, along with stream network position and connectivity. Summer water temperature and streamflows were modeled from GIS-derived habitat characteristics, climate data, continuous stream temperature, and flow. Fish species occurrence/abundance data were compiled from existing sources, primarily state natural resource agency databases. Habitat characteristics and fish species data are linked to stream reaches to map fish species occurrence and habitat, and develop fish species-habitat models to predict distributions. Classification and regression tree (CART) and artificial neural network (ANN) models were developed with an accuracy of 70 to 90 percent, and used to estimate fish species distribution/abundance at un-sampled reaches. This paper describes how the NHD provided an essential framework for this project that would not be possible with digital line graphs or the River Reach File 3, alone; however, the NHD still had significant limitations that required additional NHD processing before it could be used effectively for fish-habitat modeling. The project began before NHDPlus development, yet had similar processing requirements to those of NHDPlus that included development of network watersheds and watershed characteristics, flow direction and accumulation, and network connectivity-the methods of which will be described.

\section{A Pilot Project to Develop and Implement StreamStats and NHDPlus Applications Using Local Resolution Data in the Upper French Broad River Basin, North Carolina, By Kirsten C. Tighe, Silvia Terziotti, and Chad Wagner}

U.S. Geological Survey, North Carolina Water Science Center, 3916 Sunset Ridge Road, Raleigh, NC 27607 919-571-4050 kctighe@usgs.go1 919-571-4090_seterzio@usgs.gol 919-571-4021 cwagner@usgs.gov

Currently (2007) StreamStats and NHDPlus applications exclusively use 10- and 30-meter Digital Elevation Models (DEMs) and 1:24,000 and 1:100,000 scale National Hydrography Data set (NHD). Whereas these data sets are adequate for some state applications, availability of higher resolution elevation data, predominately from Light Detection and Ranging (LiDAR), is promoting demand to incorporate these more accurate data into scientific applications and decision making. In 2007, the State of North Carolina completed development of a local resolution NHD product for 19 western counties. The best available combination of digital orthophotography, digital terrain models derived from LiDAR, and existing hydrography was used to create the local resolution NHD.

The U.S. Geological Survey (USGS), in cooperation with the North Carolina Department of Transportation (NCDOT), has initiated a pilot project to develop and implement NHDPlus and StreamStats applications for the Upper French Broad River Basin in western North Carolina. The pilot project utilizes the local resolution NHD product, 20-foot DEMs (derived from LiDAR data), the most current regional streamflow regression equations, and data sets of landscape characteristics. Basin characteristics developed for the streamflow regression application, including National Oceanic and Atmospheric Administration (NOAA) rainfall intensity data, topographic variables (for example slope and drainage area), and best available land-cover classifications, will be incorporated into StreamStats and NHDPlus tables. Issues and recommendations on data set development and application implementation for future similar use of high resolution data sets will be documented.

National Atlas Digital Streams Data Recompilation at 1:1,000,000-Scale Using the 1:100,000-Scale National Hydrography Data set and ArcObjects, By Zachary D. Wilson, Robin H. Gary, and Christy-Ann M. Archuleta

U.S. Geological Survey, Texas Water Science Center, 8027 Exchange Drive, Austin, TX 78754

512-927-3511 Edwilson@usgs.gor. 512-927-3512 rhgary@usgs.gor 512-927-3516 carchule@usgs.gov

The National Atlas program is recompiling their 1:2,000,000-scale digital data at 1:1,000,000-scale (1:1M). The 1:100,000-scale National Hydrography Data set (NHD) is the base for creating the new National Atlas 1:1M streams and waterbodies data sets. The prototype phase of the project focused on refining a method that maximizes the use of the NHD network and attributes in generalizing to $1: 1 \mathrm{M}$. In the production phase of the project, headwater reaches appropriate for inclusion in the $1: 1 \mathrm{M}$ streams data set are identified in NHD using ancillary data sets, for example the 1:2M National Atlas, Vector Map level 0 (VMAP0), and 
the International Map of the World series. After headwater reaches have been determined, a downstream trace algorithm attributes streams for inclusion in the 1:1M data set. The downstream trace algorithm was written in Visual Basic for Applications (VBA), using ArcObjects, and implemented as an easy-to-use tool within the ArcMap environment. The tool considers flow direction, number of adjacent downstream reaches, stream names, and feature type to extract preliminary 1:1M flow paths from NHD. Existing similar scale data and consultations with cartographers and hydrologists indicate that the selection algorithm creates a 1:1M data set with appropriate density and preserves hydrologic significance. Automation of the selection process increases repeatability and facilitates feature-level documentation. The final data sets will be available as nationwide shapefiles or regional networked geodatabases.

Comparison of Two Stream Networks as Framework for the Spatially Referenced Regression On Watershed Attributes Model for the Southeastern United States, By Silvia Terziotti' and Anne Hoos ${ }^{2}$

${ }^{1}$ U.S. Geological Survey, North Carolina Water Science Center, 3916 Sunset Ridge Road, Raleigh, NC 27607 919-571-4090 seterzio@usgs.gov

${ }^{2}$ U.S. Geological Survey, Tennessee Water Science Center, 640 Grassmere Park Drive, Suite 100, Nashville, TN 37211 615-837-4760abhoos@usgs.gol

The U.S. Geological Survey's National Water-Quality Assessment (NAWQA) Program is compiling surface-water-quality data and estimates of nutrient sources (agricultural, atmospheric, urban runoff, and wastewater) from Federal, state, and local waterresource agencies throughout the southeastern United States to estimate rates of nitrogen and phosphorus transport in surface water and to determine which sources and watersheds contribute the highest nutrient loads. The Spatially-Referenced Regression On Watershed Attributes (SPARROW) water-quality model is used to quantify the nutrient source loads and the transport of these nutrients to downstream water bodies and coastal areas, and provide information that can assist water-resource managers in selecting nutrient control strategies.

The model area includes river basins draining to the South Atlantic Coast and the eastern Gulf Coast, as well as the Tennessee River Basin. Two resolutions of SPARROW models, one based on the RF1 stream reach network (Reach File Version 1.0, 1:500,000-scale hydrography) and one based on the NHD Plus stream reach network (National Hydrography Data set, 1:100,000-scale hydrography), are being calibrated. The RF1 stream reach network has 8409 stream reaches and average catchment area of 95 square kilometers in the study area, compared to 395,426 stream reaches with average catchment area of 2 square kilometers in the NHD Plus data set.

Annual load of nitrogen and phosphorus was estimated for monitoring sites on streams and rivers sampled quarterly, with a minimum of 10 samples collected since 1995, and for which daily streamflow data also were collected (or could be estimated from a nearby streamflow-gaging station). Although more than 3,000 sites in the region met the criteria for sampling frequency, only 782 sites had sufficient streamflow data for load estimation, and only 392 sites could be associated with an RF1 reach and used in a calibration set for a model based on the RF1 network. Using the more detailed NHD Plus stream network increases from 392 to 610 the number of water-quality sites that can be located on the stream network and used to calibrate the SPARROW model for the southeastern United States.

The increase in density of stream features from the RF1 to the NHDPlus allows the SPARROW model to estimate total nitrogen and phosphorous loads with finer resolution. The more detailed spatial distribution of monitoring sites allows for better characterization of processes affecting nutrient levels in streams, particularly in headwater streams. The more detailed distribution of model predictions can better enhance monitoring efforts and management strategies.

\title{
Data Integration and Interoperability: Operational, 3:15 pm - 5:10 pm, Moderated by Carma San Juan
}

\author{
Not Everything is a Map: Browsing Geography by Place Name, By Peter N. Schweitzer \\ U.S. Geological Survey, National Center, 12201 Sunrise Valley Drive, Reston, VA 20192 \\ 703-648-6533 pschweitzer@usgs.gov
}

The names of commonly known geographic areas serve as useful guides for navigation on the web. Simple uses of geographic names appear throughout the web as lists of states or counties or as map images employed as graphical links (image maps). However, these uses show only the simplest relationships among the geographic areas. 
Drawing on techniques used in library science, the geographic relationships among well known areas are represented using concepts and data structures designed for controlled vocabularies, specifically formal thesauri. Hierarchical relationships (broader or narrower terms) are used to describe subdivisions of the same type of geographic area (for example states are broader terms for counties, countries are broader terms for states). Generic related terms are used to link geographic areas that overlap spatially but are not of the same type (counties and map quadrangles, for example).

When used as index terms, the geographic thesaurus that results is a browseable hierarchy of terms that enable an alternative strategy for finding geospatial information. Such interfaces have several benefits: a textual interface can be more efficient than a graphical interface for finding spatially relevant information (for example, when the user knows some of the geographic areas by name but may be unclear as to their position on a map); users unable to negotiate a graphical display can make use of a textual interface; and the textual interface can reveal relationships among geographic areas that are not necessarily evident in a map display.

Terminological relationships among named geographic areas were derived by carrying out simple spatial intersect analyses on commonly available geographic framework data, principally from the National Atlas and the U.S. Geological Survey (USGS). Unique identifiers for areas were drawn, where possible, from common coding schemes such as Federal Information Processing Standards (FIPS) 10-4 and FIPS 6-4, and by deriving simple identifiers where standards did not exist already.

The result is a hierarchical controlled vocabulary containing areas of five distinct types: continents and oceans; political areas (countries, states or provinces of United States, Canada, and Mexico, and United States counties); USGS map quadrangles (scales 1: 250,000, 1:100,000, and 1:24,000); hydrologic units [(2-, 4-, and 8-digit Hydrologic Unite Codes (HUCs)]; and U.S. Federal lands. The vocabulary produced is used as a source of index terms for the USGS Science Topics web site catalog, and the Mineral Resources spatial data catalog.

\title{
Integrating Data Collection and Management Tools to Support Multidisciplinary Research of Sturgeon on the Lower Missouri River, By Kimberly A. Chojnacki, Emily K. Tracy-Smith, Sandra J. Clark-Kolak, and Aaron J. DeLonay
}

U.S. Geological Survey, Columbia Environmental Research Center, 4200 New Haven Road, Columbia, MO 65201 573-441-2990 kchojnacki@usgs.gov, 573-876-1803 etracy@usgs.gov, 573-876-1878 adelonay@usgs.gov

The U.S. Geological Survey is engaged in a multidisciplinary study supported by the U.S. Army Corps of Engineers to investigate reproductive physiology, movement, and spawning habitat use of Lower Missouri River sturgeon. Central to this effort is an extensive, large scale telemetry effort using pallid sturgeon (Scaphirhynchus albus) and shovelnose sturgeon (Scaphirhynchus platorynchus). To facilitate data collection for sturgeon telemetry relocations and document tracking vessel search efforts, a customized Environmental Systems Research Institute (ESRI) ArcPad application has been developed for mobile geographic information system (GIS) field mapping and data recording. Custom data entry forms prompt users to collect data for each relocation event including water quality, hydrologic conditions, habitat, and substrate. In addition, the software automatically records date, time, and spatial coordinates from a Global Positioning System. All data for sturgeon relocations and search efforts are uploaded daily to a secure server located at the Columbia Environmental Research Center by remote field crews using a secure internet webpage. A relational database schema has been developed to house tabular data for the initial capture and reproductive physiology of each sturgeon and water quality. Relationships have been established between spatial data and database tables using mutually exclusive identifiers for each individual sturgeon, allowing summary reports and maps to be generated using information from several sources. These links allow the spatial data to be maintained in its native format, while still being accessible through the database, making it possible to maintain data in a near-real time environment. Leveraging the power of dynamic segmentation in ArcGIS (ESRI Inc.), movement maps are created for individual sturgeon, showing the release location, all relocation events, the last known relocation, and lines connecting the relocations to interpolate upstream and downstream movements. These maps, in conjunction with several near-real time reports, give a sense of the movements of each individual sturgeon through space and time, allowing staff to prioritize and schedule field crew efforts to track, map, and recapture sturgeon.

\section{Building Texas-Sized Geodatabases, By Daniel K. Pearson', Sachin D. Shah', and Toby L.Welborn²}

\author{
${ }^{1}$ U.S. Geological Survey, Texas Water Science Center, 8027 Exchange Drive, Austin, TX 78754-4733 \\ 512-927-3507dpearson@usgs.gov, 512-927-3572sdshah@usgs.gov \\ ${ }^{2}$ U.S. Geological Survey, Nevada Water Science Center, 2730 N. Deer Run Road, Carson City, NV 89701 \\ 775-887-7671 twelbor@usgs.gov
}

The U.S. Geological Survey (USGS) Texas Water Science Center Geographic Information Systems (GIS) team has built and used geodatabases for project-specific needs during the past 6 years. Geodatabase technology has enabled tabular and geospatial data relationships and has proven useful for data mining, data visualization, and data gap analysis. Various geodatabases have 
been developed to deal with hydrologic, water quality, and geologic data. The flexibility of the data structure and the ability to perform complex queries make geodatabases ideal tools for geospatial analysis. Specifically, geodatabases have been used for three key projects: Panhandle Groundwater Conservation District (PGCD), U.S. Environmental Protection Agency (USEPA)/ Longhorn Army Ammunition Plant (LHAAP), and the Geologic Database of Texas (GDOT). The PGCD geodatabase was built to manage a network of water wells in the Ogallala Aquifer near Amarillo, Texas. The GIS team reconstructed the existing PGCD geodatabase to effectively input and manage data, allowing the PGCD to distribute static and dynamic information to stakeholders and the public. The geodatabase built for the LHAAP includes current (2008) and historical data related to the movement of contaminants in the ground water near Karnack, Texas. The USEPA uses the LHAAP geodatabase for data gap analysis and to monitor and assess ongoing environmental cleanup work. The GDOT is a compilation of geologic data from four geographic scales and multiple map sheets covering the state of Texas and parts of eastern New Mexico. The GDOT allows researchers to spatially view and analyze surface geology within a GIS as opposed to using multiple paper map sheets for interpretation.

\section{Streamlining Report Map Production, By Christy-Ann M. Archuleta}

U.S. Geological Survey, Texas Water Science Center, 8027 Exchange Drive, Austin, TX 78754 512-927-3516 carchule@usgs.gov

Report-quality maps can be created easily and efficiently using only ArcGIS for map production. This presentation describes the cartographic transition from Adobe Illustrator to ArcGIS to produce maps for a map series that has been published annually for 30 consecutive years. Historically, ArcGIS was used to produce the data and base data sets, and Adobe Illustrator was used for the final report-quality layout. To seamlessly incorporate data editing with map layout edits, geographic information system (GIS) staff worked with cartographers and report specialists to create an ArcGIS map template that complies with U.S. Geological Survey (USGS) cartographic and Visual Identity standards. Each of the maps in the series uses the same base data and map template; only the study data vary. As the scientists working on the report modify and edit their GIS data, the maps are concurrently updated. This production process results in fewer editing cycles between the publishing department and the scientists working on the data. The new maps are as aesthetically pleasing as the previous versions and maintain the accuracy of the geospatial data. This presentation will describe the steps taken to transition from Adobe Illustrator and ArcGIS in tandem to using ArcGIS exclusively. Some techniques covered in this discussion are: base map templates, annotation, color reproduction, and maintaining USGS cartographic and Visual Identity standards.

\section{The Role of Environment and Wildlife in Human Health / A National Program to Assess Hazards, Risk and Resiliency, 3:15 pm - 5:10 pm, Moderated by Yvonne Baevsky}

\section{Are Environmental Exposures to Chlorophenoxy Herbicides Associated With Adverse Human Health Effects? By Dina M. Schreinemachers}

U.S. Environmental Protection Agency, National Health and Environmental Effects Research Laboratory, MS 58A, Research

Triangle Park, NC 27711

919-966-5875 schreinemachers.dina@epa.gov

Exposures to environmental pollutants are suspected of playing a role in the observed increases of many diseases. However, it is difficult to establish a causal link between exposure and disease because environmental exposures can be widespread and low dose in nature, and because it may be difficult to find non-exposed control populations; the question is how to approach linking environmental exposures to disease. Several publications have suggested that a series of multilevel, multidisciplinary studies are required, starting with population studies comparing regions, to be followed by more targeted studies based on subjects. An example of how to initiate such a series of studies is presented. Minnesota, Montana, North Dakota, and South Dakota produce most of the spring and durum wheat grown in the United States. More than 85 percent of the spring wheat acreage in these states is treated with chlorophenoxy based herbicides. Because information on herbicide use is not readily available, it was decided to use wheat acreage within each county as a surrogate exposure. Information on herbicide use by state and crop acreage by county was obtained from the U.S. Department of Agriculture. Information on birth defects and mortality from cancer, ischemic heart disease, and diabetes was obtained from the National Center for Health Statistics. Rates of adverse health effects in rural, agricultural counties of the combined four states were analyzed in association with the level of wheat agriculture per county. Results indicated that rates of adverse health effects were increased in counties with a high level of wheat farming compared to counties with lower levels of wheat farming, indicating a possible association between adverse health effects and wheat farming. The 
next question asked if rates of health effects could be directly linked to herbicide exposure instead of to crop level. An ongoing study comparing exposed to non-exposed subjects investigates associations between biomarkers of exposure (e.g. presence of herbicides or related metabolites in urine or blood) and biomarkers of effect (e.g. levels of lipids and glucose in blood). Because chlorophenoxy herbicides are among the most widely used herbicides in the United States, it is useful to complete this series of studies starting with comparison of regions followed by more definitive studies based on comparison of subjects. These methods can be applied to other environmental pollutants thought to be associated with adverse health effects.

Environmental- and Health-Hazards Characterization of Ash and Burned Soils from the October 2007 Southern California Wildfires, By Geoffrey S. Plumlee', Deborah A. Martin², Todd Hoefen', Raymond Kokaly', Philip L. Hageman', Suzette A. Morman', Ruth E. Wolf, Gregory P. Meeker', Paul J. Lamothe', Robert N. Fisher ${ }^{3}$, Eric Reichard ${ }^{\beta}$, Michael Anthony', Monique Adams', and Greg Mendez

${ }^{1}$ U.S. Geological Survey, Denver Federal Center, MS 964, Box 25046, Denver, CO 80225-0046

303-236-1204 gplumlee@usgs.gor, 303-236-2456 thoefen@usgs.go1, 303-236-1359 raymond@usgs.gor, 303-236-2494

phageman@usgs.gol, 303-236-1205 smorman@usgs.gol,303-236-2470 rwolf@usgs.gol, 303-236-3188 gmeeker@usgs.gol,

303-236-1923 blamothe@usgs.gov, 303-236-1857manthony@usgs.gor, 303-236-2402 madams@usgs.gov

${ }^{2}$ U.S. Geological Survey, 3215 Marine Street, Suite E-127, Boulder, CO 80303

303-541-3024 damartin@usgs.gov

${ }^{3}$ U.S. Geological Survey, 4165 Spruance Road, Suite 200, San Diego, CA 92101

619-225-6422 [fisher@usgs.gol, 619-225-6134 Egreich@usgs.gol, 619-225-6178 gomendez@usgs.gov

Samples of ash and underlying burned soils were collected from 28 sites in southern California areas burned by the October 2007 wildfires, including the Harris, Witch, Ammo, Santiago, Canyon, and Grass Valley fires. The samples were collected from November 2 through 9, 2007, before the onset of the winter rains. Most samples were collected from wildland burn areas, with the goal to understand potential differences in ash and soil characteristics that may result from differences in the type of burned vegetation, burn severity, and underlying bedrock geology. Composite samples of ash/debris and underlying soil from two burned residential areas provide a good comparison of ash/burned soil compositions between burned residential and wildland areas.

Water leach tests indicate ash from burned residential areas, and to a lesser extent wildland areas, can generate substantial caustic alkalinity when the ash comes in contact with rainwater or water-based body fluids (such as perspiration or fluids lining the respiratory tract). Residential ash samples can contain elevated levels of some metals or metalloids that substantially exceed average United States soil levels and/or that exceed Environmental Protection Agency (EPA) residential soil remediation guidelines, including arsenic, lead, antimony, copper, zinc, and chromium.

These U.S. Geological Survey (USGS) findings are consistent with the scientific knowledge about wildfire ash that has led the California Department of Health Services, California EPA, various California counties, and The National Institute for Occupational Safety and Health (NIOSH) to issue advisories regarding appropriate precautionary measures that should be followed by persons working in burned wildland areas or cleaning up burned residences to avoid possible health problems associated with ash exposure. The results also indicate that rainwater runoff from the burned residential and wildland areas may adversely affect water quality and endangered species habitat in receiving streams by causing spikes in alkalinity, suspended solids, concentrations of some metals, and levels of some nutrients.

In tandem with the ash characterization, the USGS also is using hyperspectral field, lab, and remote sensing data to develop methods for mapping chemical impacts to soils, stream habitat, aquatic wildlife, and water quality from wildfire ash. These studies are being linked directly to the ash characterization studies through the collection of ground-based spectral measurements at the same sampling sites, lab-based spectral measurements of the collected samples, and the collection of 10,000 square kilometers of hyperspectral remote sensing data with coincident air photos after the fires. 
Geographic Information System-based Assessment of Post Fire Debris-flow Hazards, Southern California, 2007, By Susan H. Cannon', Joseph E. Gartner', John A. Michael', Mark A. Bauer², Susan C. Stitt', Yvonne M. Rique ', Donna L. Knifong ${ }^{3}$, and Bernard J. McNamara ${ }^{3}$

${ }^{1}$ U.S. Geological Survey, Colorado School of Mines Campus, MS 966, Box 25046, Denver, CO 80225-0046

303-273-8604 cannon@usgs.gor.303-273-8542 jegartner@usgs.gov303-273-8562 imichael@usgs.gov

${ }^{2}$ U.S. Geological Survey, Denver Federal Center, MS 516, Box 25046, Denver, CO 80225-0046

303-202-4332 mabauer@usgs.gov303-202-4351 sstitt@usgs.gov

${ }^{3}$ U.S. Geological Survey, Placer Hall, 6000J Street, Sacramento, CA 95819-6129

916-278-3050_vmroque@usgs.go1, 916-278-3081 dknifong@usgs.gor, 916-278-3135 bjmcnamara@usgs.gov

The October 2007 southern California wildfires burned in excess of 450,000 acres in 11 areas from east of Ventura south to the United States-Mexico border. Although the area burned by these fires was less than the 750,000 acres that burned in 2003, these fires were notable for their collective impacts on residential areas, with more than 1500 homes lost, more than 500,000 people evacuated, 6 fatalities, injuries to 85 persons, and more than $\$ 1.5$ billion in direct losses. Under the auspices of the Southern California Multi-Hazards Demonstration Project (MHDP), the U.S. Geological Survey (USGS) began an extensive interdisciplinary study in response to the fires, even while many of the fires were still burning. This collective response, which involved scientists from all USGS disciplines and regions, and multiple cost centers, illustrates the unique role for and capabilities of the USGS in disaster response.

This talk will describe one component of the response, assessing potential hazards posed by debris flows from the recentlyburned areas. The debris-flow hazard assessments are presented as a series of maps showing a relative ranking of the predicted volume of debris flows that can issue from basin outlets in response to a 3-hour duration rainstorm with a 10-year return period. The calculation of debris-flow volume is based on a multiple-regression statistical model that describes the median volume of material that can be expected from a recently-burned basin as a function of the area burned at high and moderate severity, the basin area with slopes greater than or equal to 30 percent, and the triggering storm rainfall.

During a 40-day period following the fires, assessments for each of the 11 fires were implemented in a Geographic Information System (GIS). These timely assessments provided critical information for issuing basin-specific warnings as part of the USGSNational Oceanic and Atmospheric Administration (NOAA) Demonstration Warning System for Recently Burned Areas in Southern California, and were incorporated into a series of "Post-Fire Hazard Awareness Maps" generated by The Federal Emergency Management Agency (FEMA) that show the combined potential impacts by floods and debris flows and were released to emergency response and land management agencies.

Follow Up for Finding and Using U.S. Geological Survey and Other Spatial Data Online and Modeling with ArcGIS 9, 3:15 pm - 4:30 pm

\section{Poster Session and Vendor Gallery at Building 810. 5:15 pm - 7:30 pm}

(Many other posters will be presented for which titles and abstracts were not submitted.)

\section{Areas of Historical Oil and Gas Exploration and Production in the United States, By Laura R.H. Biewick}

U.S. Geological Survey, Denver Federal Center, MS 939, Box 25046, Denver, CO 80225-0046

303-236-7773 biewick@usgs.gov

The U.S. Geological Survey (USGS) is publishing a map compilation of historical oil and gas exploration and production in the United States. This digital map product is an updated version of a similar USGS map that was published in 1998. In addition to a hardcopy map product, the data were refined and made more accessible using geographic information system (GIS) tools. For this map compilation:

- Oil and gas data are from several databases. Digital data were used from the more than 3 million wells in IHS Energy, Inc.'s PI/Dwights PLUS Well Data on CD-ROM (current to September, 2005). In certain areas, the 
PI/Dwights data tend not to be complete, particularly for pre-1920 production. For Indiana, Pennsylvania, Kentucky, Illinois, and Ohio, databases for all wells in each of those states also were used (current as of 2004 to 2006).

- Base cartographic reference data are included, using the USGS The National Map and a World Shaded Relief map service from the geography network.

- An internet map service is available online.

- Alaska oil and gas data are included.

- Software packages used to create this digital map include: Environmental Systems Research Institute, Inc. ArcGIS 9x, Python, Adobe Photoshop CS, Illustrator CS, and Acrobat 7.0.

Because of the proprietary nature of many of the databases, the United States was divided into cells one-quarter mile square and the production information of all wells in a given cell was aggregated. The cells were then coded to indicate whether or not the wells included within the cell predominantly are oil-producing, gas-producing, are both oil- and gas-producing, are dry, or the type of production is unknown. No proprietary data are included in the cell maps.

\title{
Minerals for America's Future-U.S. Geological Survey Active Mines and Mineral Processing Plants Data Sets, By Robert M. Callaghan
}

\author{
U.S. Geological Survey, National Center, 12201 Sunrise Valley Drive, MS 983, Reston, VA 20190 \\ 703-648-7709 rcallaghan@usgs.gov
}

The U.S. Geological Survey (USGS) provides statistics and information on the worldwide supply of, demand for, and flow of minerals and materials essential to the United States. A part of this information is the geography of the mineral and metals industries. About 90 mineral commodities ranging from abrasives to zinc are the subject of USGS reports. Companies involved in the mining and mineral processing industries are canvassed for data on production, consumption, trade, and stocks. The mailing list for the canvasses provides the starting point for the domestic geographic information system (GIS) data set. Government responses to voluntary questionnaires, Government and company reports, and industry publications provide the starting point for the region-based international data sets. The attributes in the domestic and international data sets include company, site, locality information, coordinates, and facility type. The international data sets also include plant capacities when known. Factors such as changing demand, the economics of importing, permitting issues, and exhaustion of ore reserves cause the number of active operations to change with time. In some cases, the number of domestic mines may decrease, but the number of processing plants may increase because of increasing imports of raw materials. The USGS data sets provide an overview of the mining industry; updating is an ongoing process.

The locational information is derived from several sources, including geocoding of addresses. Because the mailing addresses used in geocoding often are distant from the mine or plant, or are unable to be geocoded, additional sources of information are required and imagery verification is used when possible. Other sources include the USGS Mineral Resources Data System, the U.S. Board on Geographic Names, other Federal agencies, and states that sometimes publish permit information. An important distinction is that just because an operation has a permit does not mean it is active. The USGS is unique in its data sets in that they are based on production and consumption data, whether reported by companies or estimated, include mines and processing plants, and have national and international scope. Individual company reported data are proprietary, and therefore are not released as part of the data sets, but have been used within the USGS in projects such as estimating water use in the United States by the mining industry. The published data sets are available through the Mineral Resources Program spatial data download site, http://mrdata.usgs.gov/.

\section{Stratigraphic Visualization Using RockWorks14: A Three-Dimensional Chronostratigraphic Model of the Colorado Plateau, By Nicole Cordier, Becky Thompson, and Kate Falconer}

\author{
RockWare Inc., 2221 East Street \#1, Golden, CO 80401 \\ 303-278-3534x107 hicole@ rockware.com,x103 becky@ rockware.com,x100 kate@ rockware.com
}

Spanning Colorado, Utah, Arizona, and New Mexico, the Colorado Plateau has many beautiful geologic sites with striking outcrops and awe-inspiring landscapes crafted by geological processes during the past 2 billion years. RockWare has developed a 3-dimensional (3D) chronostratigraphic geological model of the Colorado Plateau in RockWorks14. Visualization and 3D representation of geological data aids interpretation, understanding and presentation for scientific and general audiences. Publicly 
available data in the form of stratigraphic columns from the U.S. Geological Survey (USGS), local surveys and universities, a RockWare stratigraphic study of the Colorado Plateau National Parks, and other sources were used to develop the 3D model. RockWare amalgamated the local rock groups into singular stratigraphic units based on geologic age to create continuity for a vast 130,000 square-mile area. Computer modeling using RockWorks14 was used to interpolate the areas between the data points to gain a better understanding of regional stratigraphy and depositional history. The 3D RockWorks14 model allows for a better comprehension of past geologic processes and offers presentation tools to improve communication and understanding.

\title{
Developing a Geodatabase and Three-Dimensional Conceptual Model for Data Management at the Longhorn Army Ammunition Plant, Harrison County, Texas, By Daniel K. Pearson and Sachin D. Shah
}

\author{
U.S. Geological Survey, Texas Water Science Center, 3027 Exchange Drive, Austin, TX 78754-4733 \\ 512-927-3507dpearson@usgs.gov, 512-927-3572 sdshah@usgs.gov
}

The Longhorn Army Ammunition Plant (LHAAP), a U.S. Environmental Protection Agency (USEPA) Superfund site, relies on current (2008) and historical environmental data for hydrologic monitoring, management, cleanup, and protection of its resources. The U.S. Geological Survey (USGS), in cooperation with the USEPA, has developed a comprehensive geodatabase to assist resource managers to efficiently manage data, conduct data gap analysis, and assess the progress of cleanup at LHAAP. Project spatial and tabular data were compiled into a single geodatabase and then integrally linked to generate a 3-dimensional (3D) conceptual model of the hydrogeologic units beneath the site by using relations between hydrogeologic and geologic data. The 3D models are based on structural and thickness configurations across the site and depict aquifers and confining units. These models also provide a framework for future conceptualization of ground-water flow and contaminant-transport modeling. The geodatabase has proven to be a successful tool for distributing static and dynamic information to regulatory agencies, managing partners, communities, and citizen groups with interest in LHAAP. As the project transitions into the geodatabase-maintenance phase, the USGS will update the geodatabase quarterly as data become available. In addition, the USGS will provide technical support to the USEPA by continuing to produce representations of the LHAAP data in two and three dimensions.

\section{Mapping Bare Ground Using Satellite Imagery at Piñon Canyon Maneuver Site, Colorado, By Susan C.F. Stitt', Carol S. Mladinich', and Jean A. Dupree ${ }^{2}$}

\author{
${ }^{1}$ U.S. Geological Survey, Rocky Mountain Geographic Science Center, MS 516, Box 25046, Denver, CO 80225-0046 \\ 303-202-4351 susan_stitt@usgs.gov, 303-202-4313 csmladinich@usgs.gov \\ ${ }^{2}$ U.S. Geological Survey, Colorado Water Science Center, MS 425, Box 25046, Denver, CO 80225-0046 \\ 303-236-4912 dupree@usgs.gov
}

Piñon Canyon Maneuver Site (PCMS), located along the Purgatoire River in southeast Colorado, is the second largest military training area in the nation, occupying 235,896 acres. The Fort Carson Directorate of Environmental Compliance and Management (DECAM) requested that the U.S. Geological Survey (USGS) investigate remote sensing methods of measuring bare ground to monitor maneuver related disturbance. The goal was to develop an automated, repeatable, and cost-effective method to differentiate bare ground and not-bare ground. During the summer of 2005, an area of the maneuver site was opened for the first time to military maneuvers. In late July and early August 2005, before any maneuver activity in this area, two IKONOS satellite scenes were acquired, and USGS personnel spent a week in the field collecting ground truth information.

During 2007, a team of three USGS remote sensing specialists evaluated methodologies for differentiating bare ground from not-bare ground. The software packages used in the evaluation included ITT's ENVI, Leica-Geosystems' ERDAS IMAGINE, Definiens' eCognition, Los Alamos National Lab's Genie Pro, and Visual Learning Systems' Feature Analyst. Processing techniques were evaluated on pansharpened and non-pansharpened images and included object-oriented classification techniques incorporating polygon shapes and their relationships, as well as traditional pixel-based image processing techniques such as supervised and unsupervised classifications, tasseled cap indexes, principal component analyses, utilizing various band combinations. Three methods were recommended to the DECAM: unsupervised Iterative Self-Organizing Data Analysis (ISODATA) classification of non-pansharpened bands, unsupervised ISODATA classification of the first two principal components of pansharpened bands, and object-based eCognition classification of pansharpened bands. Overall accuracy of the results of the three methods ranged from 94 to 98 percent in distinguishing between bare ground and not-bare ground. Results from these techniques will be illustrated. The team concluded that the final decision regarding which of these three methods is best would require another image collection event to evaluate stability and reproducibility. 


\title{
Formalizing Model-Specific Geographic Information System Methodology with the GIS Weasel, By Roland J. Viger
}

U.S. Geological Survey, Denver Federal Center, MS 412, Box 25046, Denver, CO 80225-0046

303-236-5030rviger@usgs.gov

The U.S. Geological Survey (USGS) Geographic Information System (GIS) Weasel is an extensive, stable interface to a GIS that facilitates execution of many of the common tasks needed to derive the geographic information used in an environmental simulation model (ESM). Despite bundling basic GIS functionality into methodological chunks that are more meaningful to modelers, the GIS Weasel still does not help new users with the learning curve on how to use the GIS Weasel in support of their particular ESM. To allow the managers of an ESM to define and communicate their ideas on this in a formal way, the GIS Weasel has been designed to integrate software "plug-ins" that can be developed, published, and distributed independently of the GIS Weasel software package. Plug-ins may include written documents, data, or new software. Most plug-ins contain a configuration file that specifies the subset of GIS Weasel functionality that should be used. Regardless of the plug-in content, this concept provides a way to formally specify how the geographic information consumed by an ESM should be prepared. This specification not only helps new users learn about an ESM and avoid inappropriate model usage, but also can serve as documentation of an ESM that is much more specific than most forms of metadata.

\section{Global Wildlife Disease News Map—Putting Wildlife Health News on the Map! By Megan K. Hines', Steven Gustafson², F. Joshua Dein'2, and Cris Marsh'}

\author{
${ }^{1}$ NBII Wildlife Disease Information Node, Room 60, Science Hall, 550 North Park Street, Madison, WI 53076 \\ 608-270-2400x2333 mkhines@wisc.edu \\ ${ }^{2}$ U.S. Geological Survey, National Wildlife Health Center, 6006 Schroeder Road, Madison, WI 53711 \\ 608-262-7785 sgustafson@usgs.gor.608-270-2450_jdein@usgs.gor, 608-270-2459 cmarsh@usgs.gov
}

The National Biological Information Infrastructure (NBII) Wildlife Disease Information Node (WDIN) is a collaborative project to develop web-based tools to provide state and federal resource managers, animal disease specialists, veterinary diagnostic laboratories, physicians, public health workers, educators, and the general public with access to data on wildlife diseases, mortality events, and related information.

This new WDIN Google Mapping application creates a visual way to explore wildlife health news provided by the WDIN Wildlife Disease News Digest. The Google Map application captures the last 45 days of georefenced entries from the Digest, and allows users to filter the contents shown on the map by wildlife health topic, wildlife/human topic, domestic animal/wildlife topic, disease type, species, or country.

WDIN populates the map by combing through authoritative Really Simple Syndication (RSS) news service feeds and email alerts, and then cataloging the metadata into a Dublin core-based database. The relevant articles also are tagged with keywords that the user can select to filter the content shown on the map.

The georefenced articles are displayed with unique pushpin icons that inform the user as to what level of geographic detail the article refers to. The locations are referenced by place, county, administrative unit, country, or continent. Locations are georefenced with latitude and longitude values from either the U.S. Geological Survey (USGS) Geographic Names Information System (GNIS) database, or internationally from the National Geospatial-Intelligence Agency's GeoNet Names Server (NGA GNS) database. Places that cannot be successfully geocoded with those two authorities often are approximated using Google Earth or referenced at the next available geographic level. Polygon level geographic information is geocoded as a geographic center of the feature (centroid). An eXtensible Markup Language (XML) file is generated on-demand from the published articles, which organizes the contents by unique latitude and longitude locations called markers. Each unique marker is linked to the associated article that populates the information windows when an icon is selected

The Google Map application connects to an initial XML file containing markers for all georefenced entries in the last 45 days. If a user selects an available filter topic, the XML file with the filtered results is requested via Asynchronous JavaScript (AJAX), $\mathrm{X}$-standard Hypertext Transfer Protocol (XHTTP) request and the map display is refreshed to display those markers where the filter is present. 
With no global surveillance system in existence for the monitoring of wildlife health, this tool helps to fill the void by harvesting unstructured, disparate information about disease outbreaks and other wildlife-related topics. The application is expected of be useful to professions working in the wildlife, domestic-animal, and human-health communities.

\section{Presentation Titles and Abstracts, Wednesday, May 14, 2008}

\section{Wednesday Plenary 8:00 am - 11:30 am}

\section{USGS Geographic Analysis and Monitoring Program, By Jonathan Smith}

U.S. Geological Survey, National Center, 12201 Sunrise Valley Drive, MS 519, Reston, VA 20192-0002

703-648-4516 jhsmith@usgs.gov

Abstract Not Submitted

USGS Land Remote Sensing Program, By Bruce Quirk

U.S. Geological Survey, National Center, 12201 Sunrise Valley Drive, MS 517, Reston, VA 20192-0002

703-648-5057quirk@usgs.gov

Abstract Not Submitted

\section{New Commercial Satellites Lead to New Exciting Products, By Scott A. Bennett}

Harris Corporation, Global Geospatial Solutions, 1746 Cole Blvd., Suite 225, Golden, CO 80401

303-215-1700 scott.a.bennett@harris.com

Land Observation Satellites have come a long way since Landsat-1, the first civil satellite, launched in 1972, and have become more prolific as more commercial companies and foreign governments have either launched or are in various stages of design and building new satellites and sensors. To date, (2008), approximately 41 different land imaging satellites are in orbit with resolutions greater than 32 meter $(\mathrm{m})$ and are operated by approximately 18 different countries. These include new high-resolution active image scanning radar, as well as passive very high-resolution sensors. Many other satellites, with sub-meter sensors, are scheduled to be launched within the next 18 months. Other new or upcoming mid-resolution multispectral sensors will have daily re-visit capabilities.

Thanks to the vision and financial support of the likes of Google, Microsoft, Yahoo, and others, and the desire to use on-line search engines to capture the public's attention, satellite imagery has entered the awareness, minds and homes of millions of people around the world, this earth imagery has so much more value than just the currency of photos that many are most familiar with. It is the usefulness of this source data, which can be used to create such a multitude of value-added derivative products, that has the greatest value. These value-added products often fall into the broad categories of classification, elevation data, 3-dimensional (3D) models, and feature extraction.

Perhaps one of the most useful value-added products to the geo-scientific community is elevation data, but not all digital elevation models (DEMs) are created equal and are used in the same way. These data vary from the broad coverage collected by Shuttle Radar Topography Mission (SRTM) at roughly $30 \mathrm{~m}$ resolution to the 3-5 m airborne Interferometric synthetic aperture radar (IfSAR) data to the very high-resolution sub-meter light detection and ranging (LiDAR) data. Stereo data from these new high-resolution satellites can be used to create digital surface models (DSMs) at roughly the same resolution as the source pixel resolution and, therefore, can closely resemble airborne LiDAR data and be used for 3D building and feature extraction. 


\section{The NASA Orbiting Carbon Observatory: Measuring Atmospheric Carbon Dioxide from Space, By Dr. David Crisp}

NASA, Jet Propulsion Laboratory, MS 183-501, California Institute of Technology, 4800 Oak Grove Drive, Pasadena, CA 818-354-2224 david.crisp@jpl.nasa.gov

The Orbiting Carbon Observatory (OCO) is under development by the National Aeronautics and Space Administration (NASA) Jet Propulsion Laboratory in preparation for launch in December 2008. During its nominal 2-year operational lifetime, this Earth System Science Pathfinder mission will make space-based measurements of atmospheric carbon dioxide $\left(\mathrm{CO}_{2}\right)$ and molecular oxygen $\left(\mathrm{O}_{2}\right)$ over the sunlit hemisphere of the Earth. These data will be analyzed with remote sensing algorithms to retrieve estimates of the column-averaged $\mathrm{CO}_{2}$ dry air mole fraction, $X_{\mathrm{CO} 2}$, with the accuracy and sampling resolution needed to identify and characterize surface sources and sinks of $\mathrm{CO}_{2}$ on regional scales over the entire globe. OCO consists of a dedicated spacecraft bus that carries and points a single instrument. This instrument incorporates three high-resolution grating spectrometers that make coincident measurements of reflected sunlight in near-infrared $\mathrm{CO}_{2}$ and $\mathrm{O}_{2}$ bands. The pre-flight qualification and calibration testing of the instrument has just been completed. These tests indicate that the instrument will provide high quality data for $X_{\mathrm{CO} 2}$ retrievals. The instrument will be integrated with the spacecraft bus during the spring and summer of 2008. The completed Observatory will then be delivered to the launch site at Vandenberg Air Force Base in California to begin integration with the launch vehicle. OCO will be launched into a 635 kilometer $(\mathrm{km})$ altitude, near-polar orbit. The on-board propulsion system will then raise the orbit to $705 \mathrm{~km}$ and insert OCO into the Earth Observing System Afternoon Constellation (also known as the "A-Train"). OCO will fly approximately 4 minutes ahead of the EOS Aqua platform, with an ascending nodal crossing time of 1:26 PM. The orbit raising and in-orbit checkout (IOC) activities are expected to last approximately 45 days. The first routine science observations are expected in early February 2009. Calibrated spectral radiances will be archived in a NASA Distributed

Active Archive Center (DAAC) starting 6 months after the end of IOC. The delivery of an exploratory $X_{\mathrm{CO} 2}$ product to the DAAC will begin within nine months of the IOC completion.

\section{Plenary Session: Remote Sensing Discussion, 10:50 am - 11:30 am, Moderated by Richard Spengler}

\section{Wednesday Hands-on Sessions}

\section{ENVI Feature Extraction Module, 1:00 pm - 5:10pm, By Adam 0'Connor}

ITT Visual Information Solutions, 4990 Pearl East Circle, Boulder, CO 80301

303-544-4433 aoconnor@ittvis.com

The ENVI Feature Extraction Module by ITT Visual Information Solutions is an easy-to-use, accurate, and repeatable software tool that allows users to find, identify, and map features of interest (extract features) from geospatial imagery. Traditional approaches utilize pixel-based image processing algorithms that commonly require a large number of spectral bands and a multi-step, time-consuming extraction process to assure accuracy. This new module uses object-based image analysis technology to allow analysts to extract features from readily available panchromatic (black and white) and multispectral (color and other spectral bands) data. In this context, an object is not only defined as a region of interest with unique spatial, spectral (including brightness and color), and texture characteristics, but also by its shape and relation to other objects at similar or at different scales. Once found and identified, these objects can then be converted to vector features (polygon, line, point) and output in Environmental Systems Research Institute (ESRI) Shapefile format for incorporation into a Geographic Information System.

\section{Introduction to ArcGIS Server, 1:00 pm - 5:10 pm, By Jeremiah Lindemann}

ESRI, One International Court, Broomfield, CO 80021-3200

ArcGIS Server provides a complete server-based geographic information system (GIS) that supports the use of centrally managed spatial data for mapping and analysis. Participants will learn how to publish maps, globes (3-dimensional software models or representations of the Earth or another planet), and geoprocessing models created in ArcGIS Desktop as ArcGIS Server 
services. A brief overview on optimizing ArcGIS Server services will be discussed. The workshop also will demonstrate how to create out-of-the-box Web applications using Manager, and how to use GIS services in Web applications and ArcGIS Explorer.

\section{Geospatial One-Stop: What's New in Publishing, Discovering, and Using Data in our National Spatial Data Infrastructure, 1:00 pm - 2:55 pm, By Robert Dollison}

U.S. Geological Survey, 510 National Center, Reston, VA 20192

703-648-4722 rdollison@usgs.gol

Find out what's new with Geospatial One-Stop (GOS, http://www.geodata.gov). New search result visualizations will be presented-including the ability to launch web services onto globes—and methods for checking the status of your published web map services will be covered. Methods of data publishing a through GOS will be reviewed. Learn how GOS and The National Map are moving forward and the future plans to help improve the National Spatial Data Infrastructure (NSDI). The workshop will give attendees hand-on experience with GOS.

\section{Introduction to Job Tracking for ArcGIS, 1:00 pm - 2:55 pm, By Sandi Belson}

ESRI-Washington DC, 8615 Westwood Center Drive, Vienna, VA 22182-2218

703-506-9515x8137sbelson@esri.com

Data production and maintenance projects, both large and small, have a vital need to have their project information (e.g., staff allocation, progress and status, changes to data) tracked as well as to have the work completed in the most efficient and timely manner possible. Being able to monitor these efforts in a way that does not encumber the production process and that is tightly integrated with the software has traditionally been the primary challenge when it comes to job tracking. Now, with Environmental Systems Research Institute's (ESRI's) Job Tracking for ArcGIS® (also referred to as JTX ${ }^{\mathrm{TM}}$ ), there is a tool designed to help organizations overcome this challenge. This workshop will introduce students to the workflow and job tracking functionality of JTX. Participants will learn how the JTX application can be used to streamline a workflow and guide the project process. They also will learn about how JTX can be used to manage the overall project.

\section{Building Custom Tools with Python, 3:15 pm - 5:10 pm, By Corey Tucker and Jason Pardy}

ESRI, 380 New York Street, Redlands, CA 92373-8100

909-793-2853 ctucker@esri.com ipardy@esri.com

Geoprocessing is a vital part of most geographic information system (GIS) operations and in ArcGIS, Python is the glue. It allows you to automate tasks and build new tools. This session will review the scripting support for geoprocessing tools in ArcGIS, focusing on the use of Python for creating new custom geoprocessing tools for sharing with others in your organization. It also will cover building tools from other executables and scripts, such as Arc Macro Language.

\section{Blue Marble Geographics Demonstration: the Geographic Calculator and the Geographic Transformer, 3:15 pm - 5:10 pm, By Sam Knight}

Blue Marble Geographics, 397 Water Street, Suite 100, Gardiner, ME 04345

800-616-2725 samk@bluemarblegeo.com

Geographic Calculator Demonstration:

Join Blue Marble for a demonstration of the latest version of the Geographic Calculator. This review will demonstrate the powerful geodetic definition and coordinate conversion tools. The Calculator includes point-to-point, databases of points, map-file based conversions, and custom definitions. New tools that focus on enabling enterprise-wide collaboration will be explored, including administrative tools for locking down definition access or views of various coordinate objects, workspaces, and a direct tie into the Open Geospatial Consortium (OGC) Web Registry Service (WRS) version of the European Petroleum Survey Group (EPSG) database. 
Geographic Transformer Demonstration:

Join Blue Marble for a demonstration on the latest version of the Geographic Transformer. This presentation will demonstrate how to leverage the power of the Blue Marble coordinate system data source and apply it to work with rasters. Tools for fast and accurate raster referencing, transformation, mosaicking, and tiling will be reviewed along with batch tools for all processes. The Transformer is the only application available that allows users to read in and write out to all of the major geographic information system (GIS) compression formats including Multi-resolution Seamless Image Database (MrSID), Enhanced Compression Wavelet (ECW), and Joint Photographic Experts Group (JPEG) 2000.

\section{Wednesday Lecture Sessions}

\section{System Design and Administration, 1:00 pm - 2:55 pm, By Dave Peters}

ESRI, 380 New York Street, Redlands, CA 92373-8100

909-793-2853 dpeters@esri.com

System architecture design is a critical part of the enterprise technology implementation process. Understanding user workflow requirements, selecting the right technology, determining the most appropriate implementation architecture, establishing target performance milestones, and managing implementation compliance establishes a framework for deployment success. This session will present a proven design process for establishing a foundation for enterprise system planning and implementation success. For more information, see: http://www.esri.com/library/whitepapers/pdfs/sysdesig.pd]

\section{Extending ArcGIS, 1:00 pm - 2:55 pm, Moderated by Curtis Price}

\section{Data East Geographic Information System (GIS) Ware: Productivity Tools for GIS, By Viacheslav Ananev and Andrei Elobogoev}

Data East LLC, 23, Musa Jalyl str., Novosibirsk, 630055, Russia

7-383-3320320info@dataeast.ru

This product demonstration session will familiarize U.S. Geological Survey (USGS) Geographic Information System (GIS) Workshop attendees with Data East's software products for ArcGIS users. A brief presentation about the company will be followed by the more detailed overview of the software. After live product demonstrations by the Data East staff, attendees will have the opportunity to try the software functionality on their own data sets.

The following software products will be presented:

- XTools Pro for ArcGIS-a well-known and one of the most popular and full-featured extensions to ArcGIS

- Personal Internet Map Server (IMS) — an Internet map server allowing publishing maps created in ArcGIS in Internet/Intranet

- MapZip—a new solution for easy and effective sharing maps created in ArcGIS

MAPublisher and Geographic Imager, By Ted Florence and David Andrec

Avenza Systems Inc, 124 Merton Street, Suite 400, Toronto, Ontario, Canada, M4S $2 Z 2$

416-487-5116 ted@avenza.com 416-487-6442 david@avenza.com

\section{MAPublisher}

This presentation will offer the attendee an introductory session to the latest version of MAPublisher 7.6 from Avenza Systems Incorporated. MAPublisher is Avenza System's flagship cartographic production product for Adobe Illustrator CS2 \& CS3.

MAPublisher is a plug-in that adds specific geographic information system (GIS) capabilities to Adobe Illustrator enabling users to incorporate and manage their GIS data within a graphics environment for the purpose of generating publishable map content and to provide access to additional graphic options typically unavailable with most GIS products on the market. This workshop will detail the processes of importing GIS data into Illustrator, how to manage and assign data scale, coordinate system settings 
and transformations, address the concept of "Map Views" and how they relate to layers in Illustrator. Further explanation will be given towards managing and manipulating map-attribute data, making selection sets, and how to make use of MAPublisher's map stylization tools based on map-data attributes in conjunction with Illustrator styles and symbols. Other topics will be covered including MAPublisher's labeling functionality and some of the map finishing tools including the grid and scalebar generators. Time will be provided toward the end of this introductory session for a brief question and answer period.

\section{Geographic Imager}

This presentation will offer the attendee an introductory session to the latest version of Geographic Imager 2.0 from Avenza Systems Incorporated. Geographic Imager is Avenza Systems' spatial imagery management tool set for Adobe Photoshop CS2 \& CS3. Geographic Imager 2.0 is a Photoshop plug-in that supports importing, editing, manipulating, and exporting geospatial images such as aerial and satellite imagery. Attendees will be instructed on how to integrate their spatial imagery with Adobe Photoshop, and specifically on how to perform such operations as assigning coordinate systems to imagery, performing coordinate system transformations, and navigating and editing the coordinate system database through the Imager palette. Additional topics covered will include how to mosaic your spatial images for the purpose of creating composite images, cropping georeferenced imagery, and generating image tiles by configuring Geographic Imager's tiling option.

\section{Elevation and Surfaces—Light Detection and Ranging (LiDAR) and Related Technologies, 1:00 pm - 2:55 pm, Moderated by Silvia Terziotti}

Integration of Bathymetric Light Detection and Ranging and Sonar Methods for Hydrographic Surveys, By Nicholas Gianoutsos', Capt. Guy T. NolR, Lt. Benjamin K. Evans', and LTJG Samuel F. Greenaway ${ }^{4}$

${ }^{1}$ U.S. Geological Survey, Denver Federal Center, Building 25, MS 939, Box 25046, Denver, CO 80225-0046

303-236-1660 ngianoutsos@usgs.gol

${ }^{2}$ NOAA, Marine and Aviation Operations Centers, 8403 Colesville Road, Suite 500, Silver Spring, MD 20910

301-713-7681guy.noll@noaa.gov

${ }^{3}$ NOAA, Program Coordination Office, HCHB, Rm. 5811, $14^{\text {th }}$ and Constitution Ave. NW., Washington, DC 20230

202-482-0683 benjamin.k.evans@noaa.gov

${ }^{4}$ NOAA Marine Engineering, 1801 Fairview Ave. East, Seattle, WA 98102

206-553-5077 samuel.greenaway@noaa.gov

The National Oceanic and Atmospheric Administration (NOAA) Ship RAINIER has conducted survey operations in Alaskan waters for the production of nautical charts since 1969. Over the past several seasons RAINIER has worked in project areas that adjoin contracted bathymetric Light Detection and Ranging (LiDAR) surveys. During this period, the methods of integrating LiDAR data into the survey process continuously have evolved. This presentation explains the contemporary operational model NOAA used to combine full bottom coverage sonar with bathymetric LiDAR survey data. In particular, an exploration of the issues involved in establishing a junction between the two bathymetric data sets is developed and attendant issues of cartographic feature management are discussed. The talk will benefit those who are interested in learning the methods used by NOAA's National Ocean Service to incorporate these tools into the bathymetric mapping process. This presentation is from the paper, "Field Integration of LiDAR and Sonar Hydrographic Surveys," that was published by members of NOAA Ship RAINIER and presented at the United States 2007 Hydrographic Conference. The paper is available online at http://www.thsoa.org/ hy07/05_05.pdf.

CLICK: The USGS Center for Light detection and Ranging (LiDAR) Information Coordination and Knowledge, By Jordan C. Menig' and Jason M. Stoker ${ }^{2}$

${ }^{1}$ SGT, Contractor to U.S. Geological Survey, EROS, $47914252^{\text {nd }}$ Street, Sioux Falls, SD 57198

605-594-6892 imenig@ usgs.gol

${ }^{2}$ U.S. Geological Survey, EROS, $47914252^{\text {nd }}$ Street, Sioux Falls, SD 57198

605-594-2579 jstoker@usgs.gov

The U.S. Geological Survey Center for Light Detection and Ranging (LiDAR) Information Coordination and Knowledge (CLICK) was created to facilitate data access, coordinate user requirements, and promote education about the use of LiDAR data (both "raw" and classified full return point clouds) for scientific needs. Bare Earth derivatives of LiDAR elevation data will be 
used to update the high-resolution data layer in the National Elevation Data set (NED), if applicable. LiDAR data have not been widely used by scientists and managers because of their cost, difficulty of access, and a lack of awareness about available data and acquisition opportunities. CLICK enables partners and potential partners to coordinate efforts to collect LiDAR data and make them widely available, thereby reducing costs to all interested parties. CLICK's primary mission is to collect and process data, provide information that facilitates research, organize and distribute LiDAR data that already have been acquired, and aid in planning future data collections. The CLICK Web portal (http://LiDAR.cr.usgs.gov) allows LiDAR users to ask and answer questions and coordinate with others who are looking for data or have data available to share. CLICK is designed to foster more use of LiDAR data and to raise awareness of LiDAR's availability and applications.

Light Detection and Ranging (LiDAR) Data Management: Maturing Our Approach to an Advancing Technology, By Karl Heidemann

U.S. Geological Survey, EROS, $47914252^{\text {nd }}$ Street, Sioux Falls, SD 57198-9801

Abstract Not Submitted

Environmental Systems Research Institute: Discussion on Cartography Topics, 1:00 pm - 2:55 pm

\section{ArcGIS and the Road Ahead, 3:15 pm - 5:10 pm, By David Vaillancourt}

ESRI, One International Court, Broomfield, CO 80021-3200

303-449-7779 dvaillancourt@esri.com

ArcGIS 9.3 builds on the 9.2 release to offer key enhancements to the ArcGIS Desktop and ArcGIS Server platforms. This session will cover the key 9.3 product enhancements and explore how these changes will improve performance, user workflows, and interoperability. A few of these enhancements include improvements in labeling, map legends, iterative modeling, Keyhole Markup Language (KML) support, and time series animation in ArcGIS. Some enhancements to ArcGIS Server include new Application Programming Interfaces (APIs), new PostgreSQL Support for the geodatabase, and on-demand caching and improved caching tools for ArcGIS Server, allowing faster mapping services.

\section{Microsoft Virtual Earth, 3:15 pm - 5:10 pm, By William B. Gail}

Director, Strategic Development, Microsoft Virtual Earth, $169038^{\text {th }}$ Street, Boulder, CO 80301

303-546-1429 bgail@microsoft.com

Online mapping has revolutionized the geospatial field over the last decade, expanding from the original vector maps to include global databases of high-resolution imagery and various analytic services. Today, the emergence of 3-dimensional (3D) online mapping is again energizing the community. Microsoft's Virtual Earth is a browser-based 2-dimensional (2D) and 3D online mapping service. The accuracy of vector and image data was a primary requirement supporting the development of Virtual Earth. The current - and potential — applications of Virtual Earth are diverse, ranging from environmental monitoring to enterprise geographic information system (GIS) and consumer-oriented mashup websites. Virtual Earth is supported by a Software Development Kit (SDK) and Application Programming Interface (API) that enable easy development of targeted applications to meet a wide range of mapping needs. Current 2D and 3D applications of Virtual Earth and the tools for creating new applications will be discussed. 


\section{Elevation and Surfaces—Light Detection and Ranging and Related Technologies (LiDAR),} 3:15 pm - 5:10 pm, Moderated by Silvia Terziotti

Evaluation of Airborne Light Detection and Ranging (LiDAR) Data to Classify and Predict Vegetation Communities, $B y$ Monica Palaseanu-Lovejoy', Amar Nayegandhi', John Brock², Robert Woodman³, and C. Wayne Wright

${ }^{1}$ Jacobs Technology, U.S. Geological Survey, 600 4th Street South, St. Petersburg, FL 33701

mpal@usgs.gov; anayegandhi@usgs.gov

${ }^{2}$ U.S. Geological Survey, 600 4th Street South, St. Petersburg, FL 33701, jbrock@usgs.gov

${ }^{3}$ National Park Service, Inventory and Monitoring Program, Gulf Coast Network, Lafayette, LA 70506

${ }^{4}$ NASA Wallops Flight Facility, Wallops Island, Virginia, 23337

This study evaluates the capabilities of the National Aeronautics and Space Administration (NASA) Experimental Advanced Airborne Research (EAARL) Light Detection and Ranging (LiDAR) for delineating vegetation assemblages in Jean Lafitte National Park (JELA), Louisiana. Five-meter-resolution grids of bare earth (BE), canopy height $(\mathrm{CH})$, canopy-reflection ratio (CRR), and height of the median energy (HOME) were derived from EAARL data acquired in September 2005.

The EAARL is a temporal waveform green-laser, small-footprint airborne LiDAR. To characterize the vertical structure of vegetation, several individual small footprints are combined to make a composite "large-footprint" waveform. BE is derived from the small footprints, whereas CH, CRR, and HOME are derived from the composite footprints. CRR represents a relative measure of the canopy closure, and HOME is sensitive to changes in vegetation structure.

$\mathrm{CH}$ was divided statistically into four distinct classes. Within each height class, a principal component analysis (PCA) and an independent component analysis (ICA) of all LiDAR metrics were conducted. For each height class, the principal components, the independent components, and the original metrics were respectively classified into four groups either by the k-means or the neural-gas algorithms. Original metrics classifications and PCA- and ICA-based classifications were compared with JELA colorinfrared aerial photography. All classifications were more sensitive in the swamp forested areas than in the open marsh, although PCA- and ICA- neural-gas classifications were somewhat better in the marsh areas than other classifications.

Ground-truth data were collected along transects to assess species composition, canopy cover, and ground cover. The responses of LiDAR metrics to the changes in vegetation was investigated using a series of generalized additive models (GAMs). Since the assumption that species exhibit monotonic relations to LiDAR metrics usually is true for short gradients, the response of the LiDAR metrics to vegetation principal components (vPCA) was modeled and to principal coordinates (vPCO) distances and similarity/dissimilarity matrices.

The GAM Gaussian model is suitable for BE and CH, and the GAM Poisson model performs best for CRR and HOME. The Euclidian distance between vegetation communities is fitting for CRR and HOME, even if with different GAM models, wheras the Bray-Curtis index of similarity/dissimilarity is best for BE and $\mathrm{CH}$. Overall, the best vPCO-fitted curves are much better than the vPCA-fitted curves, although the proportion of total variability explained by GAMs is not above 70. This probably is because of high vegetation beta-diversity and LiDAR metrics may be more affected by overstory and midstory composition than by understory composition.

Laser-Derived Ground Surface, Plant Canopy, and Geomorphology of a Florida Coastal Lowland, By Ellen A. Raabe', Melanie S. Harris ${ }^{2}$, Ramesh L. Shrestha ${ }^{3}$, William E. Carter ${ }^{3}$, and Elizbieta Bialkowska-Jelinska ${ }^{4}$

${ }^{1}$ U.S. Geological Survey, Florida Integrated Science Center, 600 Fourth Street South, Saint Petersburg, FL 33701

727-803-8747x3039 eraabe@usgs.gov

${ }^{2} 17108^{\text {th }}$ St. North, St. Petersburg, FL 33704

727-823-5028meli100@verizon.ne

${ }^{3}$ University of Florida, Civil and Coastal Engineering, 404 Reed Lab, Gainesville, FL 32611-6580

352-392-4999 rshre@ce.ufl.edu, 352-392-5003 bcarter@ce.ufl.edu

${ }^{4}$ Jacobs Technology Inc., USGS 600 Fourth Street South, St. Petersburg, FL 33701

727-803-8747 ebialkowska@usgs.gov

Topography and plant canopy of marsh-dominated coastal lowlands were derived from airborne laser-altimetry data collected on Florida's Gulf Coast near Cedar Key. The landscape was partitioned into three functionally unique units for a non-automated 
approach. Each unit was processed separately to maximize use of the laser-intercept data cloud, using parameters based on feature scale and frequency of laser penetration to ground surface. Surface models were developed using low- and high-point filters to separate ground-surface and plant-canopy intercepts, adjusting filter-search space to achieve a balance between generalizing elevation under canopy and preservation of topographic detail. Comparisons between field-surveyed orthometric heights (O.H.) and bare-earth models produced errors of $+0.17-0.22 \mathrm{~m}$. The laser-derived ground-surface models effectively delineated topography of coastal habitats with a geographic coverage and vertical detail previously unavailable.

Flatwoods and hydric hammock cover the low-gradient karst plain, oak scrub conceals relict sand dunes, and thick marsh envelops the broad tidal zone in Levy County, Florida. The coastal lowlands are vulnerable to storm surge as documented by sea-level rise-induced forest-morbidity (Williams and others, 1999; Raabe and others, 2004). A topographic increase of less than $0.5 \mathrm{~m}$ can make the difference between tidal flooding and terrestrial habitat; however, currently available topography for this region is too coarse to identify vulnerable topographic lows near the coast.

Management in this region is focused on habitat conservation, fire management, threatened species, and multiple-use issues. Three additional products were derived from the laser-altimetry data to assist land management and improve understanding of vulnerable habitat. 1) A fine-resolution shoreline was delineated, revealing the inland extension of tidal creeks and un-navigable shallow areas. 2) Transect profiles were extracted from the ground-surface and canopy models. The profiles were filtered and combined to demonstrate geomorphic features indicative of stability and vulnerability in the coastal system, such as creek levees, karst features, relict dunes, and topographic lows. 3) The ground-surface and plant-canopy models were combined with intensity values in a classification scheme and land-cover map. Land-cover maps show flood zones in the marsh, mesic flatwoods, hydric hammock, oak scrub, and areas susceptible to tidal flooding.

Results demonstrate the use of airborne laser-altimetry data to model the ground surface and plant canopy of coastal marsh and forest. Such data sets can be instrumental in effective coastal-resource management. The results further demonstrate the capacity to derive shoreline, land cover, and geomorphic characteristics from laser-altimetry data.

Raabe, E.A., Streck, A.E., and Stumpf, R.P., 2004, Historic topographic sheets to satellite imagery: a methodology for evaluating coastal change in Florida's Big Bend tidal marsh: U.S. Geological Survey Open-File Report 2002-211, 44 p.

Williams, K., Ewel, K.C., Stumpf, R.P., Putz, F.E., and Workman, T.W., 1999, Sea-level rise and coastal forest retreat on the west coast of Florida, USA: Ecology, v. 80, no. 6, p. 2,045-2,063.

\section{LiDAR: Practical Techniques for Quality Assurance and Analysis, By Michael Umansky}

Applied Imagery, 8070 Georgia Avenue, Silver Spring, MD 20910

301-589-4047 mumansky@appliedimagery.com

Light Detection and Ranging (LiDAR) data frequently are underutilized. The primary reasons for this underutilization are a lack of universally applied LiDAR quality metrics and metadata standards, a lack of commonly understood analytical techniques, and a lack of LiDAR-specific analysis tools. This presentation covers three topics. First, the presentation details key LiDAR workflow methodologies and quality metrics that enable users to gain an understanding of LiDAR data's quality before using it in production. Second, the presentation will outline common uses of LiDAR data such as flood-plain mapping, impervious surface coverage calculation, and urban planning, as well as the associated tools and techniques required to perform these functions. Lastly, the presentation will illustrate promising emerging LiDAR applications such as feature extraction, aerial/terrestrial LiDAR integration, and geographic information system (GIS) data fusion.

\section{Follow Up for System Design and Administration and Introduction to Job Tracking for ArcGIS (JTX), 3:15 pm - 4:30 pm}




\title{
Presentation Titles and Abstracts, Thursday, May 15, 2008
}

\author{
Thursday Plenary 8:00 am - 11:30 am
}

\section{Update on Geospatial Line of Business and Geospatial Modernization Blueprint, By Lorri Peltz-Lewis}

U.S. Bureau of Reclamation, MP 450, 2800 Cottage Way, Sacramento, CA 95825

916-978-5271 Zpeltzlewis@mp.usbr.gov

The purpose of the Federal Geospatial Line of Business and the Department of Interior (DOI) Geospatial Modernization Blueprint is to define how geospatial data and technology will be used to enhance DOI business activities and to achieve our mission and goals. The Federal Geospatial Line of Business http://www.whitehouse.gov/omb/egov/c-6-8-glob.htm is a Presidential initiative to identify opportunities for optimizing and consolidating Federal geospatial-related investments. Interior's Geospatial Modernization Blueprint http://www.doi.gov/ocio/architecture/modblu/geo/know.htm is part of the DOI Enterprise Architecture process that is developing a take-action approach to align business needs and technologies. The talk will include why DOI is doing this, why do the geographic information system (GIS) professionals care, and what is being done.

\section{Update from “0'Reilly Where 2.0 Conference," By Sandy Williamson}

U.S. Geological Survey, Washington Water Science Center, 934 Broadway, Suite 300, Tacoma, WA, 98402 253-552-1683akwill@usgs.gov

Abstract Not Submitted

\section{Geographic Information System Trends: Deploying Geographic Information Systems in Government, By Clint Brown}

ESRI, Director of Software Products, 380 New York Street, Redlands, CA 92373-8100

909-793-2853 cbrown@esri.com

Geographic Information System (GIS) has been growing and evolving from project-based systems running on workstations to the delivery of content across the Web and throughout large organizations and enterprises. A few key trends are driving these changes. GIS user's work has been evolving to include serving information to end users. New servers make it possible to leverage and build on quality geographic information compiled and crafted by GIS practitioners.

Many GIS organizations are beginning to publish and serve many of their key sets of geographic information. In this talk, an attempt will be made to lay out a framework for how to use GIS in these settings and what the implications might mean for your organization in the coming years. Some of the key topics will include:

- How GIS's role is evolving;

- Example applications of GIS;

- The ArcGIS 9.3 platform and product plans;

- GIS's changing role in the Web 2.0 world (GeoWeb, Google, Microsoft, etc.); and

- A framework for implementing GIS.

Other topics that may be discussed are server GIS and how GIS services are deployed and used in applications running in web browsers, globe explorers, desktops, custom applications, mobile GIS, and more. 


\section{Thursday Hands-on Sessions}

\section{Putting NHDPlus to Work: Applying a National Geospatial Surface-Water Framework-Basics Session, 1:00 pm - 2:55 pm, By Alan Rea', Richard B. Moore², and Craig M. Johnston ${ }^{2}$}

${ }^{1}$ U.S. Geological Survey, Idaho Water Science Center, 230 Collins Road, Boise, ID 83702 208-387-1323ahrea@usgs.gov

${ }^{2}$ U.S. Geological Survey, NH/VT Water Science Center, 361 Commerce Way, Pembroke, NH 03275-3729

603-226-7825rmoore@usgs.gov.603-226-7843 cmjohnst@usgs.gov

Two sessions will be offered to users interested in learning how to apply the National Hydrography Data set Plus (NHDPlus). The NHDPlus is an integrated suite of application-ready geospatial data sets that incorporate many of the best features of the National Hydrography Data set (NHD), the National Elevation Data set (NED), the National Land Cover Data set (NLCD), and the Watershed Boundary Data set (WBD). The first session will include presentations describing the data content and basic use of NHDPlus. The second session will cover advanced applications and tools, including watershed delineation and characterization, catchment attribute allocation and accumulation, aquatic exposure analysis, and simple models. Both sessions will include hands-on exercises.

\section{Working with ModelBuilder and Geoprocessing Tools, 1:00 pm - 2:55 pm, By Corey Tucker and Jason Pardy}

ESRI, 380 New York Street, Redlands, CA 92373-8100

909-793-2853 ctucker@esri.comipardy@esri.com

Geographic Information System (GIS) professionals require a system that allows the automation of their workflows within a GIS to accomplish large tasks and reproduce their work. The combination of several hundred tools and a geoprocessing framework with ArcGIS fulfills this requirement. This session will explore the tools and how to combine them to create workflows using ModelBuilder. Tips also will be presented on working with intermediate data, using variables, documenting models, and guidelines for building models ready to share with others.

\section{Cartography with ArcGIS, 1:00 pm - 5:10 pm, By Charlie Frye}

ESRI, 380 New York Street, Redlands, CA 92373-8100

909-793-2853 cfrye@esri.com

The geodatabase, cartographic representations, and Maplex are three of the most important features in ArcGIS for cartographers. The geodatabase has data management functions that automate key tasks for cartographers, and is the data format that supports cartographic representations. Cartographic representations are a better way to symbolize geographic information and are considered an improvement over earlier methods. Cartographic representations are optimized for drawing speed, often drawing faster than other ArcGIS symbols; stored and travels with the data; and editable at the level of individual features, making it possible to create maps that are correct graphically while not compromising the geographic information system (GIS) geometry. Maplex is used to label maps and offers many improvements over the Environmental Systems Research Institute (ESRI) Standard labeling engine because just by turning Maplex on more labels will be placed with improved visual association between the labels and their geographic feature.

Workshop participants will gain a basic understanding of how to set up a geodatabase, add shapefile (or coverage) data to the geodatabase, and best practices for using that data to create maps that take advantage of cartographic representations and Maplex.

\section{Introduction to MAPublisher 1:00 pm - 2:55 pm, By Ted Florence}


Global Positioning System 101, 1:00 pm - 5:10pm, By Steve Reiter

U.S. Geological Survey, Infoservices, Denver Federal Center, Box 25286, Denver, CO 80225

303-202-4168 snrieter@usgs.gov

The Global Positioning System (GPS) 101 workshop will introduce students to the basic principles of using GPS receivers as navigation aids and data-collection tools. The differences among recreational, mapping, and survey grade GPS receivers will be reviewed. A combination of classroom work and outdoor field navigation will teach students to use GPS data with various mapping applications. No prior knowledge is assumed and all workshop material is provided.

\section{Putting NHDPlus to Work: Applying a National Geospatial Surface-Water Framework-Advanced Session, 3:15 pm - 5:10 pm, By Alan Rea', Richard B. Moore², and Craig M. Johnston ${ }^{2}$}

${ }^{1}$ U.S. Geological Survey, Idaho Water Science Center, 230 Collins Road, Boise, ID 83702

208-387-1323 ahrea@usgs.gov

${ }^{2}$ U.S. Geological Survey, NH/VT Water Science Center, 361 Commerce Way, Pembroke, NH 03275-3729

603-226-7825 rmoore@usgs.gov 603-226-7843 cmjohnst@usgs.gov

Two sessions will be offered to users interested in learning how to apply the National Hydrography Data set Plus (NHDPlus). The NHDPlus is an integrated suite of application-ready geospatial data sets that incorporate many of the best features of the National Hydrography Data set (NHD), the National Elevation Data set (NED), the National Land Cover Data set (NLCD), and the Watershed Boundary Data set (WBD). The first session will include presentations describing the data content and basic use of NHDPlus. The second session will cover advanced applications and tools, including watershed delineation and characterization, catchment attribute allocation and accumulation, aquatic exposure analysis, and simple models. Both sessions will include hands-on exercises.

\section{Surface Interpolation with ArcGIS, 3:15 pm - 5:10 pm, By Steve Kopp}

ESRI, 380 New York Street, Redlands, CA 92373-8100

909-793-2853 skopp@esri.com

One of the most important kinds of spatial analysis is the exploration of trends and patterns in geospatial data. A common application is the development of a continuous surface from samples to use in further visualization or analysis. This session will provide understanding of deterministic and geostatistical interpolation methods, what tools are available in ArcGIS for interpolation, and guidelines on when and how to use them.

Integrated Geological Data Management, Analysis, and Visualization Using RockWorks14, 3:15 pm 5:10 pm, By Nicole Cordier, Becky Thompson, and Kate Falconer

RockWare Inc., 2221 East Street \#1, Golden, CO 80401

303-278-3534x107nicole@rockware.com x103 becky@rockware.comx100 kate@ rockware.com

RockWorks14 is the latest version of an integrated collection of programs that are designed for the management, analysis, and graphical display of geological data. This abbreviated hands-on course will focus on borehole and measured section data including lithology, stratigraphy, geochemistry, geophysics, fractures, and water levels. Particular attention will be devoted to generating striplogs, cross sections, profiles, fence-diagrams, and block models. Other topics include volumetric calculations, gridding, solid-modeling, and logical operations. 


\title{
Thursday Lecture Sessions
}

\section{System Design and Administration, 1:00 pm - 2:55 pm, By Dave Peters}

\author{
ESRI, 380 New York Street, Redlands, CA 92373-8100 \\ 909-793-2853 dpeters@esri.com
}

System architecture design is a critical part of the enterprise technology implementation process. Understanding user workflow requirements, selecting the right technology, determining the most appropriate implementation architecture, establishing target performance milestones, and managing implementation compliance establishes a framework for deployment success. This session will present a proven design process for establishing a foundation for enterprise system planning and implementation success. For more information, see: http://www.esri.com/library/whitepapers/pdfs/sysdesig.pd],

\section{Data Integration and Interoperability: Operational, 1:00 pm - 2:55 pm, Moderated by Carma San Juan}

\author{
When an Ecosystem is your Enterprise, By Sean P. Finn, Linda Schueck, and Thomas Zarriello \\ U.S. Geological Survey, Forest and Rangeland Ecosystem Science Center, 970 Lusk Street, Boise, ID 83706 \\ 208-426-2697sfinn@usgs.gov,208-426-5211 lschueck@usgs.gov.208-426-5204tom_zarriello@usgs.gov
}

Since 2001 the Forest and Rangeland Ecosystem Science Center's Snake River Field Station has been identifying, generating, documenting, cataloging, and distributing ecological and ancillary spatial and non-spatial data describing the 2 million square kilometer Sagebrush Biome of the western United States. The Sagebrush Biome is the largest contiguous ecosystem in North America and has been identified as one of the three most threatened systems in the United States (Noss and Others. 1995.

National Biological Service Biological Report 28) The region is subject to rapid and broad-sweeping environmental changes that could lead to irreversible alterations of the ecosystem. We identified a web-based solution to this problem by building the SAGEMAP portal (http://sagemap.wr.usgs.gov), a geographic information system (GIS) database for sage-grouse and shrub-steppe management. Our goal was to create a central location for users to access available spatial data sets to facilitate regional-scale analyses and quantify cumulative effects on the landscape. In 2003, SAGEMAP was added to the National Biological Information Infrastructure's (NBII) Great Basin Information Project (http://greatbasin.nbii.gov), which catalogs and distributes nonspatial data and information such as bibliographic records, metadata, images, tabular biological data, and various information about specific projects. This presentation will highlight some of the challenges we encountered during the last 7 years and the solutions generated. Problems encountered with incompatible technologies will be discussed, as well as personalities, and the strategies devised to overcome those problems. Advances in GIS software and services (i.e., on the fly projection, web services for large government data sets, state-level GIS distribution) have helped with some of these issues.

\section{Delivering Model Results to Resource Specialists, By Tim Kern}

ASRC Contractor for Information Science Branch, Fort Collins Science Center, Building C, 2150 Centre Ave., Fort Collins, CO 80526

970-226-9366 kernt@usgs.gov

The Fort Collins Science Center is developing a pilot U.S. Geological Survey (USGS) Web-based forecasting system for invasive species, with the vision of an enterprise system responsive to the operational needs of land-use managers and decision makers. The system, the Invasive Species Modeling and Assessment System (ISMAS), will allow land managers and decisionmakers to generate modeled results for their area of interest, as well as assess these model results.

Technically, ISMAS is less a destination web site than a portal to a set of services. These services, based on the open source GeoTools project and the proprietary ArcGIS server product, let users run models on-line (use existing survey data to forecast potential occurrence), and then publish these outputs as web services (including map products). Model results will be packaged with a confidence layer, providing users with an indicator of whether or not the output has meaning for their set of input parameters. The system also acts as a broker for custom subsets of National Aeronautics and Space Administration (NASA) Moderate Resolution Imaging Spectroradiometer (MODIS)-based phenology data, model-specific USGS spatial data, and field surveys. 
ISMAS allows users to use either a browser-based digitizing application or their own geographic information system (GIS) tools to cut-out subsets of these data for use as model inputs.

This talk will discuss the data preparation, modeling, and assessment methodologies provided by ISMAS. The focus will be on system architecture and component integration, as well as technical options that the ISMAS project researched and did not implement.

Leveraging the U.S. Geological Survey National Water Information System (NWIS) with Geodatabases-NWIS on G-ISteroids, By Robin H. Gary and Brian D. Reece

U.S. Geological Survey, Texas Water Science Center, 8027 Exchange Drive, Austin, TX 78754

512-927-3512 rhgary@usgs.gon, 512-927-3573 bdreece@usgs.gov

The National Water Information System (NWIS) stores a vast amount of data ranging from water quality, ground-water levels, and water quantity to site location, well construction, and gage instrumentation. NWIS is an efficient, well-supported and maintained data storage warehouse; however, it is not an optimal platform for analyzing data and spatial trends. The geodatabase format provides several advantages over other methods that have been used to spatially enable NWIS, such as shapefiles, coverages, or event themes. Creating a NWIS geodatabase snapshot automatically defines intuitive aliases for field, table, and feature class names, creates domains to interpret codes stored in the NWIS database, and establishes relationship classes (feature class to table or table to table) to link sites with related data. By increasing the readability and usability of NWIS data, the geodatabase snapshot facilitates spatial analysis and data presentation.

\section{Light Detection and Ranging Solutions (LiDAR), 1:00 pm - 2:55 pm, Moderated by Silvia Terziotti}

\section{Using LP360 to integrate Light Detection and Ranging (LiDAR) with ArcGIS, By Torin Haskell and Mike Watry}

QCoherent Software, 1880 Office Club Pointe, Colorado Springs, CO 80920-5002

719-386-6900x8 thaskell@qcoherent.com 719-386-6900x7 mwatry@qcoherent.com

Light Detection and Ranging (LiDAR) presents a challenge to integrate into a Geographic Information System (GIS) because of the large size of the associated data sets; however once the data are integrated into a GIS environment, there are significant outcomes and advantages. LP360 by QCoherent Software is an extension for Environmental Systems Research Institutes (ESRI's) ArcGIS for analyzing LiDAR data sets in Log ASCII Standard (LAS) format, a standard non-proprietary binary format for LiDAR data. The presentation will demonstrate how LiDAR point cloud data sets can be combined with vector and imagery data in the ArcGIS environment and how LP360's customizable capabilities extend the usefulness of LAS point clouds in analysis. In particular, the presentation will demonstrate the combining of LiDAR LAS data as a layer with other ArcGIS data layers. Imagery color values will be fused to the LiDAR data points and multiple visualizations will be presented along with LP360's on-the-fly dynamic modeling capabilities. LP360's useful processing tools for LiDAR quality assurance, classification, breakline creation, and surface integration, and LiDAR byproduct generation also will be presented.

\section{Terrains: Light Detection and Ranging (LiDAR) Data Support in ArcGIS 9.2, By Clayton Crawford}

ESRI, 380 New York Street, Redlands, CA 92373-8100

909-793-2853 ccrawford@esri.com

Light Detection and Ranging (LiDAR) data are voluminous is size, often involving literally billions of point observations of elevation. At ArcGIS 9.2, Environmental Systems Research Institute (ESRI) supports the ability to directly convert these data into the geodatabase and organize the data sets into terrains. Terrains are a new data model for storing and managing 3-dimensional (3D) surface information that can originate from (3D) coordinates associated with point, line, and polygon information. Terrains organize these data into varying levels of resolution using a methodology similar to image pyramids. Selected coordinate information is organized to generate surfaces dynamically at varying resolutions. This means that a user can continuously zoom in on an area with software dynamically accessing higher resolutions of terrain information. As the user increases scale, more points are used, and the user's visualization and analysis is improved.

In addition, ArcGIS 9.2 allow terrain data to be edited using standard ArcEditor tools. Terrain measurements have been engineered as point, line, and polygon feature classes in the geodatabase. This means that extremely large terrain data sets can be 
supported (for example, greater than one billion points). Unlike file implementation of surface models, they can be shared among a number of users and editing tools support a multi-user environment with standard version management technology in ArcGIS.

Introduction to Visual Learning Systems LiDAR Analyst, By Raj Mohan Rao

Visual Learning Systems, Inc., P.O. Box 5012, Missoula, MT 59806

1-866-your-vls

This presentation will provide an introduction to Light Detection and Ranging (LiDAR) Analyst, including what specifications of LiDAR data are important for feature extraction, the workflow that LiDAR Analyst enables, and LiDAR Analyst features. The presentation will demonstrate LiDAR Analyst—showing an end-to-end work flow.

\section{Merrick Advanced Remote Sensing (MARS®) Software Suite Demonstration, By Bill Emison}

Merrick \& Company, 2450 S. Peoria Street, Aurora, CO 80014

Bill.emison@merrick.com

The Merrick Advanced Remote Sensing $\left(\right.$ MARS $^{\circledR}$ ) software product demonstration will include a full functionality review of the application and a live demonstration featuring data sets from recent collection projects. The purpose of this informational session is to instruct attendees regarding technical issues involving Light Detection and Ranging (LiDAR) data management, Quality Control and Quality Assurance (QA/QC) procedures, automated data classification methodologies, multi-sensor data fusion, breakline compilation (used for hydro-enforcement) and data analysis functions.

MARS ${ }^{\circledR}$ software is developed and sold by Merrick \& Company, a full-service engineering firm headquartered in Aurora, Colorado. MARS ${ }^{\circledR}$ is a production-quality Windows application specifically designed for processing, analyzing and managing terrain data.

\section{Getting the Most out of ArcGIS Explorer, 1:00 pm - 2:55 pm, By Jeremiah Lindemann}

ESRI, One International Court, Broomfield, CO 80021-3200

ArcGIS Explorer is free, lightweight application that offers an easy way to view geographic information and offer geographic information system (GIS) content and capabilities to a broad audience. ArcGIS Explorer includes a resource center providing access to ArcGIS Online, which provides a variety of online basemaps and reference layers. ArcGIS Explorer allows users to connect to ArcGIS Online services as well as services published via ArcGIS Server, ArcIMS, and Open Geospatial Consortium (OGC) Web Mapping Services (WMS). In addition, ArcGIS Explorer supports local data such as shapefiles, imagery, file geodatabases, ArcSDE, Keyhole Markup Language (KML)/KML zipped (KMZ), and more.

In this session you will learn:

- What is ArcGIS Explorer and how you can use it;

- How to explore and navigate 2-dimensional and 3-dimensional services;

- How to access and fuse data from various sources, including Web and local sources;

- What tasks are, and how to use them and share results with others;

- How to integrate other types of content, like documents, movies, and files from the internet and local sources;

- How to centralize ArcGIS Explorer administration, setup your own Explorer home, and centralize management and deployment within your organization; and

- How to author and publish services for ArcGIS Explorer, both content and functional (geoprocessing) services. 
Coviz: A Multi-Disciplinary 3-Dimensional Subsurface Data Viewer for Collaborative Teams, 3:15 pm - 5:10 pm, By Skip Pack

Dynamic Graphics, Inc., 2603 Augusta Drive, Suite 1080, Houston, TX 77057-5639

713-952-2611 skip@houston.dgi.com

Coviz, a system for visualization of 3-dimensional (3D) subsurface multi-disciplinary data, is used for management and decision support in the oil industry. Under development for the last 4 years, Coviz is analogous to Environmental Systems Research Institutes (ESRI's) ArcView and its successors with three distinctions:

1) Rather than using a database that is at the heart of the system, Coviz is focused on using data from the systems in use at each client site. This will include well data and geophysical databases, and dynamic model outputs among other data sources. The goal is to use data from each discipline as it exists rather than requiring clients to use either a Dynamic Graphics Incorporated (DGI) provided database or reformat to our specification.

2) Coviz is capable of displaying 3D volumetric data and models of many types from geophysical data cubes to static (descriptive) geologic models, to predictive engineering models as well as non-spatial data that can be accessed through queries on spatial entities in the volume.

3) Much development has been focused on chronological viewing, allowing the user to animate different types of data that change at various points along a time scale for the purpose of relating changes in one data type to near contemporary changes in other data types. This is a surprisingly effective method of discovering previously unobserved phenomena.

The example that will be shown in this presentation concerns an offshore oil field. The analogies to a multi-agency group researching and managing an important aquifer threatened by overproduction or development can be easily drawn.

\section{Extending ArcGIS, 3:15 pm - 5:10 pm, Moderated by Curtis Price}

\section{MAPublisher and Geographic Imager, By Ted Florence and David Andrec}

Avenza Systems Inc., 124 Merton Street, Suite 400, Toronto, Ontario, Canada, M4S $2 Z 2$

416-487-5116 ted@avenza.com 416-487-6442 david@avenza.com

Abstract Not Submitted

\section{MAPublisher}

This presentation will offer the attendee an introductory session to the latest version of MAPublisher 7.6 from Avenza Systems Incorporated. MAPublisher is Avenza System's flagship cartographic production product for Adobe Illustrator CS2 \& CS3. MAPublisher is a plug-in that adds specific geographic information system (GIS) capabilities to Adobe Illustrator enabling users to incorporate and manage their GIS data within a graphics environment for the purpose of generating publishable map content and to provide access to additional graphic options typically unavailable with most GIS products on the market. This workshop will detail the processes of importing GIS data into Illustrator, how to manage and assign data scale, coordinate system settings and transformations, address the concept of "Map Views" and how they relate to layers in Illustrator. Further explanation will be given towards managing and manipulating map attribute data, making selection sets and how to make use of MAPublisher's map stylization tools based on map data attributes in conjunction with Illustrator styles and symbols. Other topics will be covered including MAPublisher's labeling functionality and some of the map finishing tools including the grid and scalebar generators. Time will be provided toward the end of this introductory session for a brief question and answer period.

\section{Geographic Imager}

This presentation will offer the attendee an introductory session to the latest version of Geographic Imager 2.0 from Avenza Systems Incorporated. Geographic Imager is Avenza Systems's spatial imagery management tool set for Adobe Photoshop CS2 \& CS3. Geographic Imager 2.0 is a Photoshop plug-in that supports importing, editing, manipulating, and exporting geospatial images such as aerial and satellite imagery. Attendees will be instructed on how to integrate their spatial imagery with Adobe Photoshop, and specifically on how to perform such operations as assigning coordinate systems to imagery, performing coordinate system transformations, and navigating and editing the coordinate system database through the Imager palette. Additional 
topics covered will include how to mosaic your spatial images for the purpose of creating composite images, cropping georeferenced imagery, and generating image tiles by configuring Geographic Imager's tiling option.

Data East Geographic Information System (GIS) Ware: Productivity Tools for GIS, By Viacheslav Ananev and Andrei Elobogoev

Data East LLC, 23, Musa Jalyl str., Novosibirsk, 630055, Russia

7-383-3320320info@dataeast.ru

This product demonstration session will familiarize U.S. Geological Survey (USGS) Geographic Information System (GIS) Workshop attendees with Data East's software products for ArcGIS users. A brief presentation about the company will be followed by the more detailed overview of the software. After live product demonstrations by the Data East staff, attendees will have the opportunity to try the software functionality on their own data sets.

The following software products will be presented:

- XTools Pro for ArcGIS - a well-known and one of the most popular and full-featured extensions to ArcGIS

- Personal Internet Map Server (IMS) — an Internet map server allowing publishing maps created in ArcGIS in Internet/Intranet

- MapZip—a new solution for easy and effective sharing maps created in ArcGIS

\section{Light Detection and Ranging (LiDAR) Solutions, 3:15 pm - 5:10 pm, Moderated by Silvia Terziotti}

An Internet-Based System for the Distribution and Interactive Generation of Digital Elevation Models From Community Light Detection and Ranging (LiDAR) Topography, By Christopher Crosby', Ramon Arrowsmith', Viswanath Nandigam², Newton Alex', Ashraf Memon', and Chaitan Baru²

${ }^{\prime}$ Arizona State University, School of Earth and Space Exploration, Tempe, AZ

Chris.crosby@asu.edu, ramon.arrowsmith@asu.edu, Newton.alex@asu.edu

${ }^{2}$ San Diego Supercomputer Center, University of California, San Diego, La Jolla, CA

858-822-3692 viswanat@sdsc.edu, 858-822-0017amemon@sdsc.edu, 858-534-5035 baru@sdsc.edu

As part of the ongoing, National Science Foundation (NSF)-funded, Geosciences Network (GEON) project (www.geongrid.org) work has begun to build a system that capitalizes on cutting-edge cyberinfrastructure technology to enable access to high-resolution community Light Detection and Ranging (LiDAR) topography data sets. The goal of the system, called the GEON LiDAR Workflow (GLW), is to provide online access to standard LiDAR-derived digital elevation models (DEMs), multi-billion point cloud data sets, and tools to allow users to produce custom DEMs.

To address the distribution of LiDAR point data as well as standard LiDAR derived DEMs, multiple pathways for users to access data from a single data portal were developed. We employ a simple Google Maps and/or Google Earth-based interface to allow users to browse and download tiled digital elevation data. For users who wish to work with the raw LiDAR point data, the GLW offers a suite of DEM generation tools to enable users to produce custom DEMs to best fit their science applications. Through these multiple pathways, we are able to service various user communities, and thereby democratize access to these challenging community data sets.

Currently (2008), the GEON LiDAR Workflow (GLW) is available as a portlet in the GEON portal (http://portal.geongrid.org/ LiDAR) and serves five data sets totaling more than 20 billion LiDAR returns and 4,000 LiDAR DEM tiles. This system is the primary distribution pathway for LiDAR data acquired by the ongoing GeoEarthScope component of the NSF-funded EarthScope project. An additional four data sets will be added to the system once acquired by GeoEarthScope. The GEON LiDAR Workflow has more than 400 users who have processed more than 48 billion LiDAR returns and downloaded more than 5,300 DEM tiles. 
Light Detection and Ranging (LiDAR) Data Processing and Applications in Open Source Geographic Resources Analysis And Support System Geographic Information System, By Helena Mitasova' and Russell S. Harmon ${ }^{2}$

${ }^{1}$ North Carolina State University, Department of Marine, Earth and Atmospheric Sciences, 1125 Jordan Hall, Campus Box 8208, Raleigh, NC 27695-8208

919-513-3127 hmitaso@unity.ncsu.edu

${ }^{2}$ USARL Army Research Office, P.O. Box 12211, Research Triangle Park, NC 27709

Russell.harmon@us.army.mil

Geographic Resources Analysis and Support System (GRASS) is a general purpose, open source geographic information system (GIS) and is one of the founding projects of Open Source Geospatial Foundation. It includes more than 350 modules supporting geospatial data management and analysis, image processing, graphics and map production, spatial modeling, and visualization. The general purpose modules have been successfully used for applications involving massive Light Detection and Ranging (LiDAR) data sets and particularly for computing high resolution Digital Elevation Models (DEMs) and comprehensive topographic analysis. Several recently contributed modules were developed specifically for processing point cloud data and extracting information from man-made and natural terrain features. The LiDAR applications of GRASS GIS will be illustrated by the assessment of spatial and temporal trends in coastal terrain evolution and the identification of vulnerable locations using a time series of LiDAR data (more than 10 surveys spanning a decade). The second application is intended to improve our understanding of the impacts of terrain changes on landscape processes and facilitate face-to-face collaboration. Real-world LiDAR based DEMs were combined with flexible laboratory 3-dimensional models, an indoor laser scanner, and projectors to create a tangible geospatial modeling system. The system allows landscape alternatives to be generated that serve as inputs to simulations of landscape response to disturbances and modifications. The simulation results are projected over the laboratory model to assist in studying the conditions that can elucidate poorly understood aspects of landscape dynamics.

Follow Up for System Design and Administration and Geoprocessing in ArcGIS, 3:15 pm - 4:30 pm, ESRI

\section{Presentation Titles and Abstracts, Friday, May 16, 2008}

\section{Friday Hands-on Sessions}

\section{CrossView for ArcGIS, 8:00 am - 9:55 am, By Steve Miller}

A-Prime Software, 1600 Broadway, Floor 24, Denver, CO 80202

877-627-3696 steve.miller@aprimesoftware.com

Since the early days of Geographic Information Systems (GIS), cross sectioning has had no discernible workflow. Using a map and tabular files containing surface and subsurface information, users had to query a series of points along a line- hoping that the points exactly corresponded to the log file - and then export it all to Computer-aided Design (CAD) to develop a single diagram.

Today, cross sections can be developed with an intuitive, wizard-based plug-in. With a product known as CrossView, users can now create cross sections within the ArcGIS environment itself, importing log file information and geodata along the way. CrossView for ArcGIS works with various levels of the suite including ArcView, ArcEditor, and ArcInfo. Additionally, CrossView can be even more powerful when leveraging ArcGIS extensions such as Spatial Analyst or 3D Analyst. Acceptable data inputs include GRIDs, Triangulated Irregular Networks (TINs,) Digital Elevation Models (DEMs) and other raster formats that would typically contain elevation data. In addition to surfaces, CrossView accepts point data sets such as Geodatabase feature classes [(personal, file and Spatial Database Engine (SDE)], Shapefiles, ArcInfo coverages and X, Y event layers. 
Unlike applications such as CAD, CrossView's output diagram and features retain the all the related attributes from the geodatabase. This link to the source features allows a rich level of control for symbolization, labeling and annotation. More importantly, this link ensures that the diagram is free of spatial errors and is robust in its demonstration.

\section{Spatial Analysis Tools of ArcGIS, 8:00 am - 9:55 am, By Steve Kopp}

ESRI, 380 New York Street, Redlands, CA 92373-8100

909-793-2853 skopp@esri.com

Spatial data anaylsis, finding answers to problems, is the heart of the geographic information system (GIS) industry. This session will present an overview of the analysis capabilities available in ArcGIS 9.2 (raster, vector, 3-dimensional, and statistics) and where to find them. It will highlight new capabilities of recent releases, with particular emphasis on the Spatial Analyst extension, http://www.esri.com/software/arcgis/extensions/spatialanalyst/index.html.

\section{ArcGIS Mobile GIS Solutions, 8:00 am - 9:55 am, By Jason Channin}

ESRI-Denver, One International Court, Broomfield, CO 80021

303-449-7779 ichanin@esri.com

Mobile Geographic Information System (GIS) enables field personnel to capture, store, update, manipulate, analyze, and display geographic information. This enables organizations to speed up analysis and decision making by using up-to-date, accurate spatial data. This workshop will focus on the aspects of building mobile GIS-centric data and workflows for deploying ArcGIS ArcPad 7.1 and ArcGIS Mobile technology.

\section{Introduction to Geodatabases, 8:00 am - 11:55 am, By Zachary D. Wilson', David E. Ladd², and Tosca Hoffmann ${ }^{3}$}

${ }^{1}$ U.S. Geological Survey, Texas Water Science Center, 8027 Exchange Drive, Austin, TX 78754

512-927-3511zdwilson@usgs.gov

${ }^{2}$ U.S. Geological Survey, Tennessee Water Science Center, 640 Grassmere Park, Suite 100, Nashville, TN 37211

615-837-4773 deladd@usgs.gov

${ }^{3}$ ESRI-Denver, One International Court, Broomfield, CO 80021

303-449-7779 thoffmann@esri.com

The geodatabase for ArcGIS offers broad functionality important to scientific research and data management in the U.S. Geological Survey (USGS). Users of coverage and shapefile formats will find familiar elements such as feature classes and topologies in geodatabases; however, enhanced functionality through other geodatabase-specific elements such as relationship classes, subtypes, domains, and geometric networks also is provided. This workshop will introduce geodatabase concepts, describe the geodatabase elements, demonstrate geodatabase use in USGS projects, and provide an opportunity to explore some practical applications of geodatabases. Workshop participants can expect to achieve a basic understanding sufficient to begin incorporation of geodatabases in their projects.

\section{Cartography with ArcGIS, 1:00 pm - 5:10 pm, By Charlie Frye}

ESRI, 380 New York Street, Redlands, CA 92373-8100

909-793-2853 cfrye@esri.com

The geodatabase, cartographic representations, and Maplex are three of the most important features in ArcGIS for cartographers. The geodatabase has data-management functions that automate key tasks for cartographers, and is the data format that supports cartographic representations. Cartographic representations are a better way to symbolize geographic information and are considered an improvement over earlier methods. Cartographic representations are optimized for drawing speed, often drawing faster than other ArcGIS symbols; stored and travels with the data; and editable at the level of individual features, making it possible to create maps that are graphically correct while not compromising the geographic information system (GIS) geometry. Maplex is used to label maps and offers many improvements over the Environmental Systems Research Institute (ESRI) standard labeling 
engine because just by turning Maplex on more labels will be placed with improved visual association between the labels and their geographic feature.

Workshop participants will gain a basic understanding of how to set up a geodatabase, add shapefile (or coverage) data to the geodatabase, and best practices for using that data to create maps that take advantage of cartographic representations and Maplex.

\section{Surface Interpolation with ArcGIS, 10:10 am - 11:55 am, By Steve Kopp}

ESRI, 380 New York Street, Redlands, CA 92373-8100

909-793-2853 skopp@esri.com

One of the most important kinds of spatial analysis is exploration of trends and patterns in geospatial data. A common application is the development of a continuous surface from samples to use in further visualization or analysis. This session will provide understanding of deterministic and geostatistical interpolation methods, what interpolation tools are available in ArcGIS, and guidelines on when and how to use them.

\section{Introduction to the Google Maps Application Programming Interface: Leveraging the Geoweb for Publishing Scientific Information, 10:10 am - 3:00 pm, By Gregory L. Gunther}

U.S. Geological Survey, Denver Federal Center, MS 939, Box 25046, Denver, CO 80225

303-236-5884 ggunther@usgs.gov

Options for publishing scientific information within the U.S. Geological Survey (USGS) have evolved dramatically in recent years. Presentation of scientific data, analyses, and interpretations in the form of traditional manuscripts, data tables, or figures will dominate the publishing landscape for the foreseeable future. However, there has been more frequent use of the World Wide Web (WWW) by USGS scientists to present products in new and exciting ways, commonly within a geographically-centered context using online mapping systems. Although effective and functional, these first-generation mapping systems generally have been associated with high overhead and costly technological requirements. Fortunately, the WWW is constantly evolving and publishing information based on geography is becoming increasingly easy. Within this new geographically-oriented web framework, commonly referred to as the Geoweb, several tools are now available for information sharing, collaboration, and data delivery. Google Maps, one of the more prolific of these tools, not only allows users to explore, discover, and consume information in a geographic context, but also provides an easy-to-use Application Programming Interface (API) for sharing and delivery of information. In this workshop, a number of interesting and useful capabilities provided through the Google Maps API are explored, and the manner in which these tools can be used in the larger context of leveraging the Geoweb is addressed. Topics covered include a "crash" course in relevant web technologies including Asynchronous JavaScript (AJAX) and Extensible Markup Language (XML)) and Document Object Model (DOM); an overview of the API reference including key functions and capabilities; the managing of markers using the Marker Manager; and a survey of selected "mashups" leveraging a variety of Geoweb oriented resources and technologies including Geography Markup Language (GML), Web Map Service (WMS), GeoRSS (Geographically Encoded Objects for Really Simple Syndication feeds) and others. A basic proficiency in web development technologies and techniques, particularly Javascript, is recommended.

\section{Introduction to Production Line Tool Set Foundation, 1:05 pm - 3:00 pm, By Sandi Belson}

ESRI-Washington DC, 8615 Westwood Center Drive, Vienna, VA 22182-2218

703-506-9515x8137 sbelson@esri.com

In a production environment, an efficient system is key to getting the job done well and on time, while still maintaining a high level of quality. Production Line Tool Set (PLTS) originated out of a need for a streamlined production process and has expanded to become a collection of software applications designed to extend ArcGIS Desktop for database and cartographic production. PLTS provides users with a single-click editing environment, menu-driven attribution tools, on-the-fly attribute validation, and a suite of tools designed for performing data quality control and cartographic map production. In this workshop, students will learn the basics of using the PLTS tools for data editing, quality control, and map series creation. They will learn how to use the PLTS editing and attribution tools for data creation and maintenance. They also will learn how to use the PLTS Geographic Information System (GIS) Data ReViewer to perform both automated and visual data reviews. Finally, students will learn how to use the PLTS Export Map (MPSAtlas) map series wizards to create and maintain a map book or series. 


\section{Working with ModelBuilder and Geoprocessing Tools, 1:05 pm - 3:00 pm, By Corey Tucker and Jason Pardy}

ESRI, 380 New York Street, Redlands, CA 92373-8100

909-793-2853 ctucker@esri.com ipardy@esri.com

Geographic Information System (GIS) professionals require a system that allows the automation of their workflows within a GIS to accomplish large tasks and reproduce their work. The combination of several hundred tools and a geoprocessing framework with ArcGIS fulfills this requirement. This session will explore the tools and how to combine them to create workflows using ModelBuilder. Tips also will be presented on working with intermediate data, using variables, documenting models, and guidelines for building models ready to share with others.

\section{Friday Lecture Sessions}

\section{Geobrowser Applications and Web Visualization, 8:00 am - 9:55 am, Moderated by Luke Blair}

\section{Serving Bay Area Geologic Hazard Information in Google Earth Keyhole Markup Language; a Network-Link Approach, By James Luke Blair}

U.S. Geological Survey, Earthquake Hazards, MS 977, 345 Middlefield Rd., Menlo Park, CA 94025

650-329-4707_blair@usgs.gov

A method to convert and provide San Francisco Bay Area geologic map information in Google Earth Keyhole Markup Language (KML) format will be presented. Google Earth software is an interactive, virtual globe that can be effective for communicating important geologic information to public and scientific audiences. The U.S. Geological Survey (USGS), California Geological Survey (CGS), and other groups have collected a wealth of geologic information in the Bay Area, but little has been done to organize and provide these data in a single location and viewing format. Static maps and associated geographic information system (GIS) files are the common output of such mapping efforts, but these are not easily obtained or viewed by the general public. Alternatively, geologic maps served in KML format can be downloaded from servers and viewed as overlays on the high-resolution static aerial imagery supplied by Google. Further, the software provides 3-dimensional terrain and the ability to search for a location by address or coordinates. Complex geologic maps result in large KML file sizes, which in turn, slow down network and Central Processing Unit (CPU) performance on the user's end. To provide for more efficiency, the method we present utilizes Environmental Systems Research Institutes (ESRI's) ArcMap Model Builder software to automate the process of breaking a large GIS data set into multiple KML tiles. An individual tile has the extent of a 7.5' USGS quadrangle and a file size small enough to be rapidly retrieved from a server and processed by Google Earth for viewing. A single KML file manages the visibility of all the tiles, retrieving only the necessary tile(s) to fill the field of view. This method is intended for use to present important geologic information such as bedrock geology and geologic hazard data, including liquefaction susceptibility, faults and fault zones, landslides, flood zones, and various shaking scenarios in the Bay Area.

Integration of Open-Source Tools for Modeling Applications-Part A: GeoTools and National Aeronautics and Space Administration World Wind, By Roland J. Viger', Ian Overgard², Steven L. Markstrom', and Olaf David²

${ }^{1}$ U.S. Geological Survey, Denver Federal Center, MS 412, Box 25046, Denver, CO 80225-0046

303-236-5030 rviger@usgs.gov, 303-236-3330 markstro@usgs.gov

${ }^{2}$ U.S. Agricultural Research Service, Bldg. D, 2150 Center Avenue, Fort Collins, CO 80526

970-492-7316 ian.overgard@qmail.com970-492-7316 olaf.david@ars.usda.gov

This presentation provides an overview of ongoing work with open-source software to allow basic geospatial data handling and visualization functionality to be embedded into pre-existing and new software. The intended result is to develop a simple, high-level programming interface that combines the capabilities of two open source software packages: GeoTools and National Aeronautics and Space Administration's (NASA's) World Wind. GeoTools, a Java code library that implements many Open Geospatial Consortium specifications, is used to generate and feed georeferenced images to the Java version of NASA World Wind. The World Wind geobrowser is an open-source, three-dimensional, globe-based visualization application. While non opensource geovisualization software is readily available, these technologies have several limitations. Some limit development to 
web browser applications or computers running only a variant of the Windows operating system. Others have restrictive licensing requirements or business models that are subject to change. Perhaps most importantly, some have relatively limited (albeit popular) programming interfaces that prohibit embedding the technology into other software or modifying the base cartographic layers used in the visualization. The use of GeoTools and World Wind avoids all of these problems.

\title{
Integration of Open-Source Tools for Modeling Applications-Part B: Object User Interface Example, By Steven L. Markstrom', Roland J. Viger', Olaf David', and lan Overgard
}

\author{
${ }^{1}$ U.S. Geological Survey, Denver Federal Center, MS 412, Box 25046, Denver, CO 80225-0046 \\ 303-236-5030rviger@usgs.gol, 303-236-3330 markstro@usgs.gol \\ ${ }^{2}$ U.S. Agricultural Research Service, Bldg. D, 2150 Center Avenue, Fort Collins, CO 80526 \\ 970-492-7316 ian.overgard@gmail.com 970-492-7316olaf.david@ars.usda.gov
}

The Object User Interface is a map based interface for development and deployment of hydrologic modeling systems. Developed by the Modeling of Watershed Systems project, it provides a general framework for coupling disparate environmental resource models and managing associated temporal and spatial data. The Object User Interface is configured with a control file that is written in the eXtensible Markup Language (XML). This allows modelers a high degree of flexibility in hardware and user interface configuration by providing a generic temporal and spatial interface for modeling projects; a mechanism for modelers to deploy a modeling project to decision makers and other users; and an extensible platform that may be adapted to many different needs. The Object User Interface components can run either as a standalone applications or as part of an integrated system that allows users to assemble components as needed for specific modeling projects. As an experiment to determine the effectiveness of Geotools and National Aeronautics and Space Administration (NASA) World Wind, a prototype version of the Object User Interface has been retrofitted with these open source Geographic Information System (GIS) tools. This presentation provides an overview of that work.

\section{A Water Census of the United States, 8:00 am - 9:55 am, Moderated by Tim McKinney}

\section{A Desktop Application to Assess the Sustainable Yields and Surface-Water Resources in Massachusetts, By Peter A. Steeves and Stacey A. Archfield}

U.S. Geological Survey, 10 Bearfoot Rd. Northborough, MA 01532

508-490-5054 psteeves@usgs.gov. 508-490-5072 sarch@usgs.gov

Federal, state, and local water supply, regulatory, and planning agencies require easy-to-use, technically-defensible, decisionsupport applications that can be used to evaluate potential impacts of proposed water withdrawals, determine baseline streamflow conditions needed for sustainability of aquatic habitat, and estimate inflows to drinking-water-supply reservoirs for safe yield analyses at ungaged locations. Building on the StreamStats toolbar in combination with a customized ArcMap toolbar, a desktop application termed the Massachusetts Sustainable Yields Estimator (MA SYE), was developed to address these needs. The decision-support application estimates daily streamflow under natural flow conditions at any user-selected location-gaged or ungaged - on a perennial stream in Massachusetts. Estimated natural flows can be compared to a user-defined instream-flow target to determine sustainable yield - the amount of water available for withdrawal without adversely impacting the ecology. Users also can obtain information on any existing water withdrawals or discharges that may be affecting the streamflow at the site.

In Massachusetts and around the country the application of StreamStats is expanding beyond the core functionality of allowing users to obtain streamflow statistics and drainage-basin characteristics, to provide a multi-purpose, decision-support foundation for a variety of applications. Because StreamStats is built on a standardized toolset (ArcHydro) and uses a multi-faceted database, it can provide other developers an ideal platform to build customized surface-water applications as a web service and on the desktop. In particular, StreamStats web-based functionality provided the foundation needed to develop the point and click application toolset for the MA SYE.

Originally published as:

Steeves, P.A., Archfield, S.A., Proceedings of the 2008 AWRA Spring Specialty Conference GIS and Water Resources V, March 17-19, 2008, San Mateo, California. 


\section{Status Update on the U.S. Geological Survey StreamStats Web Application, By Alan Rea}

U.S. Geological Survey, Idaho Water Science Center, 230 Collins Road, Boise, ID 83702

208-387-1323 ahrea@usgs.gov

The ability to estimate streamflow statistics is important for water management, environmental protection, hazard mitigation, and other hydrologic applications. StreamStats is a partnership between the U.S. Geological Survey (USGS) and the Environmental Systems Research Institute (ESRI) to develop an online application that links USGS digital map data, streamflow statistics, and regression equations with ESRI's ArcHydro Tools. The application delineates the drainage basin above a user-selected point on a stream, calculates the basin characteristics (such as area, slope, elevation, and precipitation), and applies USGS regression equations to those characteristics to estimate a variety of low, mean, and peak streamflow statistics.

StreamStats implementation involves extensive development of geospatial data sets, the application of existing regression equations, and, frequently, the development of new regression equations. Implementation is proceeding on a state-by-state basis. Development efforts are underway in more than one-half of all states. This session presents a description of StreamStats functionality and an update of the current implementation status.

\section{A Geographic Information System Approach to Delineate Areas Prone to Ground-water Flooding on Long Island, New York, By Jack Monti, Jr.}

U.S. Geological Survey, New York Water Science Center, 2045 Bldg. 4, Route 112, Coram, NY 11727

631-736-0783 imonti@usgs.gov

Temporary or continuous rise of ground water can flood subsurface structures such as subway tunnels and basements, and can cause septic-system failures in areas of shallow water-table on Long Island, New York. In some cases, recovery of the water table in Kings and Queens Counties from severe drawdowns has caused flooding, at depths even greater than 10 feet, in subway tunnels and deep basements in banks, schools, and hospitals. The water table beneath Long Island is within the upper glacial aquifer except in some parts of Nassau and Suffolk Counties, where it is within the underlying Magothy aquifer. The upper surface of the upper glacial aquifer forms the present-day land surface throughout most of Long Island. Shallow and possibly flood-prone water-table conditions - where the depth to water is less than 10 feet — are present throughout Long Island, typically in low-lying areas along the coast and near freshwater streams, lakes, and wetlands, where the water table is perennially above land surface; water table in other lowland areas rises above land surface only intermittently.

A Geographic information system (GIS) was developed by the U.S. Geological Survey to delineate areas on Long Island where the depth to water is less than 10 feet and thus possibly prone to basement flooding and septic-system failures. Depth to water in this study was interpreted from 342 measurements of the water-table altitude in 2006 throughout Long Island; the values were then converted to a GIS raster model for calculation of depth below land surface in relation to National Elevation Data (NED). Results provided an island-wide depth-to-water GIS raster model, which was compared with the 342 measurements for verification. The verification showed a close fit to the depth-to-water raster model and provides a systematic tool to estimate the depth to water for structural and environmental concerns, such as tunnel and basement flooding, septic failure, and susceptibility to aquifer contamination.

\section{Custom Tools, Scripting, and Tweaks, 8:00 am - 9:55 am, Moderated by Bill Oatfield}

\section{An Introduction to Interpolation Methods Commonly Used in Geographic Information Systems, By Nicholas Gianoutsos and Philip H. Nelson}

U.S. Geological Survey, Denver Federal Center, Building 25, MS 939, Box 25046, Denver, CO 80225-0046

303-236-1660 ngianoutsos@usgs.gor. 303-236-1322 pnelson@usgs.gov

The process of interpolation used in computing geologic models often is difficult to comprehend because of its foundation in geostatistics, the complexity of algorithms used for interpolation, and the abundant number of potential input parameters. Often the intimidation factor of the endless choices in producing a geologic data model, and in constructing a contour map that adequately reflects the complexities of the data set, is overwhelming to the average user, resulting in avoidance of these powerful tools. This presentation provides a brief introduction to the process of modeling techniques relevant to geological disciplines; explores the popular interpolation algorithms used for gridding data such as kriging, inverse distance weighting, and spline 
curve; and discusses, in addition to the use of ArcGIS Geostatistical Analyst, contouring algorithms in other popular software packages such as Landmark Geographix and Dynamic Graphics, Inc. (DGI) EarthVision. Attendees will leave the presentation with a better understanding of the interpolation process, having gained knowledge of how and when to apply certain geostatistical techniques and their implementation in common geographic information system (GIS) systems.

\title{
ArcGIS and the Road Ahead, 8:00 am - 9:55 am, By David Vaillancourt
}

ESRI, One International Court, Broomfield, CO 80021-3200

303-449-7779 dvaillancourt@esri.com

ArcGIS 9.3 builds on the 9.2 release to offer key enhancements to the ArcGIS Desktop and ArcGIS Server platforms. This session will cover the key 9.3 product enhancements and explore how these changes will improve performance, user workflows, and interoperability. A few of these enhancements include improvements in labeling, map legends, iterative modeling, Keyhole Markup Language (KML) support, and time series animation in ArcGIS. Some enhancements to ArcGIS Server include new Application Progamming Interfaces (APIs), new PostgreSQL Support for the geodatabase, and on-demand caching and improved caching tools for ArcGIS Server, allowing faster mapping services.

\section{Energy and Minerals for America's Future, 10:10 am - 11:55 am, Moderated by Laura Biewick}

\author{
Mapping Oil Spills with Imaging Spectroscopy in Areas Impacted by Hurricane Katrina, By Gregg Swayze and K. Eric \\ Livo
}

U.S. Geological Survey, Denver Federal Center, Bldg. 20, MS 964, Box 25046, Denver, CO 80225-0046

303-236-0925 gswayze@usgs.gor, 303-236-1388 elivo@usgs.gov

New Orleans endured flooding on a massive scale subsequent to Hurricane Katrina in August of 2005. Contaminant plumes were noticeable in satellite images of the city and surrounding areas. Effluent plumes such as these pose a potential health hazard to humans and wildlife in the aftermath of hurricanes and potentially from other catastrophic events (e.g., earthquakes, shipping accidents, chemical spills, and terrorist attacks). Whereas the extent of the effluent plumes were gauged with synthetic aperture radar and broad-band visible-infrared images (e.g., Radarsat and Landsat ETM+), the composition of the plumes could not be determined because these instruments lack the spectral resolution necessary to do chemical identification. Imaging spectroscopy can help solve this problem. More than 60 flight lines of National Aeronautics and Space Administration (NASA) Airborne Visible/Infrared Imaging Spectrometer (AVIRIS) data were collected over New Orleans, the Mississippi Delta, and the Gulf Coast from 1 to 2 weeks after Katrina's landfall. These data provide a unique opportunity to determine the identity of these flood-related plumes.

Many organic chemicals, including crude oil, have unique spectral signatures in the ultraviolet to near-infrared range (0.2-2.5 microns) that can be used as fingerprints for their identification. To facilitate spectral mapping, laboratory measurements were made of crude oil films on water, gel-like crude oil-water emulsions, and crude oil mixed with wet sand. These measurements were used as reference spectra to look for oil spills in the AVIRIS images using the U.S. Geological Survey (USGS) Tetracorder spectral shape-matching algorithm. Thin oil films were detected on the Mississippi River, thicker oil-water emulsion plumes in Gulf waters south of the Chanledeur Islands, and an oil spill in a residential neighborhood surrounding the Murphy Refinery south of New Orleans.

The study indicates that oil does not have diagnostic narrow spectral absorptions at visible wavelengths, but does brighten water's reflectance, allowing its detection based on a multicolor sheen or brighter sky reflectance. Even though oil is dark at visible wavelengths, it has distinct C-H stretch overtone and combination absorptions in the near-infrared that can be remotely mapped when it forms an emulsion with seawater or spreads on wet soil. Imaging spectroscopy is a promising tool for identifying oil spills, but more research is needed to better define the types of situations where it can be used in an effective and timely way. 


\section{Geographic Information System Methods for Ranking Mineralization Potential, By Gregory K. Lee}

U.S. Geological Survey, Denver Federal Center, MS 973, Denver, CO 80225-0046

303-236-2491 glee@usgs.gov

Previously, the U.S. Geological Survey (USGS) mineral resource assessments typically resulted in maps that portrayed ranked potential for mineralization. The rankings were expressed in qualitative terms such as "low," "moderate," "high," and were based on expert knowledge and consideration of various geoscientific indicators such as geochemistry, geology, and geophysics, together with known mineral occurrence information. Although those maps provided valuable information for many users, landuse planners found shortcomings in USGS qualitative assessments for including mineral resource development when comparing valuations of different use scenarios.

For USGS mineral resource studies to be relevant and useful for the needs of land-use planning, it therefore became necessary to provide interpretations of mineral potential in quantitative terms. To facilitate direct cost-benefit comparisons among various land-use alternatives, including potential mineral resource development, methods were developed to provide USGS assessments in quantitative terms of mineral endowment.

Thus, in more recent times, results of USGS mineral resource assessments have been expressed in terms such as the expected number of undiscovered tons of copper in an area that is "permissive" for a certain type(s) of ore deposit. Permissive tracts for a type of ore deposit are delineated as polygons within which there is judged to be some possibility of the existence of undiscovered deposit(s) of that type. Permissive area polygons, however, are homogenous with respect to the likely spatial distribution of mineral potential within them, and do not, therefore, provide information that indicates where mineralization is more or less likely to occur within the tract(s). In this regard, the previous, qualitative assessments provided greater detail. The advantages of historical maps of qualitatively ranked mineral resource potential can be combined with more modern quantitative assessments by using geographic information system (GIS) methods to model ranked potential within the permissive areas. If there are known examples of the assessed mineral deposit type in the study area, then data-driven approaches, based on those deposits, can be used to assign weights to categories and classes of various input layers of geoscientific information, and to combine those weights to map ranked favorability within the permissive tracts. Alternatively, expert knowledge can be used to assign weights to different data layers, provide input such as fuzzy memberships for model calculations, or modify weights calculated from datadriven methods. These GIS approaches for mapping ranked potential can effectively be used to provide spatial distribution of the likelihood of mineralization within the otherwise homogeneous permissive tracts.

\section{U.S. Geological Survey Oil and Gas Assessment Explorer: an Interactive Web Application to Access U.S. Geological Survey Assessment Research, By Chris Skinner, Greg Gunther, Dave Ferderer, and Laura Biewick}

U.S. Geological Survey, Denver Federal Center, MS 939, Box 25046, Denver, CO 80225-0046

303-236-1651 cskinner@usgs.go1.303-236-5884 ggunther@usgs.go1, 303-236-3611 dferdere@usgs.gor. 303-236-7773

lbiewick@usgs.gor

The U.S. Geological Survey Energy Resources Program (USGS-ERP) conducts objective geology-based assessments of the quantity and distribution of oil and gas resources throughout the world. This information is provided to the public through a wide variety of publications, reports, maps, geospatial data, and map services.

The Energy Resources Program is developing a new service-oriented web application, 'USGS Oil and Gas Assessment Explorer', which is a streamlined method to access these published data. This application provides users with a global view of the latest oil and gas assessment estimates in both map and tabular form, and a common framework for discovering more detailed information, including current and historical publications, data and services. A primary objective is to augment, and ultimately replace, current assessment content on the USGS-ERP's web site.

The initial phase of the new application, which provides an overview map of assessment research, will be demonstrated. The approach to data modeling, Environmental Systems Research Institute (ESRI) ArcGIS Server technology, and relevant public standards will be discussed. 
Integrated State Geologic Map Database of the United States, By Connie L. Dicken', Suzanne W. Nicholson', Douglas B. Stoeser ${ }^{2}$, Frederic H. Wilson ${ }^{3}$, and Steve D. Ludington ${ }^{4}$

${ }^{1}$ U.S. Geological Survey, National Center, 12201 Sunrise Valley Drive, MS 954, Reston, VA 20192

703-648-6482 cdicken@usgs.got,703-648-6344 swnich@usgs.gov

${ }^{2}$ U.S. Geological Survey, Denver Federal Center, MS 973, Box 25046, Denver, CO 80225-0046

303-236-99817dstoeser@usgs.gov

${ }^{3}$ U.S. Geological Survey, 4200 University Drive, Anchorage, AK 99508

907-786-7448fwilson@usgs.gov

${ }^{4}$ U.S. Geological Survey, MS 901, 345 Middlefield Road, Menlo Park, CA 94025

650-329-5371 slud@usgs.gov

During the last 10 years the U.S. Geological Survey (USGS) Mineral Resources Program has completed a database of national digital geologic maps for use in various mineral resource studies and environmental assessments in the range of 1:250,000- to 1:1,000,000-scale. The compilation used either existing digital state geologic maps, or new digital maps were prepared by the USGS or in cooperation with respective state geologic surveys. A standardized database structure was developed for consistent fields, attributes, and data dictionaries. Each state map was imported and fitted to a standardized state boundary file created from USGS 100,000-scale Digital Line Graphs file, thus creating a map without slivers or overlaps at adjacent boundaries. Fitting was performed on the lower 48 states by extending and/or clipping arcs to the state boundary file with no "rubber-sheeting" applied. Inconsistencies between mapped geologic units in neighboring states were not resolved.

In addition to the spatial data, stratigraphic unit descriptions, age, lithology, and reference information presented on the original source map was transferred to additional tables. Several fields were added to the tables to maintain a consistent set of terms for age and rock type to allow queries from multiple databases. For example, a single query can produce a regional or national derivative map using the age or lithology field. Each state has a minimum standard file set consisting of two parts; the first part is the spatial geology database, including metadata, and the second part, which consists of four supplementary attribute tables. Other features from the source map also may be included as additional spatial databases, such as faults, dikes, or volcanic features when present.

The conterminous state spatial files are published on-line as USGS Open-File Reports and are available as coverages (.e00) and shapefiles (.shp). The supplemental related tables are provided in Filemaker Pro format (.fp5), comma-separated value (.csv), and dBase format (.dbf). New maps are being compiled for Alaska and Hawaii with inconsistencies between quadrangles being resolved. Alaska maps are being published as a series of 1:500,000-, 1:350,000-, and 1:250,000-scale regional compilations as USGS Open-File Reports.

\section{A Water Census of the United States, 10:10 am - 11:55 am, Moderated by Tim McKinney}

\section{A Semi-Automated Hydrologic Unit Naming Method, By Sally L. Holl}

U.S. Geological Survey, Texas Water Science Center, 8027 Exchange Drive, Austin, TX 78754 512-921-9060 slholl@usgs.gov

A national Watershed Boundary Data set (WBD) is under development by the Natural Resources Conservation Service and consists of hydrologic units delineated from U.S. Geological Survey (USGS) 1:24,000 scale topographic maps. Hydrologic units are similar to watersheds and each is identified by a unique numeric Hydrologic Unit Code (HUC). HUCs, which have from 2 to 12 digits, are an efficient way to uniquely identify each hydrologic unit and provide specific information about where each unit lies within a larger, hierarchical drainage system; however, numeric identifiers may be cryptic to the layperson or novice end user. To facilitate the use of the WBD by a broader audience and add versatility to end user query options, common names are assigned to selected 10- and 12-digit HUCs in eastern and coastal Texas. Naming conventions are dictated by guidelines set forth in the "Federal Standard for Delineation of Hydrologic Unit Boundaries" (ftp://ftp.fc.sc.egov.usda.gov/NCGC/products/watershed/ hu-standards.pdf).

Using these guidelines, a semi-automated method is developed to assign unique names to each HUC. Two USGS data sets are used to assign names to each HUC: The USGS National Hydrography Data set Plus (NHD+) flowlines attributed with Geographic Names Information System (GNIS) names and selected HUC boundaries delineated by the Texas Water Science Center. 
First, NHD+ flowlines are pre-processed in ArcMap. Next, decision code is developed in Microsoft Access to select and assign a name to each HUC based on flowline length, presence of a name, and uniqueness of the name. Lastly, named HUCs are checked manually for accuracy against digital topographic quadrangles in ArcMap.

This method demonstrates a diversified use of the NHD+ as well as the tandem use of ArcMap and custom programming in Microsoft Access to manipulate and assign attributes to features in a geodatabase. The final product is a geodatabase consisting of 1,474 10- and 12-digit HUCs, each attributed with a unique common name.

\section{Estimating Perennial Streams in Idaho Using a Regression Model Of 7-Day, 2-Year Low Flows, By Alan Rea}

U.S. Geological Survey, Idaho Water Science Center, 230 Collins Road, Boise, ID 83702

208-387-1323 ahrea@usgs.gov

The perennial or intermittent status of a stream has bearing on many regulatory requirements. Idaho Administrative Code defines an intermittent stream as one having a 7-day, 2-year low flow (7Q2) less than 0.1 cubic feet per second ( $\left.\mathrm{ft}^{3} / \mathrm{s}\right)$. The USGS has developed regional regression equations for Idaho streams for several low-flow statistics, including 7Q2. Using these regression equations in conjunction with a geographic information system (GIS) technique known as weighted flow accumulation allows for an automated and continuous estimation of 7Q2 streamflow at all points along a stream. This estimation, in turn, can be used to determine whether or not a stream is intermittent or perennial based on the $0.1 \mathrm{ft}^{3} / \mathrm{s}$ criterion. One problem with this approach is that, in most cases, it entails using the regression equations on small headwater streams far outside the range of drainage-area values used in their development. Such extrapolation cannot be avoided, however, because of a lack of streamgage data measuring such small streams. This extrapolation can result in unreasonable flow estimates, as well as unreasonable spatial patterns in the modeled stream networks when extrapolating to estimate flows in streams having very small drainage areas. The spatial patterns resulting from continuous estimation of $7 \mathrm{Q} 2$ flows were used to evaluate regression models for 7Q2, and alternative models were chosen for five of eight low-flow regression regions. The selected regression equations were applied to create continuous grids of 7Q2 estimates for the eight regression regions of Idaho. By applying the $0.1 \mathrm{ft}^{3} / \mathrm{s}$ criterion and transferring attributes to the National Hydrography Data set linework, the perennial streams have been estimated in each low-flow region. It is important to recognize, however, that considerable uncertainty exists in the model of perennial streams presented. The geospatial data set of modeled perennial streams is considered to be a first-cut estimate, and should not be construed to override site-specific flow data.

\section{Custom Tools, Scripting, and Tweaks, 10:10 am - 11:55 am, Moderated by Catherine Costello}

\section{Customizing the ArcGIS Server .NET Mapping Application, By David S. McCulloch}

U.S. Geological Survey, 505 Science Drive, Madison, WI 53711

608-238-9333 dmccullo@usgs.gov

The ArcGIS Server Manager can generate a .NET based mapping application that provides a framework for customization. This presentation demonstrates how to customize the ArcGIS Server.NET mapping application templates by describing two specific customizations. The first customization modifies the mapping application to accept Uniform Resource Locator (URL) parameters to initialize the map to a specific geographic area. The second customization demonstrates how to add Hyper Text Markup Language (HTML) links to the map identify tool using the SimpleTaskResults object.

\section{Roadless Space-The Interior Southwest, By Catherine Costello', Roger W. Compton', and Raymond D. Watts \\ ${ }^{1}$ U.S. Geological Survey, Rocky Mountain Geographic Science Center, DFC, MS 516, Box 25046, Denver, CO 80225-0046 303-202-4278 ccostello@usgs.gov 303-202-4294 rwcompton@usgs.gov \\ ${ }^{2}$ U.S. Geological Survey, Fort Collins Science Center, 2150 Centre Ave., Bldg. C, Fort Collins, CO 80526 970-226-9378 rwatts@usgs.gov}

How far away can a person get from a road in the conterminous United States without encountering another road? Many people are surprised by the answer. The total area of the lower 48 states is just over 2.87 million square miles, yet the largest roadless circle [based on the national Geographic Data Technology, Inc. (GDT) roads data set] is only 43 miles in diameter. 
The U.S. Geological Survey (USGS) has developed metrics to measure and map roadless space in the United States. Other metrics, such as road density, do not measure how much space is between roads or how much is lost as new roads are added. The roadless volume (RV) metric is based on measurements of distance to the nearest road (distance to road-DTR). DTR measurements are made on a 30-meter grid aligned with the cells of the National Land Cover Database (NLCD). RV is calculated by selecting an area, adding the DTR values for the cells within the area, and multiplying by the area of one cell (900 square miles).

An atlas currently in production focuses on the roadless space in the interior southwestern states. The report explores some of the many ways to visualize and use roadless space as a metric, the causes of and barriers to roads in the West, and the limitations of the metrics based on the quality of the road network data.

\section{Blue Marble Geographics Demonstration: the Geographic Calculator and the Geographic Transformer, 10:10 am - 11:55 am, By Sam Knight}

Blue Marble Geographics, 397 Water Street, Suite 100, Gardiner, ME 04345

800-616-2725 samk@bluemarblegeo.com

\section{Geographic Calculator Demonstration:}

Join Blue Marble for a demonstration of the latest version of the Geographic Calculator. This review will demonstrate the powerful geodetic definition and coordinate conversion tools. The Calculator includes point-to-point, databases of points, map-file based conversions, and custom definitions. New tools that focus on enabling enterprise-wide collaboration will be explored, including administrative tools for locking down definition access or views of various coordinate objects, workspaces, and a direct tie into the Open Geospatial Consortium (OGC) Web Registry Service (WRS) version of the European Petroleum Survey Group (EPSG) database.

\section{Geographic Transformer Demonstration:}

Join Blue Marble for a demonstration on the latest version of the Geographic Transformer. This presentation will demonstrate how to leverage the power of the Blue Marble coordinate system data source and apply it to work with rasters. Tools for fast and accurate raster referencing, transformation, mosaicking, and tiling will be reviewed along with batch tools for all processes. The Transformer is the only application available that allows users to read in and write out to all of the major geographic information system (GIS) compression formats including Multi-resolution Seamless Image Database (MrSID), Enhanced Compression Wavelet (ECW), and Joint Photographic Experts Group (JPEG) 2000.

Publishing support provided by:

Rolla Publishing Service Center

For more information concerning this publication, contact:

Director, USGS Mid-Continent Geographic Science Center

1400 Independence Road

Rolla, M0 65401

(573) 308-3652

Or visit the Mid-Continent Geographic Science Center Web site at: http://mcgsc.usgs.gov 



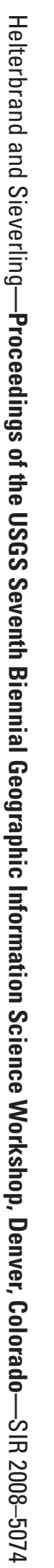

8 Printed on recycled paper 